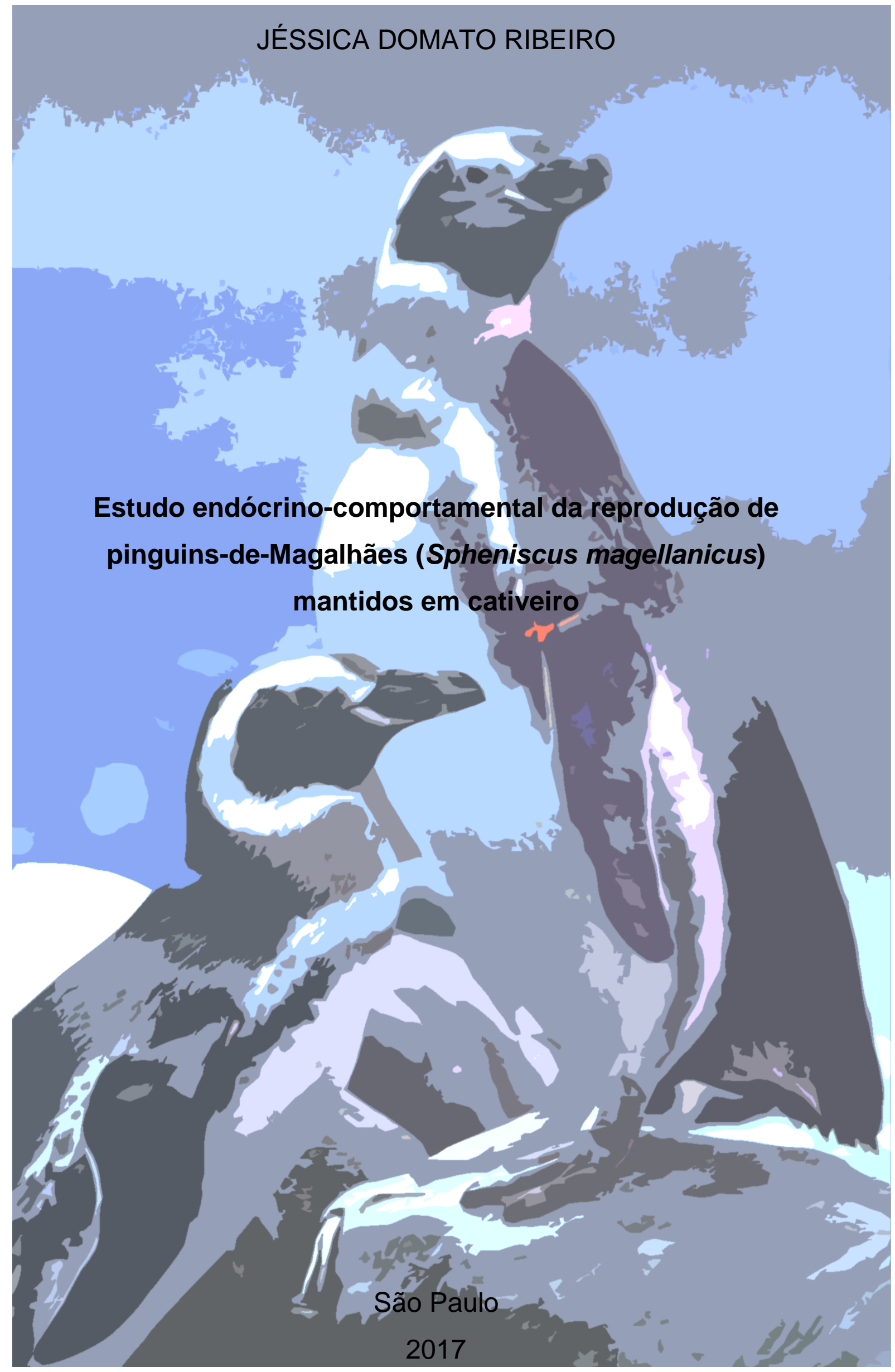




\title{
JÉSSICA DOMATO RIBEIRO
}

\section{Estudo endócrino-comportamental da reprodução de pinguins-de-Magalhães (Spheniscus magellanicus) mantidos em cativeiro}

\begin{abstract}
Dissertação apresentada ao Programa de Pós-Graduação em Reprodução Animal da Faculdade de Medicina Veterinária e Zootecnia da Universidade de São Paulo para a obtenção do título de Mestre em Ciências
\end{abstract}

Departamento:

Reprodução Animal

Área de concentração:

Reprodução Animal

Orientador:

Prof. Dr. Ricardo José Garcia Pereira

Co-orientador:

Profa. Dra. Cristiane Schilbach Pizzutto

De acordo:
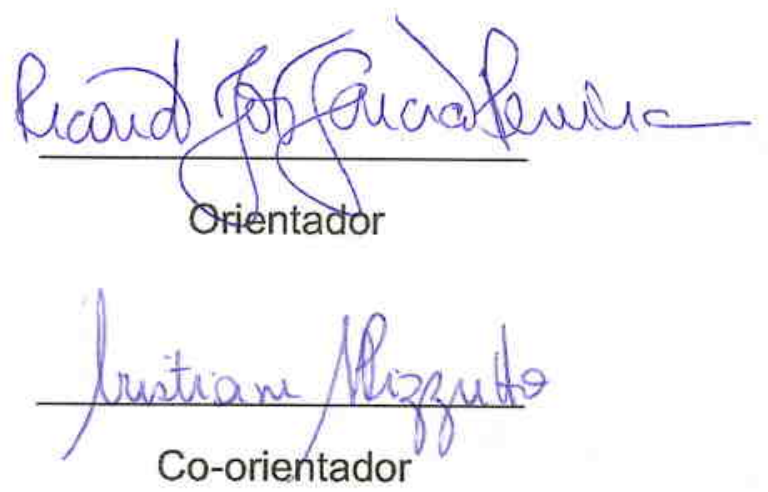

\section{São Paulo}

2017

Obs: A versão original encontra-se disponível na Biblioteca da FMVZuUSP 
Autorizo a reprodução parcial ou total desta obra, para fins acadêmicos, desde que citada a fonte.

\section{DADOS INTERNACIONAIS DE CATALOGAÇÃO NA PUBLICAÇÃO}

(Biblioteca Virginie Buff D’Ápice da Faculdade de Medicina Veterinária e Zootecnia da Universidade de São Paulo)

Ribeiro, Jéssica Domato

Estudo endócrino-comportamental da reprodução de pinguins-de-Magalhães (Spheniscus magellanicus) mantidos em cativeiro. / Jéssica Domato Ribeiro. -2017.

103 f. : il.

Dissertação (Mestrado) - Universidade de São Paulo. Faculdade de Medicina Veterinária e Zootecnia. Departamento de Reprodução Animal, São Paulo, 2017.

Programa de Pós-Graduação: Reprodução Animal.

Área de concentração: Reprodução Animal.

Orientador: Prof. Dr. Ricardo José Garcia Pereira.

Coorientador: Profa. Dra. Cristiane Schilbach Pizzutto.

1. Spheniscidae. 2. Fotoperíodo. 3. Atividade sexual. 4. Esteroides sexuais.

5. Manejo reprodutivo I. Título. 
UNIVERSIDADE DE SAO PAULO

Slo Paub, 18 de maio de 2016 CEUAN 4982271014

IImo(a), Sria)

Responsável: Ricardo José Gardia Pereira

Area: Reproduçăo De Aves

Prof. Dr. Ricardo josé Garcia Pereira (orientador)

Título da proposta: "AVALLACĀO ENDOCRINO-COMPORTAMENTAL DO EFEITO DE PROGRAMAS DE LUZ ARTIFICIAL SOBRE OS CICLOS REPRODUTIVOS DE PINGUNSS-DE.MAGALHÃES (Spheniscus magellanicus) MANTIDOS EM CATIVEIRO".

Parecer Consubstanciado da Comissão de Etica no Uso de Animais FMVZ/USP

A Comissăo de Ética no Uso de Animais da Faculdade de Medicina Veterinária e Zootecnia da Universidade de Săo Paulo, no cumprimento das suas atribuiçōes, analisou e APROVOU o Relatório Parcial (versáo de 13/maio/2016) da proposta acima referendiada.

Resumo apresentado pelo pesquisador: "1. Qual o estágio do estudo no momento? Respco estudo está no estágio de análise das amostras fecais coletadas. Todas as amostras já foram submetidas a etapa de extraçăo hormonal e seguem agora as dosagens hormonais. 2. Qual o $N$ amostral abcado até o momento? Resp: Sajo 690 amostras de extrato fecal alocadas no laborat ório. Sendo que os animais utilizados na pesquisa permanecem na instituiçăo em Santo André sem nenhuma interferênda referente a esta pesquisa como consta no projeto. 3. Por quanto tempo mais o estudo se estenderá? Resp: 0 estudo se estenderá até inicio de 2017 quando dever ser apresentada a dissertaçảo referente a ele, entretanto nảo haverá mais coleta de material dos animais, somente analise laboratorial, resultados e confeç̧ăo da dissertaçăa. 4. Resultados parciais ou totais apresentados em congresso? Resp: Alguns resultados parciais serăo apresent ados em formato de poster no Intemacional Penquin Conference 9 em setembro deste ano 5. Resultados parciais ou totals já publicados? Resp: Ainda nảo Segue em anexo o projeto apresentado para a qualificaçăo do mestrado."

Comentário da CEUA: =

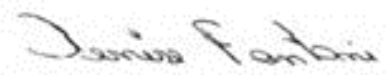

Profa. Dra. Denise Tabacchi Fantoni

Presidente da Comissajo de Ética no Uso de Animais

Faculdade de Medicina Veterinária e Zootecnia da Universidade de Săo Paub

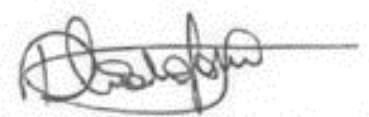

Roseli da Costa Gomes

Secretaria Executiva da Comisço de Ética no Uso de Animais Faculdade de Medicina Veterinária e Zootecnia da Universidade de Säo Paub 


\section{FOLHA DE AVALIAÇÃO}

Autor: RIBEIRO, Jéssica Domato

Título: Estudo endócrino-comportamental da reprodução de pinguins-de-Magalhães (Spheniscus magellanicus) mantidos em cativeiro

Dissertação apresentada ao Programa de Pós-Graduação em Reprodução Animal da Faculdade de Medicina Veterinária e Zootecnia da Universidade de São Paulo para obtenção do título de Mestre em Ciências

Data:

Banca Examinadora

Prof. Dr.

Instituição: Julgamento:

Prof. Dr. Instituição: Julgamento:

Prof. Dr. Instituição: Julgamento: 
SOLI DEO OLORIII 


\section{AGRADECIMENTOS}

Agradeço primeiramente a Deus, pois sei que tudo é Dele, por Ele e para Ele (Rm 11:36).

Agradeço a toda minha amada família que sempre quer meu bem. Em especial ao André e a Lígia, pais amorosos. A mais querida irmã, Talita, que me deu um irmão, Vinícius e, a soma dos dois nos presenteou com a linda Sarinha.

Agradeço aos meus amigos, mais chegados que irmãos, que me suportam nos momentos mais difíceis e riem o meu riso nos mais alegres!

Agradeço imensamente ao meu orientador Ricardo Pereira, pelo grande exemplo de dedicação e excelência. Sempre nós incentivando a fazer o nosso melhor! Já faz alguns anos que o "projeto pinguins" está no quadro de avisos, espero que essa seja só a primeira etapa! Obrigada pela paciência, pelos conselhos, pelas broncas e principalmente pelos devaneios e conversas sobre a vida! Tenho em você um amigo.

Agradeço a minha co-orientadora Cristiane Pizzutto. Lembro a primeira palestra que assisti sobre seu trabalho, estava no segundo ano da veterinária e, certamente, mudou completamente minha visão sobre bem-estar animal. Foi inspirador! É um privilégio hoje tê-la por perto.

Agradeço a Profa. Solange Gennari. Sem ela, nada disso seria possível. Agradeço seus ensinamentos e incansável incentivo a todos a sua volta. Obrigada por me trazer ao mundo da ciência!

Agradeço a equipe do Aquário da SABINA. O sucesso reprodutivo também é fruto da dedicação e trabalho árduo de vocês! Que isso seja um singelo incentivo para que continuem fazendo a diferença! Ronaldo Barros, Rafael Torres, Julia Alves, Jorge Soares, Leandro Otero, Felipe Domingos, Marcus Corradini e, principalmente, a minha querida amiga e sempre parceira de manejos impossíveis! Catherina Bartalini, sou muito grata por, além de tudo, ter sua amizade.

Agradeço a Prefeitura de Santo André, e principalmente a direção da SABINA - Escola Parque do Conhecimento pelo constante apoio durante todos os anos de monitoramentos.

A querida amiga Valeria Ruoppolo, que me incentiva constantemente e tanto me ajudou na elaboração do primeiro capítulo. Obrigada pelas fotos inspiradoras e pelas conversas deliciosas. Obrigada por acreditar em mim! Also, special thanks for Eric Woehler, for such wonderful pics that made this dissertation much more pleasant!

Agradeço ao professor Catão pelas importantes considerações feitas na qualificação e ao constante apoio a este trabalho.

Aos amigos do mundo dos pinguins! Ralph Vanstreels, Renata Hurtado, Laura Reisfeld e Bruna Schwarz, obrigada por estarem sempre dispostos a ajudar, seja com condutas dirigidas aos animais, 
sugestões na elaboração deste trabalho, ou mesmo com o empréstimo de lindas fotos para deixá-lo ainda mais bonito!

Agradeço aos queridos amigos do GEMA, que quando não estavam me ajudando, certamente me faziam rir! Obrigada pessoal! Mayra Frediani, Bruno Rui, Allison Kawaoku, Daniel de Biase, Fabio Shibuya e, Marcel Blank, a quem agradeço especialmente por ter me ajudado nas dosagens hormonais.

Agradeço ao professor Marcílio pela ajuda no delineamento estatístico deste trabalho e a Giulia Kawai por transformar as planilhas magicamente em estatística!

Agradeço a Coordenação de Aprimoramento Pessoal de Nível Superior (CAPES), pelo apoio financeiro em parte do projeto.

Agradeço a todos os professores e funcionários do Departamento de Reprodução Animal, foi um prazer estar com vocês esses anos.

E, por fim, aos "meus" queridos pinguins! Animais incríveis que tive o privilégio de conviver por 5 anos. Amo cada personalidade, conheço cada jeito de andar, o cantar, e as pintinhas de cada um A vocês, todo meu coração

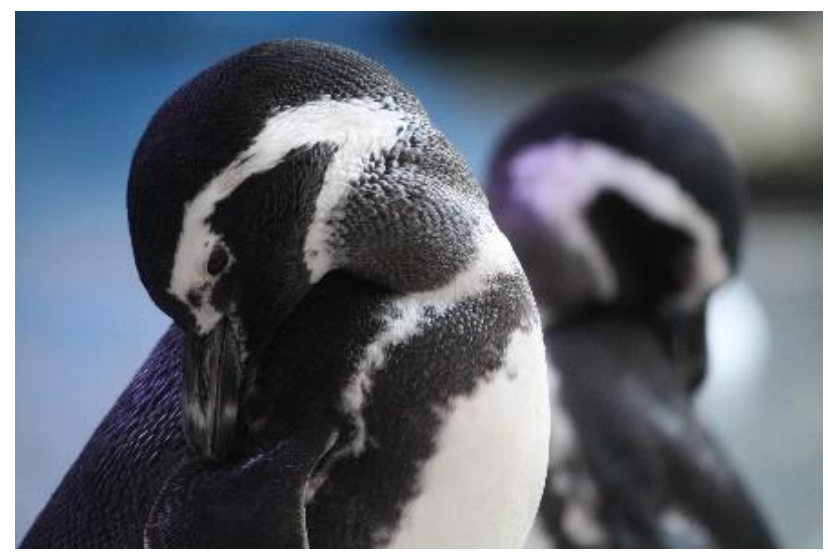


"Tudo o que for verdadeiro, tudo o que for nobre, tudo o que for correto, tudo o que for puro, tudo o que for amavel, tudo o que for de boa fama, se houver algo de excelente ou digno de louvor, pensem nessas coisas" 


\section{RESUMO}

RIBEIRO, J. D. Estudo endócrino-comportamental da reprodução de pinguinsde-Magalhães (Spheniscus magellanicus) mantidos em cativeiro. [Endocrine and behavioral study of captive magellanic penguins (Spheniscus magellanicus)]. 2017. 103 f. Dissertação (Mestrado em Ciências) - Faculdade de Medicina Veterinária e Zootecnia, Universidade de São Paulo, São Paulo, 2017.

A vasta maioria dos pinguins são aves de reprodução sazonal. O pinguim-deMagalhães (Spheniscus magellanicus) forma colônias reprodutivas em latitudes superiores a $42^{\circ} \mathrm{S}$ no Chile, Argentina e Ilhas Malvinas/ Falklands, demonstrando comportamento sazonal como outras aves de clima temperado. Durante o inverno, os pinguins migram em direção ao norte, sendo frequentemente avistadas em águas brasileiras nas regiões sul e sudeste. Apesar de diversas instituições no Brasil abrigarem esta espécie de pinguim em seus plantéis, sua taxa reprodutiva em cativeiro é baixa e irregular em todo o país. Desde 2009, a Sabina Parque Escola do Conhecimento (Santo André - SP) mantem um plantel de aproximadamente 20 pinguins que nunca apresentara histórico reprodutivo ou se quer sinais de acasalamento. Em 2012, um programa de luz mimetizando o fotoperiodo vivenciado pelas colonias reprodutivas in situ foi instaurado, e a resposta endócrinocomportamental de parte desse plantel (9 machos e 9 fêmeas) foi registrada. Com o início do programa de luz a população não apenas aumentou gradativamente 0 número de indivíduos pareados, como também iniciou a postura de ovos (férteis e inférteis) e a criação de filhotes. Oscilações nos esteróides fecais e comportamentos de machos e fêmeas com diferentes resultados reprodutivos são detalhadas para duas estações reprodutivas consecutivas (setembro a janeiro). De modo geral, os níveis hormonais no segundo ano de monitoramento foram mais altos, sugerindo uma infuência da idade sobre a secreção de esteróides sexuais. No segundo ano de avaliação, machos que obtiveram filhotes apresentaram concentrações de andrógenos fecais aparentemente mais elevadas que machos pareados sem ovos ou com ovos inférteis, mas similares aos machos despareados cujo os níveis mantiveram-se altos de outubro a janeiro. Não foi possível tirar conclusões sobre os padrões de secreção de progestégenos e estrógenos fecais nos machos monitorados. Nas fêmeas, aumentos nos níveis de andrógenos fecais foram notórios 
apenas nos indivíduos com ovos e sem filhotes. Elevações na secreção de progestágenos fecais em fêmeas despareadas ou sem postura não resultaram na produção de ovos, apesar desses aumentos serem compativeis àquelas observadas nas fêmeas com ovos ou filhotes. Adicionalmente, em outro período deste trabalho, uma falha mecânica no controle do fotoperíodo desencadeou na elevação do comprimento de luz durante os meses de inverno (24 horas luz/ dia - de maio a agosto). Esta superexposição a luz artificial induziu comportamentos reprodutivos em três casais monitorados (inclusive com a postura de ovos por uma fêmea), além de induzir uma segunda muda quatro meses após a primeira muda. Estes achados demonstram a alta susceptibilidade da espécie aos programas de luz, e levantam a possibilidade de utilizar essa ferramenta não só para a estimular a reprodução em cativeiro, mas talvez para induzir uma segunda estação reprodutiva no ano ou reduzir o intervalo entre estações reprodutivas. Ambos desdobramentos possuem aplicabilidade na propagação de indivíduos da família Spheniscidae, a qual $60 \%$ das espécies é classificada em alguma categoria de ameaça da IUCN.

Palavras-chave: Spheniscidae. Fotoperíodo. Atividade sexual. Esteroides sexuais. Manejo reprodutivo. 


\begin{abstract}
RIBEIRO, J. D. Endocrine and behavioral study of captive magellanic penguins (Spheniscus magellanicus). 103 f. Dissertação (Mestrado em Ciências) Faculdade de Medicina Veterinária e Zootecnia, Universidade de São Paulo, São Paulo, 2017.
\end{abstract}

Most penguin's species are seasonal breeders. Magellanic penguins have their breeding sites in Chile, Argentina and Malvinas/ Falklands Islands $\left(42^{\circ} \mathrm{S}\right.$ and higher latitudes), demonstrating their seasonal behavior as other birds from temperate zones. During the winter, penguins migrate north, and are commonly seen in waters from Brazilian south and southeast regions. Although many institutions keep magellanic penguins in Brazil, the breeding success among these birds is low and irregular all over the country. Since 2009, Sabina Park School of Knowledge (Santo André - SP), maintain approximately 20 magellanic penguins without any breeding history or reproductive behavior. In 2012, a lighting program simulating the photoperiod of the penguins' breeding sites in situ was initiated, and the endocrinal and behavioral responses from part of the animals (9 males and 9 females) was surveyed. After the lightning program started, there was not only a progressive rise in the number of paired animals, but also an outset of laying (fertile and infertile eggs) and raise of chicks. Fecal steroids and behaviors of males and females with different outcomings are exposed for two consecutive breeding seasons (September January). Generally, the hormonal levels of the second year monitored were higher, suggesting an influence of the animal's maturity upon the sex steroids. On the second year's evaluation, males with chicks apparently presented higher androgens levels as compared with males without eggs or with infertile eggs, but similar to nonpaired males whose levels were high the from October to January. It was not possible to obtain any conclusions on progestogens nor estrogens secretions standards. Fecal androgens on females showed a notorious rise only in the paired without chick group. Rises on the secretion of fecal progestogens on females of the non-paired and without-laying groups did not progress to egg production, although the rises were compatible with the ones seen on females with-egg laying, and withchicks. Father, on a different stage of this survey, a mechanic failure on the photoperiod control triggered an elevation on the light length during winter months 
(24 hours light/ day from May to August). This over exposition of artificial light induced reproductive behaviors on three surveyed animals (including an egg laying of one of the females), as well as induced a second molt four months after their annual molt. Those findings demonstrate the high susceptibility to lightning programs showed by this specie, also raise a possibility of using it as a tool, not only to stimulate captivity breeding, but also to induce a second breeding season during the year or decrease the breeding season interval. Both results have applicability on the conservation of Spheniscisdae individuals, which has $60 \%$ of species classified in endangered categories (IUCN).

Keywords: Spheniscidae. Photoperiod. Sexual activity. Sexual steroids. Reproductive management. 


\section{LISTA DE FIGURAS}

Figura 1 - Fotografias exemplificando as diferentes espécies pertencentes a família Spheniscidae.

Figura 2 - Fotografias exemplificando as diferentes espécies pertencentes a família

Spheniscidae. .22

Figura 3 - Distribuição das colônias reprodutivas de pinguins. .24

Figura 4 - Reprodução do pinguim-de-Adélia (Pygoscelis adeliae) .33

Figura 5 - Reprodução do pinguim-de-Magalhães (Spheniscus magellanicus) 34

Figura 6 - Ciclo biológico anual do pinguim-de-Magalhães. 36

Figura 7 - Programa de Luz realizado na Sabina - Parque Escola do Conhecimento.

Figura 8 - Início da estação reprodutiva na Sabina - Escola Parque do Conhecimento. 48

Figura 9 - Estação reprodutiva na Sabina - Escola Parque do Conhecimento. 49

Figura 10 - Dinâmica de pareamento dos animais estudados. .51

Figura 11 - Dados reprodutivos da Sabina - Parque Escola do Conhecimento de $2010-2016$. .56

Figura 12 - Médias dos registros comportamentais dos machos nos anos 1 e 2. ....58

Figura 13 - Médias dos registros comportamentais das fêmeas nos anos 1 e 2 .......59 Figura 14 - Médias das concentrações de hormônios fecais dos machos nos anos 1 e 2 .

Figura 15 - Médias das concentrações de hormônios fecais das fêmeas nos anos $1 \mathrm{e}$ 2. .63

Figura 16 - Programa de luz feito durante o monitoramento dos pinguins-deMagalhães. .78

Figura 17 - Dispersão das mudas entre os animais monitorados de $2010-2015 \ldots . .83$ Figura 18 - Médias das concentrações hormonais mensais em machos pareados e não pareados. .85

Figura 19 - Médias das concentrações hormonais mensais em fêmeas pareadas e não pareadas.

Figura 20 - Médias dos registros comportamentais mensais em machos pareados e não pareados. 
Figura 21 - Médias dos registros comportamentais mensais em fêmeas pareadas e não pareadas. 89

Figura 22 - Médias de concentrações hormonais e registros comportamentais de machos pareados e não pareados de acordo com a exposição a luz. 91 Figura 23 - Médias de concentrações hormonais e registros comportamentais de fêmeas pareadas e não pareadas de acordo com a exposição a luz. .92 


\section{SUMÁRIO}

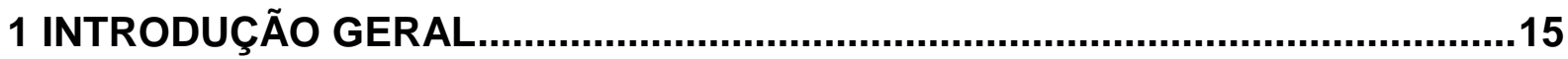

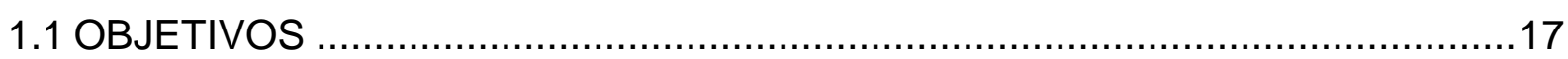

1.1.1 Geral

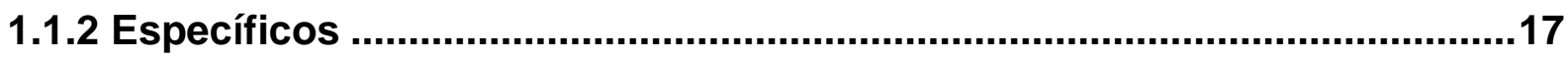

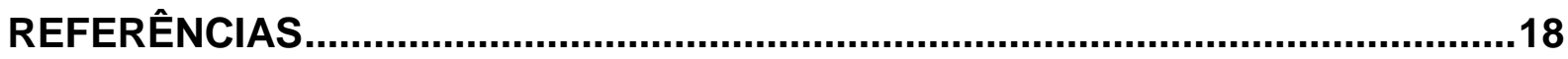

2 REPRODUÇÃO NA FAMÍLIA SPHENISCIDAE ..............................................19

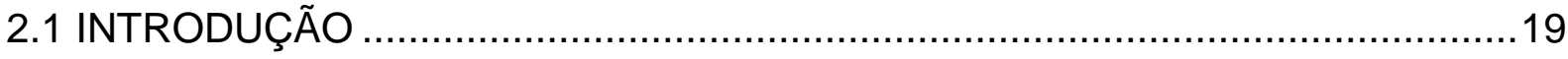

2.2 CARACTERISTICAS GERAIS DAS ESPÉCIES DE PINGUINS .......................20

2.3 FATORES QUE DETERMINAM O INÍCIO DA REPRODUÇÃO .......................23

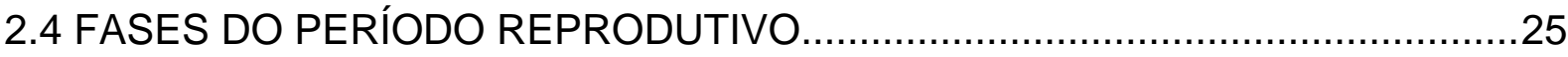

2.4.1 Formação das colônias reprodutivas ...........................................................26

2.4.2 Escolha e fidelidade de parceiros...............................................................30

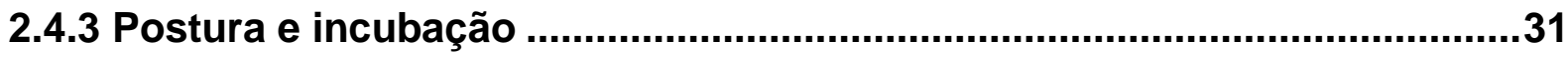

2.4.4 Cuidado parental e emancipação do filhote .................................................32

2.5 A REPRODUÇÃO DE PINGUINS EM CATIVEIRO …....................................35

2.5.1 A reprodução de pinguins-de-Magalhães em cativeiro no Brasil ...............35

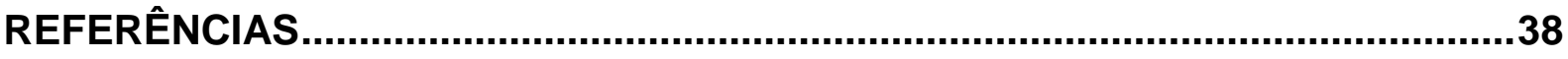

3 ESTUDO ENDÓCRINO-COMPORTAMENTAL DA REPRODUÇÃO DE PINGUINS-DE-MAGALHÃES (SPHENISCUS MAGELLANICUS) MANTIDOS EM

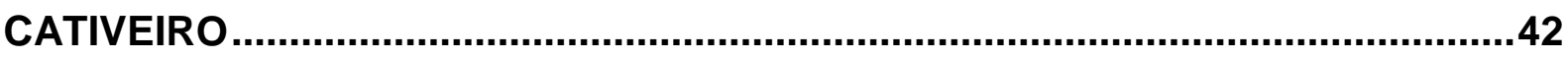

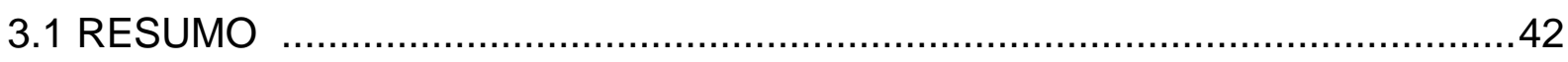

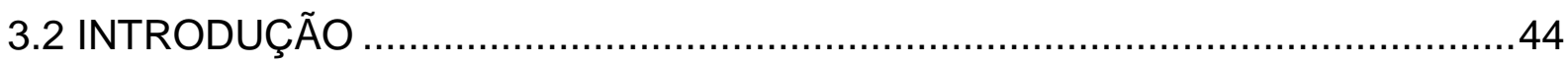

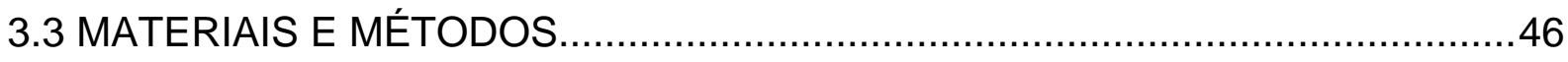

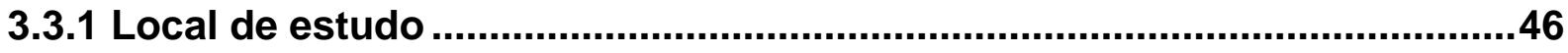

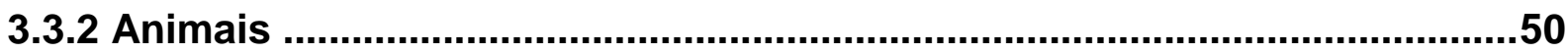


3.3.3 Coleta de amostras e dados comportamentais .52

3.3.4 Extração de metabolitos hormonais e ensaios enzimáticos .......................53

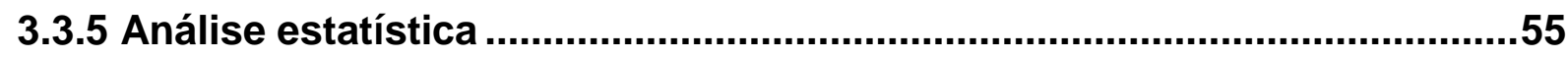

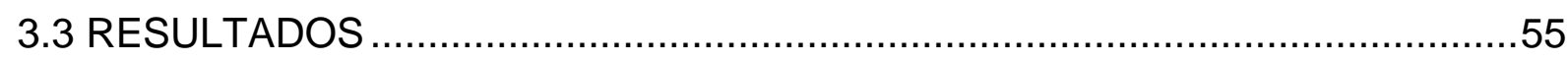

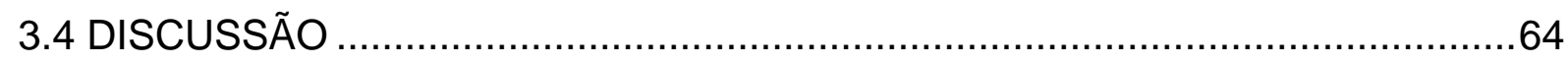

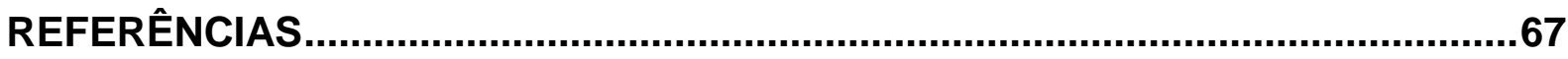

4. INFLUÊNCIA DO PROGRAMA DE LUZ NA RESPOSTA COMPORTAMENTAL E HORMONAL DE PINGUINS-DE-MAGALHÃES (SPHENISCUS MAGELLANICUS)

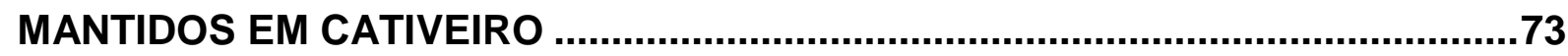

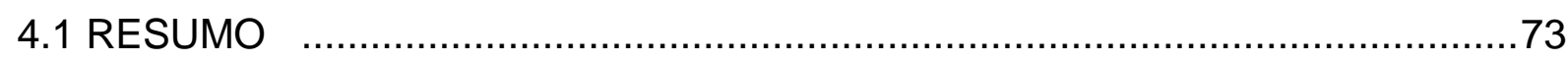

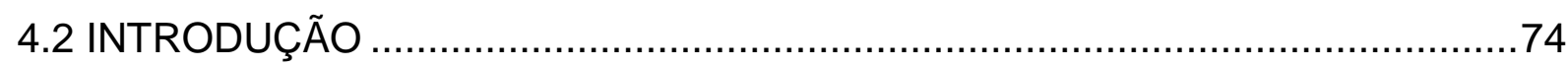

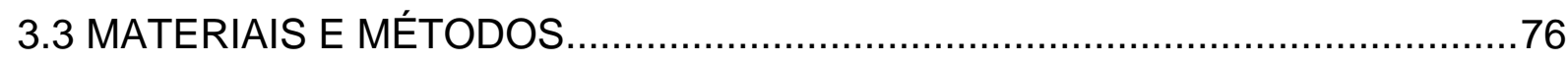

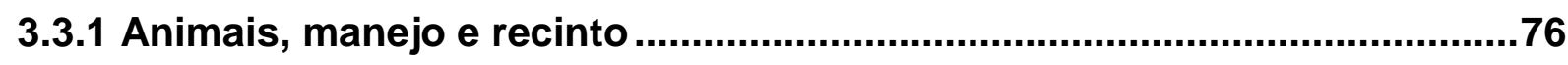

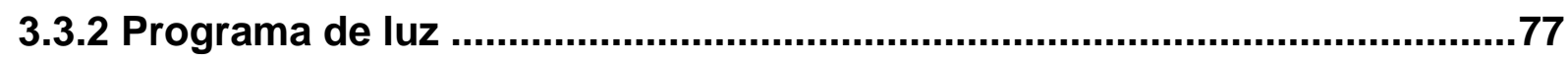

3.3.3 Coleta de amostras e dados comportamentais .............................................79

3.3.4 Extração de metabolitos hormonais e ensaios enzimáticos .......................80

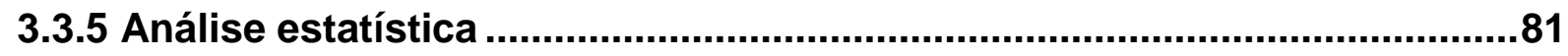

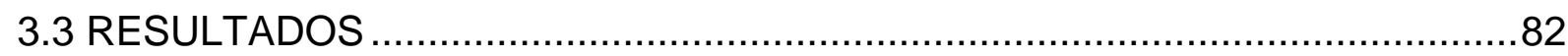

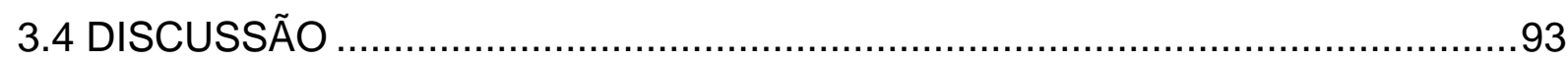

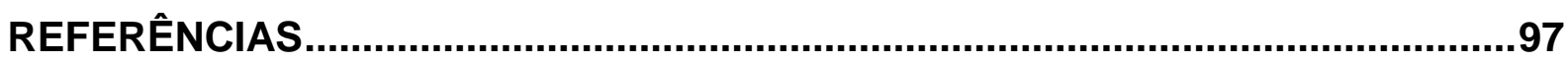

5 CONSIDERAÇÕES FINAIS ..................................................................100

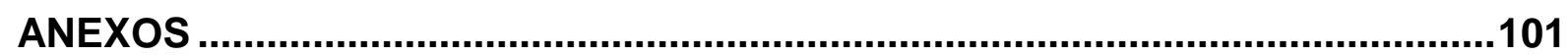




\section{INTRODUÇÃO GERAL}

Pinguins são aves únicas em virtude de seu estilo de vida verdadeiramente aquático. Eles compõem cerca de $80 \%$ da biomassa de aves do Oceano Antártico, apresentando um papel ecológico indiscutível na dinâmica energética dos oceanos do Hemisfério Sul, de onde são exclusivas (BOERSMA, 2008). Contudo, apesar da imensa afinidade destas espécies ao mar, seu vínculo com o ambiente terrestre ainda permanece dada a extensa época reprodutiva que compreende desde a busca por ninhos e parceiros, até cuidado biparental dos filhotes (WILLIAMS, 1995; GARCÍA-BORBOROGLU; BOERSMA, 2013)

No Brasil, apenas uma espécie é habitualmente avistada na costa, o pinguimde-Magalhães (Spheniscus magellanicus), que embora não forme colônias reprodutivas em território nacional frequenta anualmente suas águas durante migração invernal em busca por alimentos (STOKES; BOERSMA, 1999; SICK, 2001; CEMAVE, 2010). Suas colônias reprodutivas estão distribuídas ao longo do litoral da Argentina, Chile e Ilhas Falkland/ Malvinas, desde a Terra do Fogo (55ㅇ) até as latitudes 41오 no Atlântico e 33오 no Pacífico (BIRDLIFE INTERNATIONAL, 2016). Entretanto, é durante a intensa migração invernal que os pinguins-de-Magalhães ficam susceptíveis aos desafios ambientais e antropogênicos, acarretando no encalhe anual de centenas a milhares de animais em praias brasileiras, os quais em sua ampla maioria são animais juvenis (SICK, 2001; CEMAVE, 2010; STOKES et al., 2014). Infelizmente, muitos destes indivíduos resgatados são considerados inaptos a vida livre e, por conseguinte, os mesmos são encaminhados ao cativeiro.

Pinguins-de-Magalhães são mantidos em cativeiro no Brasil desde 1945, quando foi inaugurado o Aquário Municipal de Santos. Foi também lá o primeiro registro de nascimento da espécie no país, no ano de 2001. Após esse registro, outros locais que mantém pinguins em seus planteis registraram alguns nascimentos, porém de maneira esporádica. Apesar do pinguim-de-Magalhães ser atualmente classificado como "quase ameaçado" (IUCN, 2016), dúvidas sobre as tendências demográficas das populações in situ ressaltam o papel da reprodução ex situ para a conservação da espécie. Todavia, para que os indivíduos mantidos em cativeiro se reproduzam é necessário que os mesmos tenham estímulos similares aos encontrados em vida-livre. Assim, a sazonalidade fortemente presente no ciclo 
do pinguim-de-Magalhães deve ser respeitada para uma reprodução bem-sucedida, e nesse contexto, o principal fator para o desencadeamento atividade reprodutiva em aves é o fotoperíodo (SHARP, 1996).

A Sabina - Escola Parque do Conhecimento abriga o Aquário Municipal de Santo André, que em 2009 inaugurou um amplo recinto para pinguins-de-Magalhães com capacidade para 28 aves. Em 2012, quando a maioria dos 22 animais se mostrava em início da idade reprodutiva (aproximadamente 4 anos de vida), um programa de luz foi instituído afim de estimular esse plantel com um fotoperíodo similar àquele vivenciado pelas colônias reprodutoras em seu habitat natural. Portanto, o objetivo deste trabalho foi apresentar as respostas endócrino-comportamentais de machos e fêmeas desse plantel durante um período de três temporadas reprodutivas sob fotoperíodo artificial. Este projeto propõe demonstrar que a implementação de programas de luz, associados ao correto manejo de pinguins-de-Magalhães, pode ser uma ferramenta de baixo custo para induzir a atividade reprodutiva da espécie em cativeiro. 


\subsection{OBJETIVOS}

\subsubsection{Geral}

Como objetivo principal, este projeto visou monitorar as estações reprodutivas de pinguins-de-Magalhães (Spheniscus magellanicus) mantidos em cativeiro sob protocolos artificiais de fotoperíodo via mensurações hormonais não-invasivas e comportamentais.

\subsubsection{Específicos}

- Pesquisar comportamentos sócio-sexuais que caracterizem secreção de esteroides sexuais dos animais, criando uma ferramenta de baixo-custo que auxiliem no monitoramento reprodutivo em cativeiro;

- Investigar a aplicabilidade de programas de luz como ferramenta de manipulação reprodutiva em populações cativas de $S$. magellanicus. 


\section{REFERÊNCIAS}

BIRDLIFE INTERNATIONAL. 2016. Spheniscus magellanicus. The IUCN Red List of Threatened Species 2016: e. T22697822A93642328. Disponível em:<http://dx.doi.org/10.2305/IUCN.UK.2016-3.RLTS.T22697822A93642328.en>. Acesso em: 05 de dezembro de 2016.

BOERSMA, P. D. Penguins as marine sentinels. BioScience, v. 58, n. 7, p. 597607, 2008.

CENTRO NACIONAL DE PESQUISA E CONSERVAÇÃO DE AVES SILVESTRES (CEMAVE). Projeto nacional de monitoramento do pinguim-de-Magalhães Spheniscus magellanicus. Cabedelo: CEMAVE, 2010. 34 p.

GARCÍA-BORBOROGLU, P. G.; BOERSMA, P. D. (Ed.). Penguins - natural history and conservation. Seattle: University of Washington Press, 2013. p 233-263.

SHARP, Peter J. Strategies in avian breeding cycles. Animal Reproduction Science, v. 42, n. 1-4, p. 505-513, 1996.

SICK, H. Ornitologia Brasileira. Rio de Janeiro: Nova Fronteira, 2001. 926 p.

STOKES, D. L.; BOERSMA, P. D. Where Breeding Magellanic penguins Spheniscus magellanicus forage: satellite telemetry results and their implications for penguin conservation. Marine Ornithology, v. 27, p. 59-65, 1999.

STOKES, David L. et al. Conservation of migratory Magellanic penguins requires marine zoning. Biological Conservation, v. 170, p. 151-161, 2014.

The IUCN Red List of Threatened Species. Version 2016-3. Disponível em: <www.iucnredlist.org $>$. Acesso em: 05 de dezembro de 2016.

WILLIAMS, T. D. The penguins: Spheniscidae. Oxford: Oxford University Press, 1995. 295 p. 


\section{REPRODUÇÃO NA FAMÍLIA SPHENISCIDAE}

\subsection{INTRODUÇÃO}

A maioria dos organismos vivos estão em ambientes sazonais que flutuam de forma previsível, precisando se ajustar a essas mudanças de forma a maximizar sua capacidade reprodutiva e, por conseguinte, seu sucesso reprodutivo (JACOBS; WINGFIELD, 2000). Neste sentido, os principais fatores controladores da sazonalidade reprodutiva em aves são o fotoperíodo, a temperatura e a disponibilidade e qualidade dos alimentos (SHARP, 1996), sendo o fotoperíodo o estímulo externo mais empregado na sincronização das alterações fisiológicas com as oscilações do ambiente (PEREIRA, 2014). Embora os pinguins sejam aves altamente adaptadas à vida no mar, aparentemente não existem diferenças desta família em relação as outras aves no que tange a regulação ambiental da sazonalidade reprodutiva. Isto possivelmente em razão de algumas fases de seu ciclo de vida, tais como reprodução e muda de penas, ser ainda dependente do ambiente terrestre (WILLIAMS, 1995).

Desse modo, o conhecimento destes e outros aspectos inerentes a reprodução da família Spheniscidae são imprescindíveis para o aprimoramento do manejo reprodutivo destes indivíduos em cativeiro, em especial nas espécies em que a reprodução ex situ pode verdadeiramente auxiliar na conservação das populações de vida livre. Tal preocupação baseia-se no fato de $60 \%$ das espécies de pinguins encontrarem-se atualmente classificadas como "ameaçada" ou "vulnerável" (IUCN, 2016), por causas que vão desde a depleção de presas (consequência da sobrepesca) a contaminação dos oceanos e degradação das áreas de nidificação (BOERSMA; STOKES, 1995; GARCÍA-BORBOROGLU; BOERSMA, 2013). Assim, o presente trabalho propõe compilar todos os dados disponíveis sobre a reprodução das 18 espécies de pinguins, além de descrever o histórico e a práticas de manejo em cativeiro desta família no mundo e no Brasil. 


\subsection{CARACTERISTICAS GERAIS DAS ESPÉCIES DE PINGUINS}

Pinguins são aves marinhas que se destacam dentre as outras por serem incapazes de voar, entretanto, são dotadas de uma incrível habilidade de nado, tornando-as capazes de percorrer grandes distâncias (WILLIAMS, 1995). Um bom exemplo são os pinguins-de-Magalhães (Spheniscus magellanicus), que percorrem todos os anos mais de $2000 \mathrm{~km}$ entre seus sítios reprodutivos e seus locais de alimentação, podendo percorrer até $170 \mathrm{~km}$ em um único dia (BOERSMA et al., 2009; RUOPPOLO et al., 2012). E ainda que a habilidade de locomoção em terra seja limitada na família como um todo, há casos como o dos pinguins-imperadores (Aptenodytes forsteri) em que indivíduos podem percorrer distâncias que chegam a $100 \mathrm{~km}$ entre o mar aberto e o local de nidificação (DEWASMES et al., 1980; ANCEL et al., 1992).

Os pinguins são agrupados na Ordem dos Sphenisciformes, constituída por uma única família (Spheniscidae) que contempla 18 espécies entre seus 6 gêneros (Fig. 1 e 2). Todas as espécies de pinguins possuem estrutura corpórea similar, corpo fusiforme, pescoço e membros curtos, que em conjunto aumentam sua hidrodinâmica (potencializando a capacidade de nado) e diminuem sua superfície corpórea (contribuindo para a manutenção do calor quando em aguas frias). Diferentemente das outras aves que possuem ossos pneumáticos para facilitar o voo, pinguins possuem ossos densos que os ajudam nos mergulhos profundos (WILLIAMS, 1995; CRANFIELD, 2003, SILVA-FILHO; RUOPPOLO, 2014). Estas e outras características tornam os pinguins altamente adaptados a vida aquática, fazendo com que os mesmos gastem cerca de $80 \%$ de seu tempo na água forrageando ou migrando, e os $20 \%$ restantes em terra reproduzindo (ANCEL; BEAULIEU; GILBERT, 2013).

Não há dimorfismo sexual evidente em nenhuma espécie de pinguim, entretanto, em algumas delas, o macho costuma ter uma massa corpórea maior em relação a fêmea, ao menos no período reprodutivo. Em pinguins-de-Magalhães existem diferenças no tamanho e espessura dos bicos de machos e fêmeas que 
Figura 1 - Fotografias exemplificando as diferentes espécies pertencentes a família Spheniscidae.
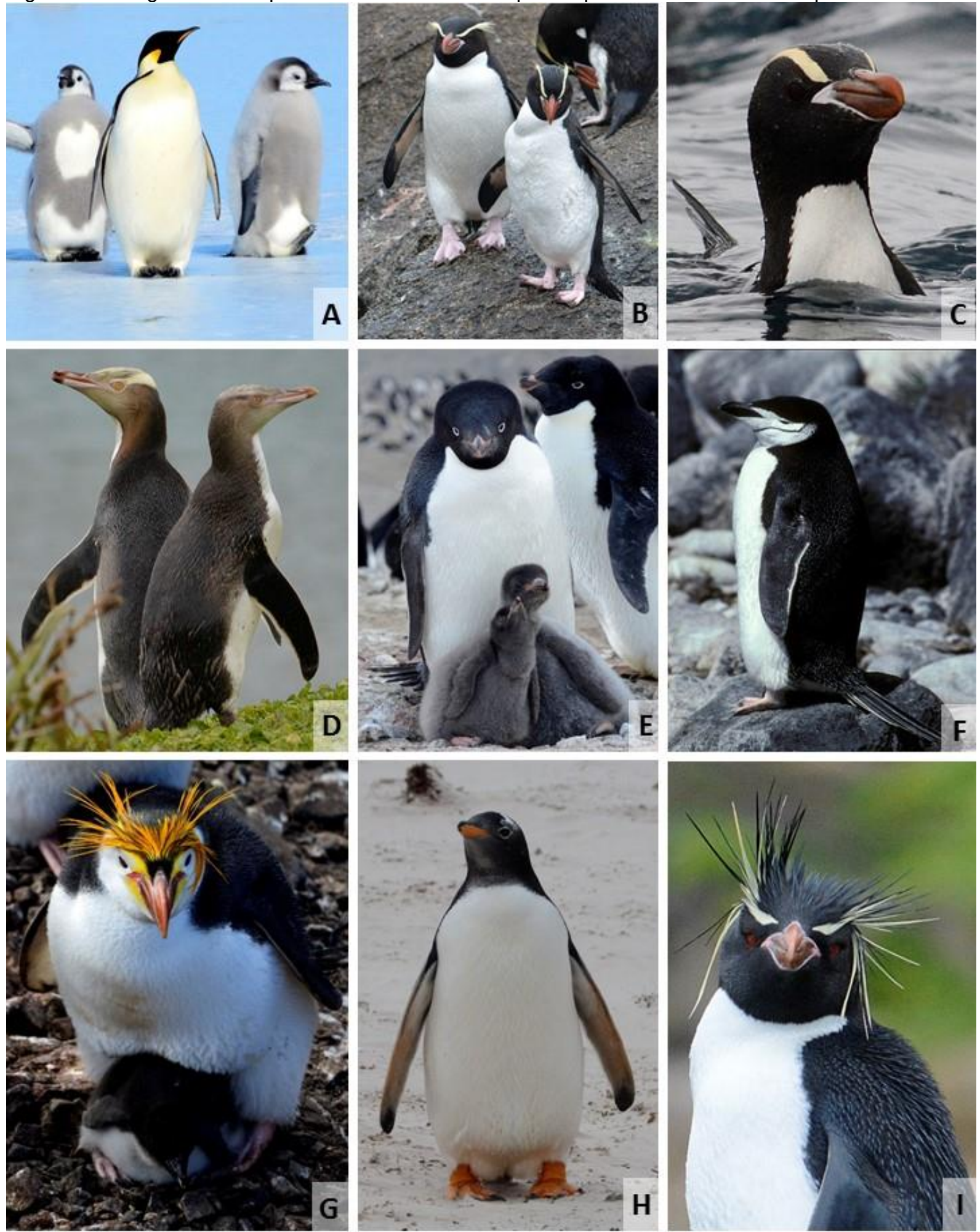

Fonte: (A), (E) e (H) RUOPPOLO, V.; 2017. (B), (C), (D), (F), (G), (I) WOEHLER, E., 2017.

Legenda: (A) Pinguim-imperador (Aptenodytes forsteri) adulto com dois filhotes; (B) Casal de pinguins-de_Snares (Eudyptes robustus); (C) Pinguim-de-crista-ereta (Eudyptes sclateri) adulto ; (D) Pinguim-de-olho-amarelo (Megadyptes antipodes) adulto com juvenil a direita; (E) Pinguim-de-Adélia (Pygoscelis adeliae) adulto com dois filhotes; (F) Pinguim-antártico (Pygoscelis antarticus) adulto; Pinguim-real (Eudyptes schlegeli) adulto com um filhote; $(\mathrm{H})$ Pinguim-papua (Pygoscelis papua) adulto e (I) Pinguim-de-penacho-amarelo-do-sul (Eudyptes chrysocome) adulto. 
Figura 2 - Fotografias exemplificando as diferentes espécies pertencentes a família Spheniscidae.
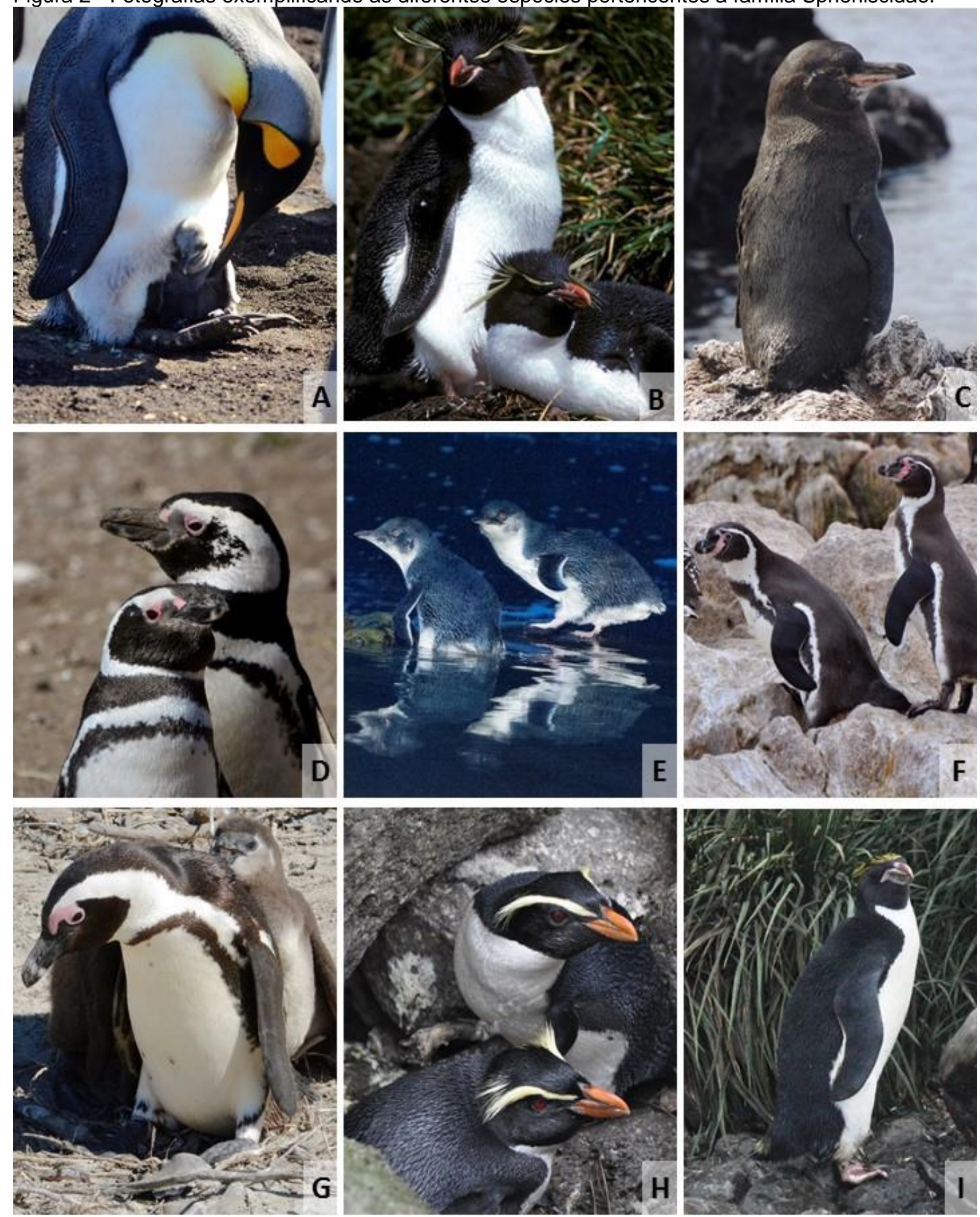

Fonte: (A), (D) e (F) RUOPPOLO, V.; 2017. (B), (E) e (G) WOEHLER, E., 2017. (C) REISFELD, L.; 2015. (H) CHILVERS, L., 2017. (I) VANSTREELS, R.E.T., 2017

Legenda: (A) Pinguim-rei (Aptenodytes patagonicus) adulto com filhote; (B) casal de pinguins-de penacho-amarelo-do-norte (Eudyptes moseleyi); (C) Pinguim-de-Galápagos (Spheniscus mendiculos) adulto; (D) Casal de pinguins-de-Magalhães (Spheniscus magellanicus); (E) Casal de pinguins-azuis (Eudyptula minor); (F) Pinguins-Humboldts (Spheniscus humboldti) adultos; (G) Pinguim-africano (Spheniscus demersus) adulto com dois filhotes; $(\mathrm{H})$ Casal de pinguins-de-Fiordland (Eudyptes achyrhynchus) e (I) Pinguim-Macaroni (Eudyptes chrysolophus) 
permitem a sexagem por morfometria com alguma margem de acerto (VANSTREELS et al, 2011; SILVA-FILHO; RUOPPOLO, 2014). Animais juvenis possuem o padrão de coloração das penas diferente dos animais adultos, portanto podem ser identificados visualmente (WILLIAMS, 1995). Já com relação ao tamanho e massa corpórea existe uma ampla variação entre espécies, com a menor espécie de pinguim conhecida (o pinguim-azul - Eudyptula minor) medindo aproximadamente $40 \mathrm{~cm}$ e pesando $1 \mathrm{~kg}$, e a maior (o pinguim-imperador Aptenodytes forsteri) podendo chegar a $130 \mathrm{~cm}$ e $37 \mathrm{~kg}$ (WILLIAMS, 1995; ANCEL; BEAULIEU; GILBERT, 2013).

A distribuição geográfica das espécies de pinguins se dá exclusivamente no Hemisfério Sul. Ao contrário da crença popular de que todos os pinguins são antárticos, a maioria deles é encontrada em zonas de clima subantártico ou temperado, sendo somente duas as espécies consideradas exclusivamente antárticas, o pinguim-imperador (Aptenodytes forsteri) e o pinguim-de-Adélia (Pygoscelis adeliae). Há também espécies vivendo em zonas de clima tropical, como o pinguim-de-Galápagos (Spheniscus mendiculus) e o pinguim-de-Humboldt (Spheniscus humboldti). As outras espécies podem ser encontradas tanto em áreas continentais da América do Sul, África e Oceania, quanto em ilhas oceânicas (Fig. 3) (DAVIS; DARBY, 1990; WILLIAMS, 1995; ANCEL; BEAULIEU; GILBERT, 2013).

\subsection{FATORES QUE DETERMINAM O INÍCIO DA REPRODUÇÃO}

A grande maioria dos pinguins, como outros grupos de aves, aguarda momentos oportunos para se reproduzir, o que inclui primordialmente o aumento na disponibilidade de alimentos e o clima favorável. É provável que o início das alterações fisiológicas para a reprodução seja dado quando os pinguins ainda estão em migração (WILLIAMS, 1995). Esta reativação gonadal é provavelmente estimulada pelo aumento das horas de luz no dia, que por sua vez induz os animais a retornarem a suas colônias reprodutivas. É interessante ressaltar que este estímulo inicial não pode ser atribuído a qualquer fator comportamental, pois a corte e a formação de pares são atividades que os animais realizam após sua chegada em terra (WILLIAMS, 1995; SHARP, 1996). 
Figura 3 - Distribuição das colônias reprodutivas de pinguins.

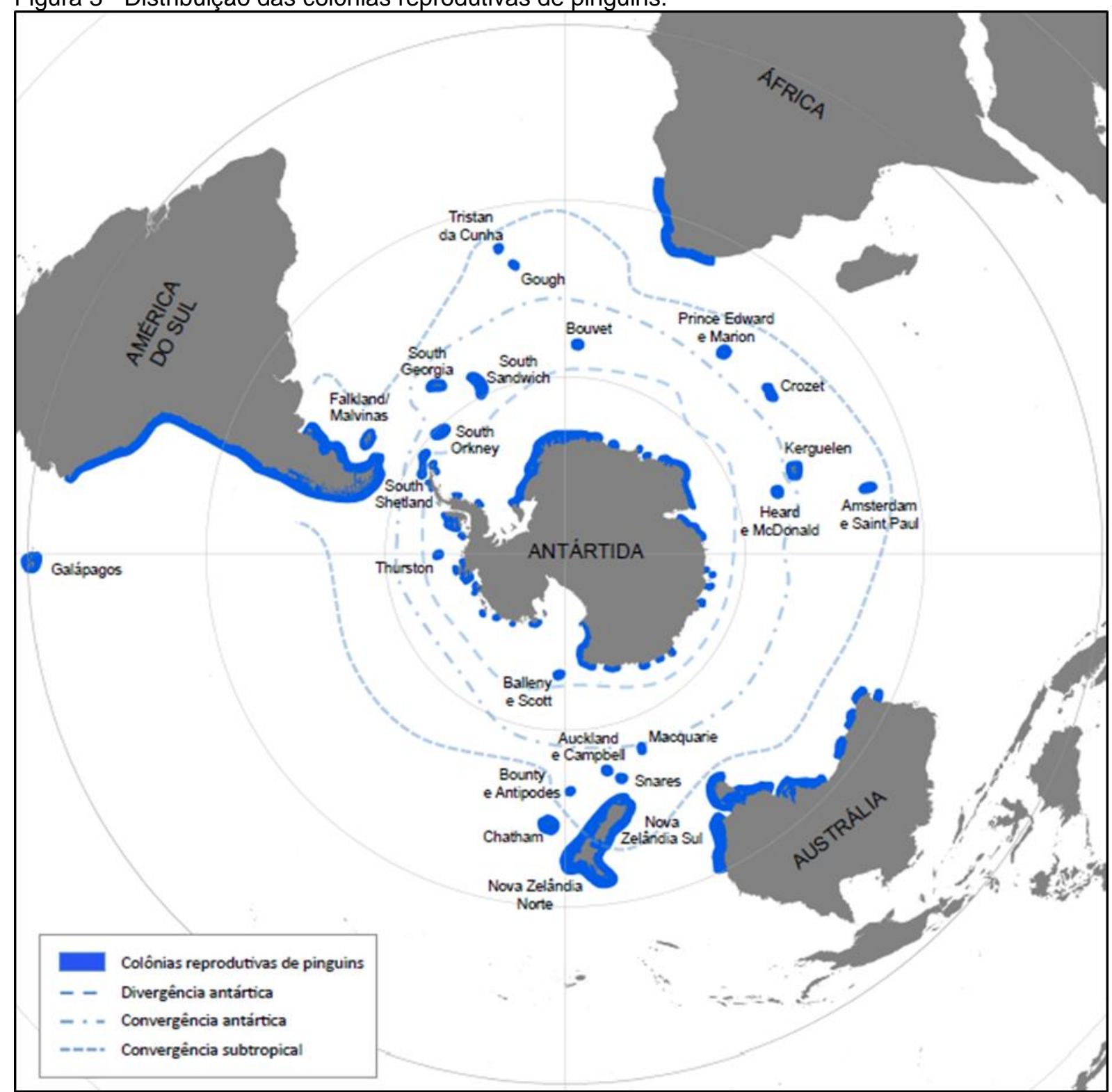

Fonte: (VANSTREELS, R.E.T., 2014).

Contrário as outras espécies de espécies está o pinguim-imperador, que foge ao padrão convencional e tem o início de sua reprodução sob fotoperíodos decrescentes, ocasião que coincide com o outono antártico e com o início de formações de geleiras importantes para a reprodução desta espécie. Inicialmente acreditava-se que o estímulo para a reprodução poderia estar associado com a visualização destas geleiras, entretanto a eficiente reprodução destes animais em cativeiro através de programas de luz que simulam o fotoperíodo antártico, demonstra que o estímulo pode estar mesmo ligado a dias curtos (GROSCOLAS et. al., 1986; WILLIAMS, 1995). 
Williams (1995) distingue os padrões reprodutivos dos pinguins em quatro classificações. A primeira é a dos "reprodutores sincrônicos do verão" que engloba a vasta maioria das espécies, tais como todas as espécies dos gêneros Pygoscelis, Eudyptes (exceto pinguim-de-Fiordland - E. pachyrhynchus), pinguins-de-olhosamarelos e pinguins-de-Magalhães e pinguins-reis. Porém, diferentemente das outras espécies que realizam esse ciclo anualmente, os pinguins-reis não seguem a mesma frequência reprodutiva em decorrência do longo tempo de cuidado parental. Excluindo esta particularidade, todas as espécies deste grupo iniciam sua reprodução entre setembro e novembro, levando cerca de 5 a 6 meses para concluíla com a emancipação do filhote. Outro tipo de padrão reprodutivo é o dos "reprodutores sincrônicos de outono e inverno", representado principalmente pelo pinguim-imperador que inicia sua reprodução no outono proporcionando a independência dos filhotes na primavera, quando há maior disponibilidade de alimentos. Também estão neste grupo os pinguins-de-Humboldt, que por se distribuírem em regiões mais tropicais tem a postura de ovos espalhada entre os meses de fevereiro a agosto. A terceira categoria é a dos "reprodutores sincrônicos de inverno e verão", representados pelos pinguins-africanos, os quais apresentam dois picos anuais dependendo da região da colônia, e os pinguins-azuis que também apresentam variações entre o período de postura, podendo ocorrer entre maio e outubro. Por último encontram os "reprodutores irregulares", que são os pinguins-deGalápagos, os mais tropicais de todos os pinguins e que não possuem um período definido para a reprodução, podendo efetuar posturas ao longo de todos os meses do ano. Portanto, é possível notar que mesmo com as diferenças quanto a época reprodutiva, em todas as espécies (a exceção dos pinguins-de-Galápagos) o fotoperíodo da região tem influência direta na sazonalidade. A vasta maioria dos Sphenisciformes inicia sua reprodução em dias crescentes, enquanto que o pinguimimperador e as espécies mais próximas aos trópicos se acasalam sob dias curtos e menores oscilações diárias de luz, respectivamente.

\subsection{FASES DO PERÍODO REPRODUTIVO}

O período reprodutivo dos pinguins pode ser dividido de diversas formas, aqui o abordaremos começando pela ocupação das colônias e formação de pares, e 
encerrando com o cuidado parental até o empenamento dos filhotes. Exemplos destes processos podem ser observados nas figuras 4 e 5 , que exemplificam as diferentes fases da reprodução em pinguins-de-Adélia $(P$. adeliae) e pinguins-deMagalhães (S. magellanicus), respectivamente.

\subsubsection{Formação das colônias reprodutivas}

O hábito de formação de colônias proporciona um efeito de diluição que, supostamente, ajuda os animais a se protegerem de predadores. É um comportamento comumente utilizado por diversas espécies de aves marinhas e pela maioria das espécies de pinguins (Quadro 01), em especial aqueles do gênero Pygoscelis e Aptenodytes (WILLIAMS, 1995). Apesar disso, existem exceções a formação de colônias como no caso do pinguim-de-olhos-amarelos (Megadyptes antipodes), que procura locais afastados de seus congêneres para fazer seu ninho e não o faz caso haja contato visual com outro casal de pinguins (SEDDON; DAVIS, 1989). O pinguim-azul e o pinguim-de-Galápagos pouco se importam com a formação de colônias (GARCÍA-BORBOROGLU; BOERSMA, 2013). Para os pinguins-imperadores, os agrupamentos não têm por objetivo a proteção contra predadores, mas sim escapar das baixíssimas temperaturas do inverno antártico, momento crucial da incubação dos ovos (DEWASMES et al., 1980).

Os locais das colônias reprodutivas geralmente ficam a apenas algumas centenas de metros do mar e a maioria dos pinguins acaba por utilizar pedras e pedregulhos como material de ninho, ou até mesmo cavar o solo para proteger seus ovos como os pinguins-de-Magalhães. Pinguins-Macaroni (Eudyptes chrysolophus) e pinguins-antárticos (Pygoscelis antarticus) podem formar seus ninhos até 500 metros acima do nível do mar, ao passo que outras espécies (como o pinguim-azul e o pinguim-de-olhos-amarelos) preferem formar seus ninhos em matas densas (Quadro 1) (DAVIS; DARBY, 1990; WILLIAMS, 1995). Neste quesito, os pinguins do gênero Aptenodytes novamente se diferem da maioria, pois não há a formação de ninho, com os ovos sendo incubados em cima das patas (GROSCOLAS, 1986; WILLIAMS, 1995). 
Quadro 1 - Características gerais e reprodutivas das 18 espécies de pinguins

\begin{tabular}{|c|c|c|c|c|c|c|c|c|c|c|c|c|c|c|}
\hline $\begin{array}{l}\text { Nome científico } \\
\text { Nome comum }\end{array}$ & $\begin{array}{r}\text { Distribuição } \\
\text { Geográfica } \\
\text { das Colônias } \\
\left({ }^{\circ} \mathbf{S}\right)\end{array}$ & $\begin{array}{l}\text { Estado de } \\
\text { Conservação } \\
\text { (IUCN, 2016) }\end{array}$ & $\begin{array}{l}\text { População } \\
\text { Estimada } \\
\text { (Indivíduos } \\
\text { maduros) }\end{array}$ & $\begin{array}{l}\text { Tendência da } \\
\text { População }\end{array}$ & Hábito & $\begin{array}{l}\text { Periodo } \\
\text { Reprodutivo }\end{array}$ & Tipo de Ninho & $\begin{array}{l}\text { Densidade na } \\
\text { Colônia }\end{array}$ & $\begin{array}{l}\text { Matur. } \\
\text { Sexual }\end{array}$ & $\begin{array}{l}\text { Massa dos } \\
\text { Ovos (g) }\end{array}$ & $\begin{array}{l}\text { Tempo de } \\
\text { Incubação } \\
\text { (dias) }\end{array}$ & $\begin{array}{l}\text { Periodo de } \\
\text { Guarda } \\
\text { (dias) }\end{array}$ & $\begin{array}{c}\text { Duração do } \\
\text { Cuidado } \\
\text { Parenteal } \\
\text { (dias) }\end{array}$ & $\begin{array}{c}\text { Fidelidade } \\
\text { Interanual } \\
\text { Par }\end{array}$ \\
\hline $\begin{array}{l}\text { Aptenodytes forsteri } \\
\text { Pinguim-imperador }\end{array}$ & $66-78$ & NT & 238.000 & Incerta & Migratório & Abril - Janeiro & Sobre as patas & 10 aves $/ \mathrm{m}^{2}$ & $4-5$ anos & $\begin{array}{c}420 \text { - } 540 \\
\text { (somente } 1 \\
\text { ovo) }\end{array}$ & $62-68$ & $45-50$ & 150 & $15 \%$ \\
\hline $\begin{array}{l}\text { Aptenodytes patagonicus } \\
\text { Pinguim-rei }\end{array}$ & $45-55$ & LC & $>1.000 .000$ & Aumento & $\begin{array}{l}\text { Parcialmente } \\
\text { migratório }\end{array}$ & $\begin{array}{l}\text { Novembro - } \\
\text { Fevereiro }\end{array}$ & Sobre as patas & 2.2 pares $/ \mathrm{m}^{2}$ & 6 anos & $\begin{array}{c}300 \text { - } 320 \\
\text { (somente } 1 \\
\text { ovo) }\end{array}$ & $53-55$ & $30-40$ & $\begin{array}{c}10-12 \\
\text { (meses) }\end{array}$ & $29 \%$ \\
\hline $\begin{array}{l}\text { Pygoscelis papua } \\
\text { Pinguim-papua }\end{array}$ & $46-65$ & LC & 387.000 & Estável & Residente & $\begin{array}{l}\text { Setembro - } \\
\text { Fevereiro }\end{array}$ & $\begin{array}{l}\text { Areia, pedras ou } \\
\text { em baixo de } \\
\text { arbustos }\end{array}$ & $\begin{array}{c}0,3-1,4 \text { ninhos/ } \\
\mathrm{m}^{2}\end{array}$ & 3- 4 anos & $120-130$ & $34-36$ & $7-10$ & $80-100$ & $80-90 \%$ \\
\hline $\begin{array}{l}\text { Pygoscelis antarticus } \\
\text { Pinguim-antártico }\end{array}$ & $54-64$ & LC & 4.000 .000 & Declínio & Migratório & Outubro - Março & $\begin{array}{c}\text { plataforma } \\
\text { circular de seixos } \\
\text { pequenos }\end{array}$ & $\begin{array}{c}0,3-1,4 \text { ninhos/ } \\
\mathrm{m}^{2}\end{array}$ & $\sim 2$ anos & $112-114$ & $33-36$ & $20-30$ & $50-60$ & $82 \%$ \\
\hline $\begin{array}{l}\text { Pygoscelis adeliae } \\
\text { Pinguim-de-Adélia }\end{array}$ & $54-77$ & LC & 3.790 .000 & Aumento & Migratório & $\begin{array}{l}\text { Setembro - } \\
\text { Março }\end{array}$ & $\begin{array}{l}\text { solo ligeriamente } \\
\text { cavado e rodeado } \\
\text { de seixos bem } \\
\text { organizados }\end{array}$ & $\begin{array}{c}0,3-1,4 \text { ninhos/ } \\
\mathrm{m}^{2}\end{array}$ & $4-6$ anos & $115-125$ & $32-34$ & 22 & $50-60$ & $60-80 \%$ \\
\hline $\begin{array}{l}\text { Magadyptes antipodes } \\
\text { Pinguim-de-olhos-amarelos }\end{array}$ & $43-52$ & EN & 1.700 & Declínio & Residente & $\begin{array}{l}\text { Setembro - } \\
\text { Março }\end{array}$ & $\begin{array}{l}\text { Florestas, } \\
\text { arbustos densos }\end{array}$ & $\begin{array}{l}1-5 \text { ninhos/ } \\
10.000 \mathrm{~m}^{2}\end{array}$ & $2-6$ anos & - & $39-51$ & $\begin{array}{l}40-50 \\
\text { (raramente } \\
\text { forma } \\
\text { créches) }\end{array}$ & $106-108$ & Alta \\
\hline
\end{tabular}


Continuação Quadro 1 - Características gerais e reprodutivas das 18 espécies de pinguins

\begin{tabular}{|c|c|c|c|c|c|c|c|c|c|c|c|c|c|c|}
\hline $\begin{array}{l}\text { Nome científico } \\
\text { Nome comum }\end{array}$ & $\begin{array}{l}\text { Distribuição } \\
\text { Geográfica } \\
\text { das Colônias } \\
\left({ }^{\circ} \mathrm{S}\right)\end{array}$ & $\begin{array}{l}\text { Estado de } \\
\text { Conservação } \\
\text { (IUCN, 2016) }\end{array}$ & $\begin{array}{l}\text { População } \\
\text { Estimada } \\
\text { (Indivíduos } \\
\text { maduros) }\end{array}$ & $\begin{array}{l}\text { Tendência da } \\
\text { População }\end{array}$ & Hábito & $\begin{array}{l}\text { Periodo } \\
\text { Reprodutivo }\end{array}$ & Tipo de Ninho & $\begin{array}{l}\text { Densidade na } \\
\text { Colônia }\end{array}$ & $\begin{array}{l}\text { Matur. } \\
\text { Sexual }\end{array}$ & $\begin{array}{l}\text { Massa dos } \\
\text { Ovos (g) }\end{array}$ & $\begin{array}{l}\text { Tempo de } \\
\text { Incubação } \\
\text { (dias) }\end{array}$ & $\begin{array}{l}\text { Periodo de } \\
\text { Guarda } \\
\text { (dias) }\end{array}$ & $\begin{array}{l}\text { Duração do } \\
\text { Cuidado } \\
\text { Parenteal } \\
\text { (dias) }\end{array}$ & $\begin{array}{c}\text { Fidelidade } \\
\text { Interanual } \\
\text { Par }\end{array}$ \\
\hline $\begin{array}{l}\text { Eudyptes schlegeli } \\
\text { Pinguim-real }\end{array}$ & 54 & NT & 850.000 & Estável & Residente & $\begin{array}{l}\text { Setembro - } \\
\text { Fevereiro }\end{array}$ & $\begin{array}{l}\text { Pedras, cascalho } \\
\text { ou areia }\end{array}$ & $\begin{array}{c}2,2-2,4 \text { ninhos/ } \\
m^{2}\end{array}$ & $7-8$ anos & $\begin{array}{l}\text { (10) } 100 \\
\text { (20) } 160\end{array}$ & 35 & 20 & 65 & Alta \\
\hline $\begin{array}{l}\text { Eudyptes chrysolophus } \\
\text { Pinguim-Macaroni }\end{array}$ & $46-65$ & VU & 6.300 .000 & Declínio & Migratório & Outubro - Março & $\begin{array}{l}\text { Ninhos } \\
\text { rudimentares, } \\
\text { geralmente usam } \\
\text { os rochedos }\end{array}$ & $\begin{array}{c}2,2-2,4 \text { ninhos/ } \\
\mathrm{m}^{2}\end{array}$ & $5-6$ anos & $\begin{array}{l}\left(1^{\circ}\right) 91-94 \\
\left(2^{\circ}\right) 145-155\end{array}$ & $33-37$ & $23-25$ & $60-70$ & Alta \\
\hline $\begin{array}{l}\text { Eudyptes sclateri } \\
\text { Pinguim-de-crista-ereta }\end{array}$ & $47-49$ & EN & 75.000 & Declínio & Migratório & $\begin{array}{l}\text { Setembro - } \\
\text { Janeiro }\end{array}$ & $\begin{array}{l}\text { Ninhos } \\
\text { rudimentares, } \\
\text { geralmente usam } \\
\text { os rochedos }\end{array}$ & $\begin{array}{c}2,2-2,4 \text { ninhos/ } \\
\mathrm{m}^{2}\end{array}$ & - & $\begin{array}{l}\text { (19) } 874-100 \\
\text { (20) } 149-151\end{array}$ & $\sim 35$ & - & - & - \\
\hline $\begin{array}{l}\text { Eudyptes pachyrhynchus } \\
\text { Pinguim-de-Fiordland }\end{array}$ & $43-48$ & VU & $2.750-3.500$ & Declínio & Migratório & $\begin{array}{l}\text { Julho - } \\
\text { Novembro }\end{array}$ & $\begin{array}{l}\text { Tocas, mata } \\
\text { densa e florestas } \\
\text { tropicais }\end{array}$ & $\begin{array}{l}\text { semi-colonial ou } \\
\text { solitário }\end{array}$ & $\sim 4$ anos & $\begin{array}{l}\left(1^{\circ}\right) 99-100 \\
\left(2^{\circ}\right) 116-120\end{array}$ & $30-36$ & $15-20$ & 75 & $\begin{array}{c}\sim 66 \% \\
(2 / 3 \text { dos } \\
\text { casais) }\end{array}$ \\
\hline $\begin{array}{l}\text { Eudyptes robustus } \\
\text { Pinguim-de-Snares }\end{array}$ & 48 & VU & 31.500 & Estável & Migratório & $\begin{array}{l}\text { Setembro - } \\
\text { Janeiro }\end{array}$ & $\begin{array}{l}\text { Tocas, mata } \\
\text { densa e florestas } \\
\text { tropicais }\end{array}$ & 2.0 ninhos/ $\mathrm{m}^{2}$ & $\sim 6-7$ anos & $\begin{array}{l}\text { (19) } 87-103 \\
\text { (20) } 112-131\end{array}$ & $31-37$ & 20 & 75 & Alta \\
\hline $\begin{array}{l}\text { Eudyptes moseleyi } \\
\text { Pinguim-de-penacho- } \\
\text { amarelo-do-norte }\end{array}$ & $37-40$ & VU & 240.300 & Declínio & Migratório & Julho - Janeiro & $\begin{array}{l}\text { Pedras e } \\
\text { Arbustos }\end{array}$ & $\begin{array}{c}2,2-2,4 \text { ninhos/ } \\
m^{2}\end{array}$ & - & $\begin{array}{c}\left(1^{\circ}\right) 69-99 \\
\left(2^{\circ}\right) 102-124\end{array}$ & $32-34$ & $20-26$ & $63-70$ & Alta \\
\hline
\end{tabular}


Continuação Quadro 1 - Características gerais e reprodutivas das 18 espécies de pinguins

\begin{tabular}{|c|c|c|c|c|c|c|c|c|c|c|c|c|c|c|}
\hline $\begin{array}{l}\text { Nome científico } \\
\text { Nome comum }\end{array}$ & $\begin{array}{c}\text { Distribuição } \\
\text { Geográfica } \\
\text { das Colônias } \\
\text { ('S) }\end{array}$ & $\begin{array}{l}\text { Estado de } \\
\text { Conservação } \\
\text { (IUCN, 2016) }\end{array}$ & $\begin{array}{l}\text { População } \\
\text { Estimada } \\
\text { (Indivíduos } \\
\text { maduros) }\end{array}$ & $\begin{array}{l}\text { Tendência da } \\
\text { População }\end{array}$ & Hábito & $\begin{array}{l}\text { Periodo } \\
\text { Reprodutivo }\end{array}$ & Tipo de Ninho & $\begin{array}{l}\text { Densidade na } \\
\text { Colônia }\end{array}$ & $\begin{array}{l}\text { Matur. } \\
\text { Sexual }\end{array}$ & $\begin{array}{l}\text { Massa dos } \\
\text { Ovos (g) }\end{array}$ & $\begin{array}{l}\text { Tempo de } \\
\text { Incubação } \\
\text { (dias) }\end{array}$ & $\begin{array}{l}\text { Periodo de } \\
\text { Guarda } \\
\text { (dias) }\end{array}$ & $\begin{array}{l}\text { Duração do } \\
\text { Cuidado } \\
\text { Parenteal } \\
\text { (dias) }\end{array}$ & $\begin{array}{c}\text { Fidelidade } \\
\text { Interanual } \\
\text { Par }\end{array}$ \\
\hline $\begin{array}{l}\text { Eudyptes chrysocome } \\
\text { Pinguim-de-penacho- } \\
\text { amarelo-do-sul }\end{array}$ & $43-54$ & VU & 1.250 .000 & Declínio & Migratório & $\begin{array}{l}\text { Outubro - } \\
\text { Fevereiro }\end{array}$ & $\begin{array}{l}\text { Pedras e } \\
\text { Arbustos }\end{array}$ & $\begin{array}{c}2,2-2,4 \text { ninhos/ } \\
m^{2}\end{array}$ & $\sim 4$ anos & $\begin{array}{l}\text { (1으 } 76-80 \\
\text { (2) } 107-112\end{array}$ & $32-34$ & $24-26$ & $65-75$ & $59 \%$ \\
\hline $\begin{array}{l}\text { Spheniscus magellanicus } \\
\text { Pinguim-de-Magalhães }\end{array}$ & $41-55$ & NT & $\begin{array}{l}1.100 .000- \\
1.600 .000\end{array}$ & Declínio & Migratório & $\begin{array}{l}\text { Setembro - } \\
\text { Fevereiro }\end{array}$ & $\begin{array}{l}\text { Pedras, tocas ou } \\
\text { em baixo de } \\
\text { arbustos }\end{array}$ & $\begin{array}{l}\text { 1ninho/ } \mathrm{m}^{2}-1 \\
\text { ninho/ } 100 \mathrm{~m}^{2}\end{array}$ & $4-6$ anos & $\begin{array}{l}\left(^{\circ}{ }^{\circ}\right) 120-145 \\
\left(2^{\circ}\right) 115-135\end{array}$ & $38-41$ & 29 & $60-70$ & $90 \%$ \\
\hline $\begin{array}{l}\text { Spheniscus demersus } \\
\text { Pinguim-Africano }\end{array}$ & 24 - 34 & EN & 25.000 & Declínio & Residente & $\begin{array}{l}\text { Ano inteiro com } \\
\text { alguns picos } \\
\text { regionais }\end{array}$ & $\begin{array}{l}\text { Areia, pedras, } \\
\text { tocas ou em } \\
\text { baixo de arbustos }\end{array}$ & $\begin{array}{l}0,001-0,012 \\
\text { ninhos/ } 10 \mathrm{~m}^{2}\end{array}$ & 4- 6 anos & $75-132$ & $36-39$ & 40 & $65-105$ & $80-92 \%$ \\
\hline $\begin{array}{l}\text { Spheniscus humboldti } \\
\text { Pinguim-de-Humboldt }\end{array}$ & $5-42$ & VU & 16.000 & Desconhecido & Migratório & $\begin{array}{l}\text { Ano inteiro com } \\
\text { alguns picos } \\
\text { regionais }\end{array}$ & $\begin{array}{l}\text { Guano, tocas em } \\
\text { pedras, arbustos }\end{array}$ & - & $3-6$ anos & $106-132$ & $40-42$ & - & 75 & - \\
\hline $\begin{array}{l}\text { Spheniscus mendiculus } \\
\text { Pinguim-de-Galápagos }\end{array}$ & $0-2$ & EN & 60.000 & Declínio & Residente & Ano inteiro & $\begin{array}{l}\text { tocas em rochas } \\
\text { ulcanicas }\end{array}$ & $\begin{array}{l}\text { distância }>1,8 \mathrm{~m} \\
\text { até } 10 \mathrm{~m}\end{array}$ & - & $46-50$ & $38-42$ & $\begin{array}{c}25-30 \\
\text { (não há } \\
\text { créches, } \\
\text { permanece } \\
\text { m no ninho) }\end{array}$ & $60-65$ & $93 \%$ \\
\hline $\begin{array}{l}\text { Eudyptula minor } \\
\text { Pinguim-azul }\end{array}$ & $32-47$ & LC & 234.880 & Estável & Residente & $\begin{array}{l}\text { Austrália: } \\
\text { Agosto - } \\
\text { Fevereiro } \\
\text { Nova Zelândia: } \\
\text { Junho - } \\
\text { Fevereiro }\end{array}$ & $\begin{array}{l}\text { Tocas, arbustos, } \\
\text { matas densas }\end{array}$ & $\begin{array}{l}\text { semi-colonial } \\
\text { (raramente } \\
\text { solitário) }\end{array}$ & $2-3$ anos & $53-54$ & $33-39$ & $13-20$ & 50 - 65 dias & Alta \\
\hline
\end{tabular}

Fonte: (WILLIAMS, 1995; GACÍA-BORBOROGLU; BOERSMA, 2013, IUCN; 2016 adaptação de RIBEIRO, J.D., 2017).

Legenda: Siglas do estado de conservação: EN - Ameaçado; VU - Vulnerável; NT - Quase Ameaçado; LC - Pouco preocupante 


\subsubsection{Escolha e fidelidade de parceiros}

A maioria das aves vive em sistemas reprodutivos monogâmicos (LACK, 1968), e isso também acontece com os pinguins que permanecem somente com um par durante toda a temporada reprodutiva. Ancel, Beaulieu e Gilbert (2013) avaliaram o período de formação de pares em cada espécie considerando a porcentagem de tempo investido para selecionar um parceiro dentro do tempo total investido na reprodução, (ou seja, até a emancipação do filhote). Nesta relação os autores concluíram que o pinguim-rei é a espécie que menos investe na seleção de parceiros (apenas $3 \%$ ), dado que é explicado pelo tempo de cuidado parental em relação ao tempo total de reprodução (15 das 16,5 semanas). Juntas, estas informações colocam o pinguim-rei no patamar de espécie que leva mais tempo para emancipar seu filhote. Enquanto isso, a média para a maioria das espécies é de 14 a $18 \%$ de investimento no pareamento, período que para alguns pinguins representa apenas 1 a 2 semanas. São nestas primeiras semanas que os níveis plasmáticos de testosterona se encontram elevados tanto nos machos quanto nas fêmeas, todavia, de forma mais evidente nos machos por coincidir com busca e defesa de ninhos (COCKREM; SEDDON, 1994; FOWLER et al., 1994).

Quanto à monogamia comumente atribuída aos pinguins, fica claro no Quadro 1 que a grande maioria das espécies realmente apresenta um alto índice de fidelidade interanual, sendo este mais baixo apenas para as espécies do gênero Aptenodytes. Tal característica pode estar associada a ausência de um local exato de ninho pois, como já descrito, a incubação para estas espécies é feita sobre as patas. Nas outras espécies, além de ser observada a fidelidade interanual dos pares, também há um alto índice de fidelidade ao ninho nas diferentes estações reprodutivas (WILLIAMS, 1995; GARCÍA-BORBOROGLU; BOERSMA, 2013). Para o pinguim-de-Humboldt (Spheniscus humboldti), o índice de fidelidade interanual não é conhecido, mas sabe-se que é a espécie é monogâmica. Entretanto, nesta espécie existem relatos de formação de mais de um par por animal além de cópulas extraconjugais no período reprodutivo, mas sem a geração de prole (SCHWARTZ et al., 1999). 


\subsubsection{Postura e incubação}

Para as espécies migratórias, o tempo entre a chegada das fêmeas as colônias reprodutivas e o início da postura é muito curto. Por exemplo, em pinguinsde-Magalhães esse tempo é em média de 11 dias (YORIO; BOERSMA, 1994). Porém, apesar de estudos terem sido conduzidos para elucidar a dinâmica folicular e os eventos que antecedem a postura, diversas lacunas ainda permanecem para animais de vida livre. Sabe-se que fêmeas e machos chegam a colônia com níveis altos de testosterona, e que as fêmeas também apresentam níveis elevados de estradiol previamente ao período de incubação (WILLIAMS, 1992; FOWLER et al., 1994).

A composição da ninhada em pinguins é de dois ovos com intervalo médio de postura de 4 a 5 dias entre os ovos, exceto para o gênero Aptenodytes que faz postura de somente um ovo (Quadro 1). Há, entretanto, casos de postura de somente um ovo dentre as outras espécies, fato que é comumente associado a animais jovens (WILLIAMS, 1981; WILLIAMS, 1995; GARCÍA-BORBOROGLU; BOERSMA, 2013). A composição dos ovos é similar dentre os membros da família Spheniscidae, apesar da diferença marcante entre os pesos. Contudo, em geral, o tamanho do ovo em pinguins é pequeno em relação ao peso das fêmeas quando comparado a outros grupos de aves. Os pinguins também diferem quanto a resistência da casca e o tamanho da gema, que é superior àquelas observadas em aves altriciais (WILLIAMS, 1981).

O processo de incubação geralmente se inicia após a postura dos dois ovos, entretanto, algumas espécies iniciam a incubação no primeiro ovo, o que gera uma prole assíncrona, prejudicando o desenvolvimento do segundo filhote que já compete por alimento com um filhote maior (SEDDON; HEEZIK, 1991; WILLIAMS, 1995; ANCEL et al., 2013). Machos e fêmeas se revezam na incubação em turnos de tempo variável entre as espécies, e novamente o pinguim-imperador torna-se a exceção uma vez que somente o macho desempenha esta tarefa enquanto a fêmea repõe a energia gasta durante a postura. Em jejum desde a chegada à colônia até o final da incubação, pinguins-imperadores chegam a perder $33-55 \%$ do peso corpóreo (DEWASMES et al., 1980; WILLIAMS, 1995). 


\subsubsection{Cuidado parental e emancipação do filhote}

Filhotes podem ser classificados como altriciais ou precociais, dependendo do grau de necessidade de cuidado parental logo após a sua eclosão. Esse espectro vai desde de a intensa dependência, altricial, até um animal que eclode pronto para buscar seu alimento, precocial (STARCK; RICKLEFS, 1998). Neste sentido, os filhotes das espécies de pinguins são classificados como semi-altriciais, pois ao nascerem já apresentam olhos abertos e alguma atividade, diferente dos animais verdadeiramente altriciais. Todavia, por possuírem uma fina camada de plumas cobrindo o corpo e nenhuma impermeabilidade, eles dependem inteiramente dos pais para a alimentação e aquecimento, até que haja ganho energético e aumento de peso para a termoregulação. Este período inicial é chamado de "guarda", e nela o filhote permanece no ninho sempre acompanhado por um dos pais. A duração do período de guarda é variável entre as espécies (Quadro 1) (WILLIAMS, 1995).

Com o crescimento dos filhotes, os pais já não conseguem contê-los nos ninhos e começam a deixá-los sozinhos enquanto ambos vão buscar alimentos, visto que a demanda dos filhotes aumenta. Dá-se então, o início do período de creche, nele os filhotes se aglomeram em grupos de número variável de indivíduos, dependendo da espécie para manutenção do calor e também proteção contra possíveis predadores. Neste período os filhotes ainda estão cobertos por plumas, mas logo realizarão uma muda que os tornará impermeáveis, como os adultos (WILLIAMS, 1995; GARCÍA-BORBOROGLU; BOERSMA, 2013).

A muda dos filhotes marca o final do cuidado parental e, portanto, da estação reprodutiva. $\mathrm{Na}$ maioria das espécies migratórias, logo após o empenamento impermeável dos filhotes, estes já saem ao mar e iniciam o período migratório sem manter qualquer vínculo familiar (WILLIAMS, 1995). Este é o momento de início da muda de penas dos animais adultos, que nos pinguins é conhecida como "muda catastrófica", processo em que os animais trocam todas as penas do corpo ao mesmo tempo num período de algumas semanas, ao invés de algumas penas por vez ao longo do ano, como nas outras aves (DAVIS; DARBY, 1990). Finalizado o processo da muda anual, os animais iniciam o período de migração, animais residentes realizam viagens de forrageio e eventualmente retornam às colônias (WILLIAMS, 1995). 
Figura 4 - Reprodução do pinguim-de-Adélia (Pygoscelis adeliae)
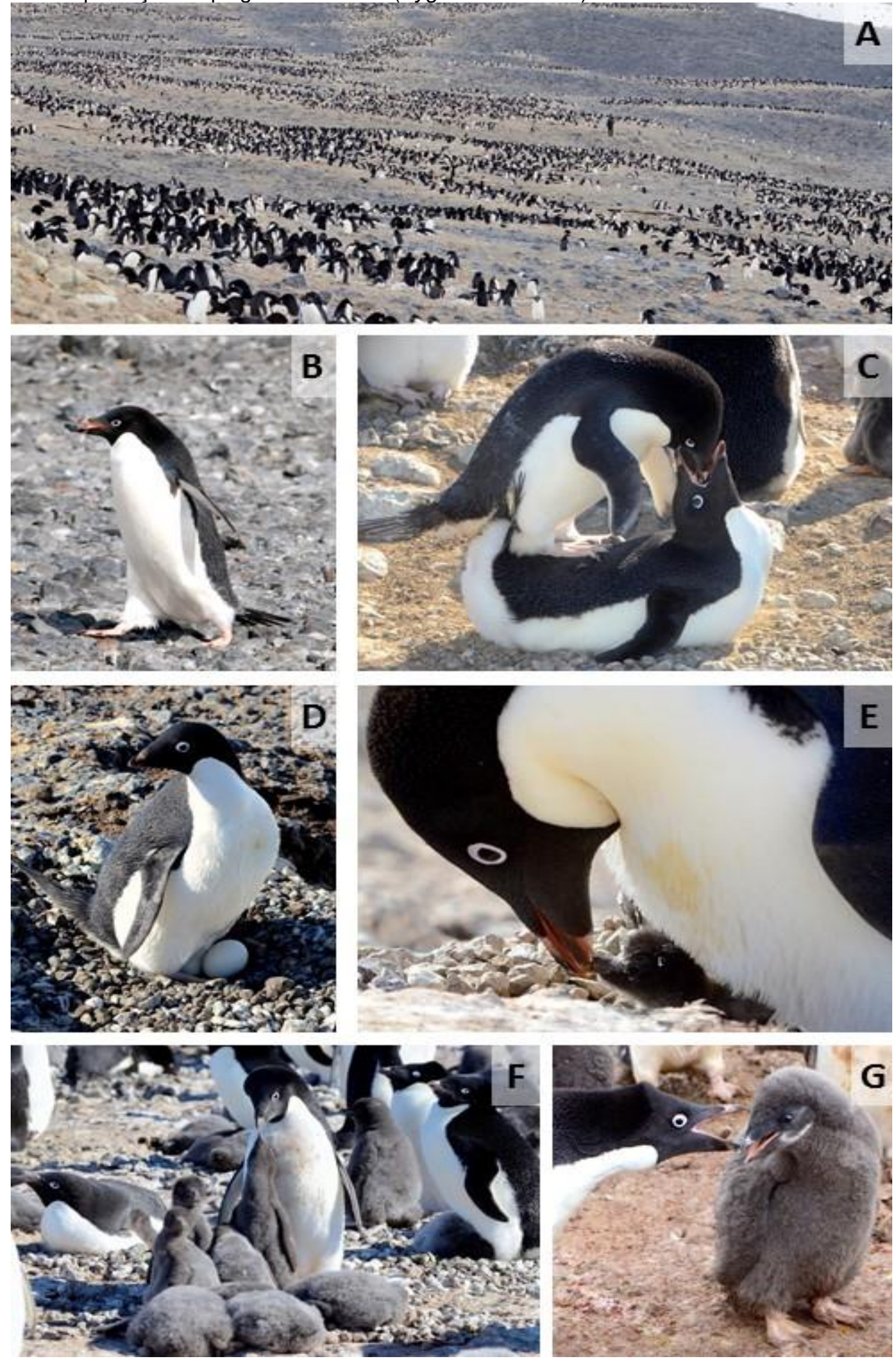

Fonte: (RUOPPOLO, V., 2015).

(A) Colônia reprodutiva de Cape Crozier, llha de Ross (Antártica); (B) Pinguim levando uma pedra para fazer o ninho; (C) Cópula; (D) Incubação dos ovos; (E) Alimentação do filhote no período de guarda; (F) Filhotes formando creche e um dos pais alimentando seu filhote; (G) Início da troca de penas para emancipação do filhote que ainda é alimentado pelos pais. 
Figura 5 - Reprodução do pinguim-de-Magalhães (Spheniscus magellanicus)
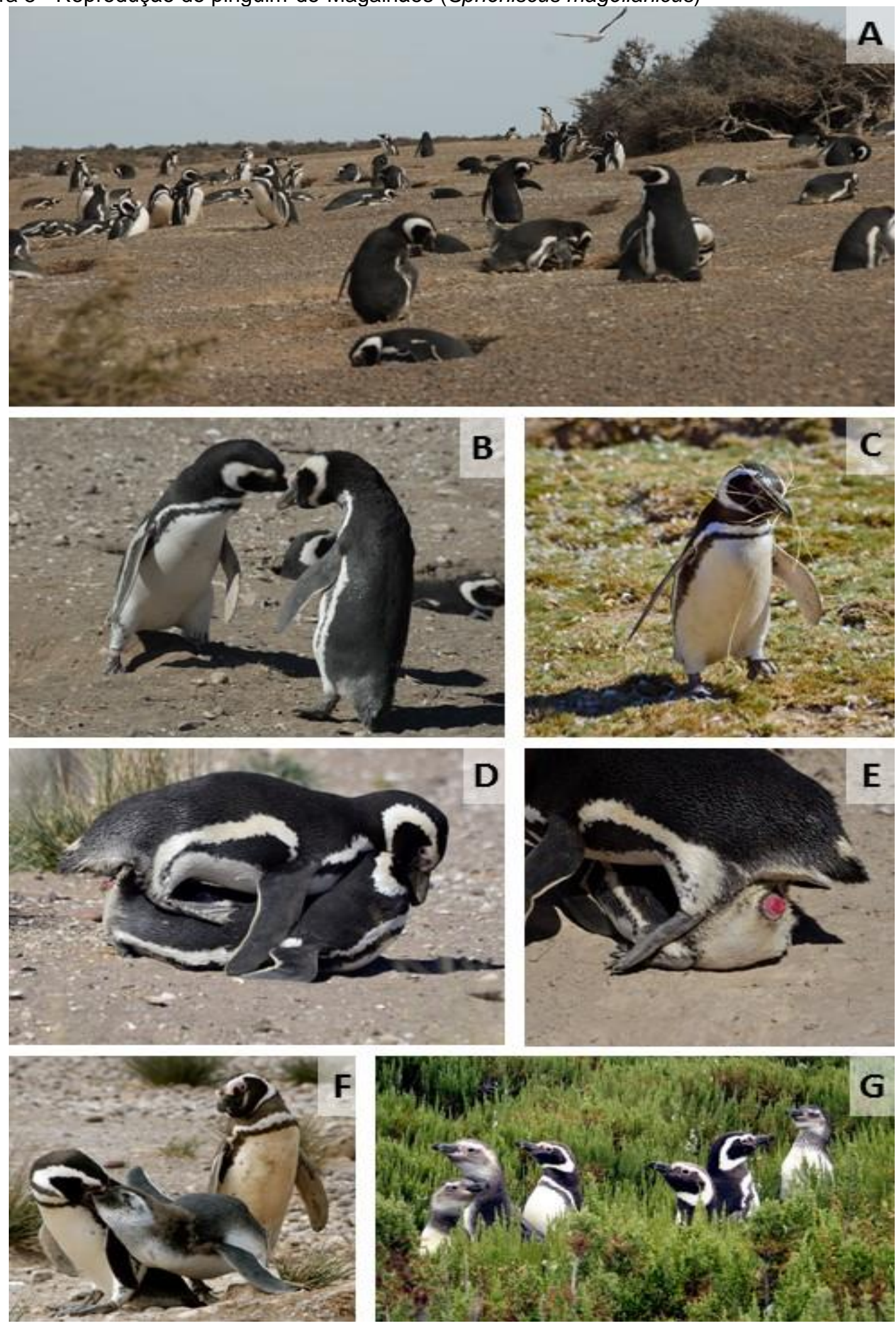

Fonte: (RUOPPOLO, V., 2012).

(A) Colônia reprodutiva de Punta Tombo (Argentina), notar os ninhos em tocas cavadas no solo e alguns animais buscando ninhos de baixo de arbustos para proteção do calor intenso; (B) Comportamento agonístico entre machos, provável disputa por ninho (início da estação); (C) Pinguim levando material para o elaboração do ninho; (D) Cópula; (E) Detalhe da cópula com demonstração da sobreposição das cloacas; (F) Alimentação do filhote já quase emancipado; (G) Animais jovens e adultos, possível notar a diferença na coloração e ausência do halo preto no juvenil. 


\subsection{A REPRODUÇÃO DE PINGUINS EM CATIVEIRO}

Pinguins são mantidos em cativeiro desde o início do século 20. Os primeiros exemplares, três pinguins-rei (Aptenodytes patagonicus), foram enviados como presentes do rei da Noruega ao zoológico de Edimburgo (Escócia), em 1913. Deste evento em diante, pinguins se tornaram aves populares no cativeiro, fato que pode estar relacionado por serem facilmente antropomórficos. O engraçado andar bípede, somado a aparência de vestir um smoking faz do pinguim um animal extremamente carismático.

Gailey-Phipps (1978) conduziu uma pesquisa com todos os zoológicos e aquários que abrigavam pinguins na época (124 por todo o mundo), e obteve alguns resultados interessantes das 64 instituições que retornaram o questionário. As instituições somavam 11 diferentes espécies de pinguins, das quais oito já haviam reproduzido em cativeiro (pinguim-rei, pinguim-de-Adélia, pinguim-papua, pinguimMacaroni, pinguim-saltador-de-rochas, pinguim-azul, pinguim-africano e pinguim-deHumboldt). Outras três espécies (pinguim-imperador, pinguim-de-Fiordland e pinguim-de-Magalhães) eram mantidas em cativeiro, porém sem reprodução ex situ relatada. Metade das instituições que tiveram sucesso reprodutivo, também reportaram a sobrevivência dos filhotes até a emancipação. A autora chegou a conclusão que o manejo adequado para obtenção de reprodução em cativeiro deveria cumprir os seguintes critérios: número de animais no plantel superior a 3 casais, piscina com ampla superfície, manejo adequado da temperatura e cuidados básicos de alimentação, suplementação vitamínica e recinto. Trabalhos mais recentes abrangendo um número inferior de instituições também chegaram as conclusões apresentadas por Gailey-Phipps (1978), e ainda enfatizaram a importância do número de indivíduos no plantel (BLAY; CÔTE, 2001; MARSHALL et al., 2016; SCHWEIZER, 2016).

\subsubsection{A reprodução de pinguins-de-Magalhães em cativeiro no Brasil}

O pinguim-de-Magalhães (Spheniscus magellanicus) é a única espécie de pinguim avistada habitualmente na costa do Brasil, é também a única a ser mantida 
em cativeiro no país. Embora não possua colônias reprodutivas na costa brasileira, durante suas migrações invernais anuais pode ser comumente avistado em águas do sul e sudeste. Durante esta migração, pode ser avistado em bandos ou indivíduos solitários durante os meses de maio a setembro (STOKES; BOERSMA, 1999; SICK, 2001; CEMAVE, 2010). O ciclo anual destas aves (Figura 6) está intimamente ligado à sua característica sazonal. Machos retornam as colônias reprodutivas em setembro, iniciando a ocupação de ninhos. Fêmeas, um pouco mais tardias, chegam as colônias pouco antes da postura de ovos. Após a incubação (cerca de 40 dias), levam aproximadamente 70 dias para emancipar o filhote. Passado o período reprodutivo, os animais realizam a muda anual de penas, encerrando seu período em terra (WILLIAMS, 1995; GARCÍA-BORBOROGLU; BOERSMA, 2013).

Figura 6 - Ciclo biológico anual do pinguim-de-Magalhães.

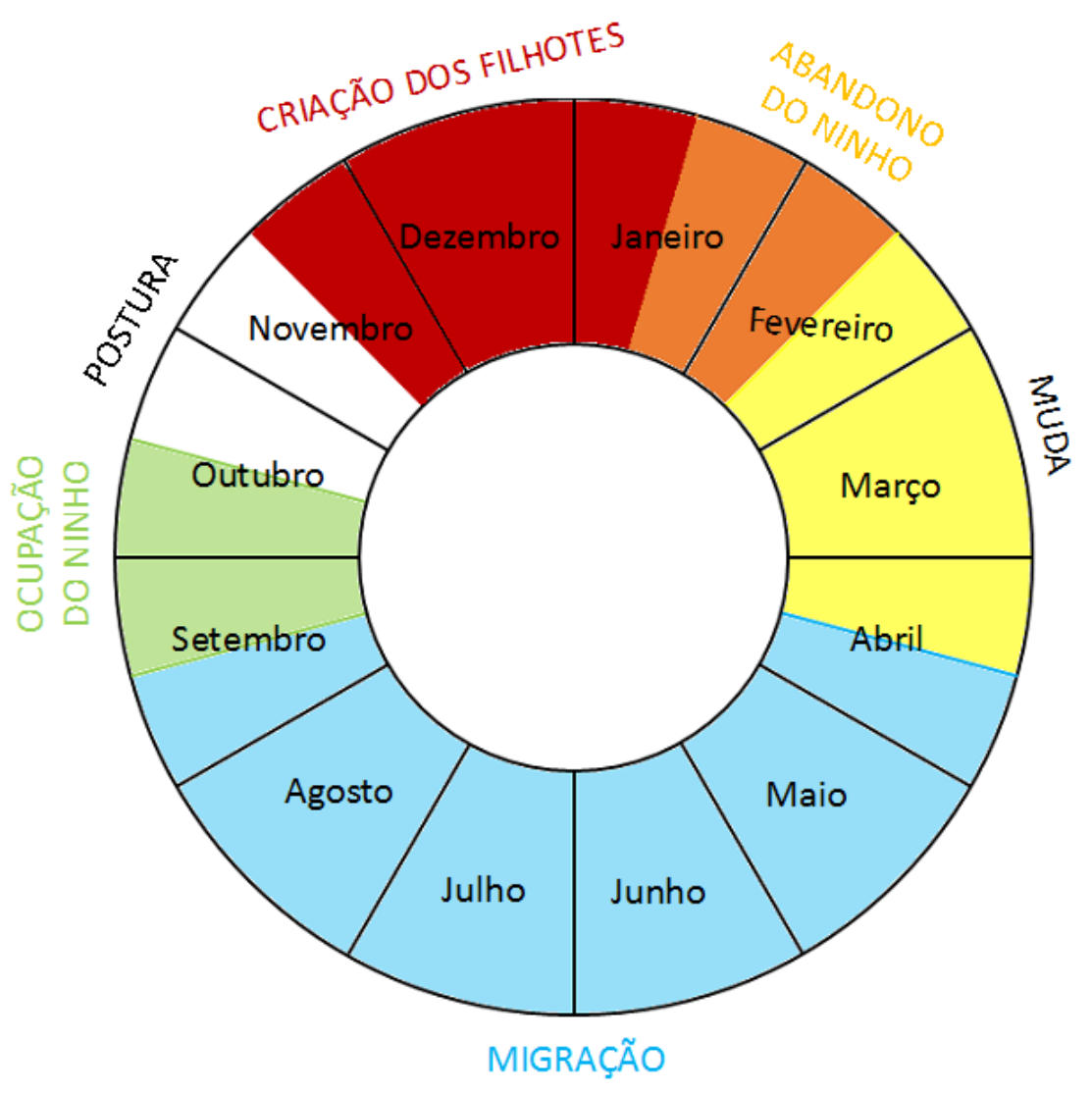

Fonte: (GARCÍA-BORBOROGLU; BOERSMA, 2013). 
O período migratório representa um momento de grandes desafios para estas aves. Dentre os principais estão a contaminação crônica do oceano com petróleo e derivados (LUNA et al., 2012; GARCÍA-BORBOROGLU et al., 2006), os acidentes com redes de pesca (TASKER et al., 2000; LUNA et al., 2002; CARDOSO et al., 2011), a ingestão de itens sintéticos (PETRY; FONSECA, 2002) e parasitoses gastrointestinais (FONSECA; PETRY; JOST, 2001). Não obstante, enfrentam ainda a competição por recursos alimentares com a pesca comercial, a captura acidental em redes de pesca e as mudanças climáticas (YORIO et al., 1999; TASKER et al., 2000; BOERSMA, 2008). O resultado de todas estas intervenções é o registro de dezenas a milhares de encalhes de pinguins nas praias brasileiras todos os anos. A ampla maioria destes animais são juvenis em seu primeiro ano de migração (SICK, 2001; PETRY; FONSECA, 2002; CEMAVE, 2010). Em geral, os encalhes são de animais debilitados, desidratados e por vezes afetados pelos problemas acima relatados, tornando-se necessária a intervenção humana. A reabilitação e soltura dos pinguins assim encontrados é a ferramenta utilizada objetivando a diminuição da mortalidade (SILVA-FILHO; RUOPPOLO, 2014), entretanto, aves que não se encontram aptas à soltura são encaminhados ao cativeiro.

Pinguins-de-Magalhães são mantidos em cativeiro no Brasil desde 1945, quando foi inaugurado o primeiro recinto específico para a espécie no Aquário de Santos (São Paulo). Em 2001, a mesma instituição registrou o primeiro nascimento em cativeiro desta espécie no Brasil. Atualmente, diversas instituições mantêm os pinguins-de-Magalhães em seus planteis, a maioria delas na região sudeste do país. Contudo, os registros de reprodução em cativeiro são esparsos e demonstram uma baixa eficiência e irregularidade no ciclo biológico destes animais. 


\section{REFERÊNCIAS}

ANCEL, A. et al. Foraging behaviour of emperor penguins as a resource detector in winter and summer. Nature, v. 360, n. 6402, p. 336-339, 1992.

ANCEL, André; BEAULIEU, Michaël; GILBERT, Caroline. The different breeding strategies of penguins: a review. Comptes rendus biologies, v. 336, n. 1, p. 1-12, 2013.

BLAY, Nicola; CÔTÉ, Isabelle M. Optimal conditions for breeding of captive Humboldt penguins (Spheniscus humboldti): a survey of British zoos. Zoo Biology, v. 20 , n. 6 , p. 545-555, 2001.

BOERSMA, P. D. Penguins as marine sentinels. BioScience, v. 58, n. 7, p. 597607, 2008.

BOERSMA, P. D.; REBSTOCK, G.; FRERE, E.; MOORE, M. Following the fish: penguins and productivity in the south Atlantic. Ecological Monographs, v. 79, n. 1, p. 59-76, 2009.

BOERSMA, P. D.; STOKES, D. L. Mortality patterns, hatching asynchrony, and size asymmetry in Magellanic Penguin Spheniscus magellanicus chicks. The Penguins: Ecology and Management. New South Wales: Surrey Beatty \& Sons, p. 3-25, 1995.

CARDOSO, L. G.; BUGONI, L.; MANCINI, P. L.; HAIMOVICI, M. Gillnet fisheries as a major mortality factor of Magellanic penguins in wintering areas. Marine Pollution Bulletin, v. 62, n. 4, p. 840-844, 2011.

CENTRO NACIONAL DE PESQUISA E CONSERVAÇÃO DE AVES SILVESTRES (CEMAVE). Projeto nacional de monitoramento do pinguim-de-Magalhães Spheniscus magellanicus. Cabedelo: CEMAVE, 2010. 34 p.

COCKREM, J. F.; SEDDON, P. J. Annual cycle of sex steroids in the yellow-eyed penguin (Megadyptes antipodes) on South Island, New Zealand. General and comparative endocrinology, v. 94, n. 1, p. 113-121, 1994.

CRANFIELD, M. Sphenisciformes. In: Fowler, M. E.; Miller, R. E. Zoo and wild animal medicine, 5. ed. Pennsylvania: W.B. Saunders, 2003. p. 103-110.

DAVIS, L. S.; DARBY, J. T. Penguin biology. San Diego: Academic Press, 1990. p. 297-315.

DAWSON, A.; KING, V. M.; BENTLEY, G. E.; BALL, G. F. Photoperiodic control of seasonality in birds. Journal of Biological Rhythms, v. 16, n. 4, p. 365-380, 2001.

DEWASMES, G. et al. Resting metabolic rate and cost of locomotion in long-term fasting emperor penguins. Journal of Applied Physiology, v. 49, n. 5, p. 888-896, 1980. 
DIEBOLD, E. N.; BRANCH, S.; HENRY, L. Management of penguin populations in North American zoos and aquariums. Marine Ornithology, v. 27, p. 171-176, 1999.

FONSECA, V. S. S.; PETRY, M. V.; JOST, A. H. Diet of the Magellanic penguin on the coast of Rio Grande do Sul, Brazil. Waterbirds, v. 24, p. 290-293, 2001.

FOWLER, Gene S. et al.. Reproductive endocrinology and weight change in relation to reproductive success in the Magellanic penguin (Spheniscus magellanicus). General and comparative endocrinology, v. 94, n. 3, p. 305-315, 1994.

GAILEY-PHIPPS, J. A world survey of penguins in captivity. International Zoo Yearbook, v.18, p. 7-13, 1978.

GARCÍA-BORBOROGLU, P. G.; BOERSMA, P. D. (Ed.). Penguins - natural history and conservation. Seattle: University of Washington Press, 2013. p 233-263.

GARCÍA-BORBOROGLU, P.; BOERSMA, P. D.; RUOPPOLO, V.; SILVA-FILHO R. P.; ADORNES, A. C.; CONTE-SENA, D.; VELOZO, R.; KOLESNIKOVAS, C. M.; DUTRA, G.; MARACINI, P.; NASCIMENTO, C. C.; RAMOS-JÚNIOR, V.; BARBOSA, L.; SERRA, S. Magellanic penguin mortality in 2008 along the SW Atlantic coast. Marine Pollution Bulletin, v. 60, n. 10, p. 1652-1657, 2010.

GROSCOLAS, R.; LELOUP, J. The endocrine control of reproduction and molt in male and female emperor (Aptenodytes forsteri) and Adelie (Pygoscelis adeliae) penguins. General and Comparative Endocrinology, v. 63, n. 2, p. 264-274, 1986.

JACOBS, Jerry D.; WINGFIELD, John C. Endocrine control of life-cycle stages: a constraint on response to the environment?. The Condor, v. 102, n. 1, p. 35-51, 2000.

LACK, David Lambert. Ecological adaptations for breeding in birds. 1968.

LUNA, G.; HENNICKE, J.; WALLACE, R.; SIMEONE, A.; WOLFAARDT, A.; WHITTINGTON, P.; ELLIS, S.; MCGOVERN, M. Spheniscus penguin conservation workshop: Final Report. Apple Valley: IUCN/ SSC Conservation Breeding Specialist Group, 2002. 83 p.

MARSHALL, Andrew R. et al. Husbandry and enclosure influences on penguin behavior and conservation breeding. Zoo Biology, v. 35, n. 5, p. 385-397, 2016.

PEREIRA, R.J.G. Reprodução das Aves. In: CUBAS, Z.S.; SILVA, J.C.R.; CATÃODIAS, J.L. (eds). Tratado de Animais Selvagens - Medicina Veterinária 2a Edição (ISBN 978-85-277-2618-4). São Paulo, Editora Roca, 2014, p. 2235-2269.

PETRY, M. V.; FONSECA, V. S. S. Effects of human activities in the marine environment on seabirds along the coast of Rio Grande do Sul, Brazil. Ornitologia Neotropical, v. 13, p.137-142, 2002. 
RUOPPOLO, V.; VANSTREELS, R. E. T.; WOEHLER, E. J.; HEREDIA, S. A. R.; ADORNES, A. C.; SILVA-FILHO, R. P.; MATUS, R.; POLESCHI, C.; KAREN GRIOT, K.; KOLESNIKOVAS, C. K. M.; SERAFINI, P. Survival and movements of Magellanic penguins rehabilitated from oil fouling along the coast of South America, 2000-2010. Marine Pollution Bulletin, v. 64, n. 7, p. 1309-1317, 2012.

SCHWARTZ, Michael K. et al. Female-solicited extrapair matings in Humboldt penguins fail to produce extrapair fertilizations. Behavioral Ecology, v. 10, n. 3, p. 242-250, 1999.

SCHWEIZER, Simone et al. King penguins in zoos: relating breeding success to husbandry practices. Journal of Zoo and Aquarium Research, v. 4, n. 2, p. 91-98, 2016.

SEDDON, Philip J.; DAVIS, Lloyd S. Nest-site selection by Yellow-eyed Penguins. Condor, p. 653-659, 1989.

SEDDON, Philip J.; VAN HEEZIK, Yolanda. Effects of hatching order, sibling asymmetries, and nest site on survival analysis of Jackass Penguin chicks. The Auk, p. 548-555, 1991.

SHARP, Peter J. Strategies in avian breeding cycles. Animal Reproduction Science, v. 42, n. 1-4, p. 505-513, 1996.

SICK, H. Ornitologia Brasileira. Rio de Janeiro: Nova Fronteira, 2001. 926 p.

SILVA-FILHO, R. P.; RUOPPOLO, V. Sphenisciformes. In: CUBAS, Z. S.; SILVA, J. C. R.; CATÃO-DIAS, J. L. (Ed.). Tratado de animais selvagens. São Paulo: Roca, 2014. p. 384-416.

STARCK, J. Matthias; RICKLEFS, Robert E. Patterns of development: the altricialprecocial spectrum. Oxford Ornithology Series, v. 8, p. 3-30, 1998.

STOKES, D. L.; BOERSMA, P. D. Where Breeding Magellanic penguins Spheniscus magellanicus forage: satellite telemetry results and their implications for penguin conservation. Marine Ornithology, v. 27, p. 59-65, 1999.

STOSKOPF, Michael K.; BEALL, Frederick B. The husbandry and medicine of captive penguins. In: Proc Am Assoc Zoo Vet. p. 81-96. 1980.

TASKER, Mark L. et al. The impacts of fishing on marine birds. ICES Journal of Marine Science: Journal du Conseil, v. 57, n. 3, p. 531-547, 2000.

The IUCN Red List of Threatened Species. Version 2016-3. Disponível em: <www.iucnredlist.org>. Acesso em: 05 de dezembro de 2016.

VANSTREELS, RALPH ERIC THIJL et al. Gender determination from morphometrics in migrating Magellanic Penguins (Spheniscus magellanicus). Marine Ornithology, v. 39, p. 215-220, 2011. 
VANSTREELS, Ralph Eric Thijl del Val et al. Estudo da malária aviária e outros hemoparasitas em pinguins na costa atlântica da América do Sul. Tese de Doutorado. Universidade de São Paulo. 2014.

WILLIAMS, A. J. Why do penguins have long laying intervals?. Ibis, v. 123, n. 2, p. 202-204, 1981.

WILLIAMS, T. D. Reproductive endocrinology of macaroni (Eudyptes chrysolophus) and gentoo (Pygoscelis papua) penguins: I. Seasonal changes in plasma levels of gonadal steroids and $\mathrm{LH}$ in breeding adults. General and comparative endocrinology, v. 85, n. 2, p. 230-240, 1992.

WILLIAMS, T. D. The penguins: Spheniscidae. Oxford: Oxford University Press, 1995. 295 p.

YORIO, P.; FRERE, E.; GANDINI, P.; CONWAY, W. Status and conservation of seabirds breeding in Argentina. Bird Conservation International, v. 9, p. 299-314, 1999.

YORIO, Pablo; BOERSMA, P. Dee. Causes of nest desertion during incubation in the Magellanic Penguin (Spheniscus magellanicus). Condor, p. 1076-1083, 1994. 


\section{ESTUDO ENDÓCRINO-COMPORTAMENTAL DA REPRODUÇÃO DE PINGUINS-DE-MAGALHÃES (SPHENISCUS MAGELLANICUS) MANTIDOS EM CATIVEIRO}

\subsection{RESUMO}

Pinguins-de-Magalhães (Spheniscus magellanicus) são aves monogâmicas que reproduzem uma vez ao ano durante os meses de setembro a março, produzindo apenas uma ninhada de no máximo dois ovos. Suas colônias reprodutivas ficam na Argentina, Chile e Ilhas Malvinas/ Falklands, entretanto, na fase migratória muitos indivíduos são frequentemente avistadas no litoral brasileiro. Apesar de serem mantidos em cativeiro no Brasil desde 1945, existem poucos relatos em literatura sobre sucesso reprodutivo no país. Desse modo, alterações nos comportamentos reprodutivos e nos níveis fecais de esteroides sexuais foram analisadas em 18 pinguins-de-Magalhães ( 9 fêmeas e 9 machos) durante duas estações reprodutivas com 0 intuito de compreender a dinâmica hormonal de indivíduos pareados e não pareados com diferentes performances reprodutivas, além de identificar comportamentos sócio-sexuais que melhor traduzam a atividade gonadal durante a fase reprodutiva. Fêmeas não pareadas não demonstraram quaisquer oscilações hormonais em ambas estações, ao passo que fêmeas pareadas independentemente de seus resultados reprodutivos (não postura, postura de ovos inférteis ou produção de filhotes) apresentaram elevações nos níveis de andrógenos e estrógenos fecais. Outro ponto importante referente as fêmeas foi 0 registro de picos de progestágenos fecais mesmo em fêmeas que não apresentaram a postura de ovos. Fêmeas não pareadas e pareadas sem postura apresentaram uma porcentagem de comportamentos reprodutivos bem inferior as fêmeas com sucesso reprodutivo (postura ou filhotes). Na primeira estação reprodutiva, machos não pareados apresentaram níveis de andrógenos fecais similares aos machos pareados, porém na segunda estação os níveis desse grupo foram de modo geral superiores. Aumentos no número de comportamentos agonísticos e cópulas foram concomitantes as elevações nos níveis de andrógenos fecais. Estes resultados endócrino-comportamentais indicam que para machos a ausência de pareamento não está relacionada a inatividade gonadal, sendo os mesmos teoricamente aptos a 
reprodução. O monitoramento não invasivo não permitiu a observação de padrões hormonais claros que distingam fêmeas com ou sem sucesso reprodutivo. 


\subsection{INTRODUÇÃO}

Pinguins são mantidos em cativeiro desde o início do século 20, quando o zoológico de Edimburgo (Escócia) foi presenteado com três espécimes de pinguinsrei (Aptenodytes patagonicus), e deste então diversas instituições mantem estes animais em seus planteis. Até o final da década de 70, mais de 124 instituições ao redor do mundo abrigavam pinguins, com representantes de 11 das 18 espécies existentes e a reprodução de pelo menos 8 espécies (GAILEY-PHIPPS, 1978). No Brasil, a manutenção de pinguins em cativeiro é bem mais recente e comtempla apenas uma espécie, o pinguins-de-Magalhães (Spheniscus magellanicus). O primeiro recinto para a espécie foi inaugurado em 1945, no Aquário de Santos, sendo que atualmente cerca de 10 instituições brasileiras abrigam espécimes deste pinguim.

O pinguim-de-Magalhães tem suas colônias reprodutivas distribuídas ao longo do litoral da Argentina, Chile e llhas Falkland/ Malvinas, desde a Terra do Fogo 55오 até as latitudes 41S no Atlântico; e 33오 no Pacífico (BOERSMA et al., 2013; BIRDLIFE INTERNATIONAL, 2016). Ainda que não existam locais de nidificação em território brasileiro, a espécie é considerada integrante de sua fauna nativa, uma vez que é frequentemente avistada em águas nacionais em busca da abundância de alimentos na plataforma continental durante o inverno (STOKES; BOERSMA, 1999; SICK, 2001; CEMAVE, 2010). Tratam-se de aves longevas, que atingem a maturidade sexual entre quatro e oito anos de vida, dependendo do sexo. Cerca de $50 \%$ dos machos iniciam sua atividade reprodutiva entre sete e oito anos de idade, enquanto que $50 \%$ das fêmeas se reproduzem pela primeira vez aos seis anos (BOERSMA et al., 2013). Em cativeiro há espécimes com mais de 30 anos, e estima-se que a longevidade do pinguim-de-Magalhães na natureza seja de 25 a 30 anos (WILLIAMS, 1995; BOERSMA et al., 2013).

Existem mais três espécies, que junto com o pinguim-de-Magalhães, compõe o gênero Spheniscus, o pinguim-africano ( $S$. demersus), o pinguim-de-Galápagos (S. mendiculus), o pinguim-Humdoldt ( $S$. humboldtı), e elas recebem classificações de grande preocupação quanto sua conservação na Lista Vermelha da União Internacional para Conservação das Espécies (IUCN). O pinguim-africano e o pinguim-de-Galápagos são classificados como "ameaçados", e o pinguim-Humboldt 
como "vulnerável". Já o pinguim-de-Magalhães, pelo declínio recente de suas populações, recebe a classificação de "quase ameaçado" apesar de ter a maior população dentre as espécies do mesmo gênero (BIRDLIFE INTERNATIONAL, 2016). Esta instabilidade nas populações do gênero Spheniscus torna alta a relevância e o domínio do manejo reprodutivo destas espécies em cativeiro, para futuramente servir como uma ferramenta para a conservação de seus representantes.

Entretanto, o Brasil apresenta registros esporádicos de nascimento de pinguins-de-Magalhães em cativeiro desde 2001, apesar de não haver uma manutenção ou crescimento populacional como consequência dessa reprodução nas diversas instituições que abrigam a espécie. A Sabina - Escola Parque do Conhecimento (Santo André) mantêm, desde 2009, um plantel de aproximadamente 20 pinguins-de-Magalhães. Com o manejo reprodutivo correto e a implementação de um programa de luz favorável, a instituição registrou sua primeira postura de ovos em 2012, progresso que foi ainda aprimorado em três temporadas subsequentes. Sendo assim, afim de obter mais informações sobre a reprodução destes animais em cativeiro, um estudo endócrino-comportamental foi desenvolvido com 18 pinguins-de-Magalhães durante duas temporadas reprodutivas (2014/ 2015 e 2015/ 2016). 


\subsection{MATERIAIS E MÉTODOS}

\subsubsection{Local de estudo}

A Sabina Escola Parque do Conhecimento no município de Santo André, São Paulo (234' $55^{\prime \prime} S 46^{\circ} 31^{\prime} 52^{\prime \prime}$ W) possui recinto para pinguins com capacidade total para 28 animais, uma área total de $144 \mathrm{~m}^{2}$ incluindo área seca de $33 \mathrm{~m}^{2}$, e piscina de $81 \mathrm{~m}^{2}$ e 110.000 litros de água salgada. A cenografia do recinto possui ninhos fixos e removíveis para que os animais utilizem durante a estação reprodutiva. $O$ recinto é totalmente fechado, entretanto, possui um teto de vidro que permite a entrada de luz solar durante o dia. Há também complementação da luz natural por meio de lâmpadas de descarga de alta intensidade (iodeto de quartzo hydrargyrum HQI) que suprem a necessidade de raios UV dos animais. Visando melhorar a condição de vida dos animais e estimulá-los reprodutivamente de acordo com seu habitat natural, um programa de luz foi elaborado e implementado em fevereiro de 2012 (figura 7). O programa de luz utilizado simula o fotoperíodo na latitude 45오 (região da maior colônia reprodutiva de pinguins-de-Magalhães, Punta Tombo na Argentina) (WILLIAMS, 1995; BOERSMA et al., 2013). As luzes artificiais são controladas por equipamentos de timer, permitindo uma oscilação luminosa de 9 horas e meia de luz por dia no inverno a 15 horas no verão. Apesar desta técnica recomendada em manuais de manejo de pinguins em cativeiro, não há registros do uso dela para pinguins-de-Magalhães em cativeiro no Brasil. 
Figura 7 - Programa de Luz realizado na Sabina - Parque Escola do Conhecimento.

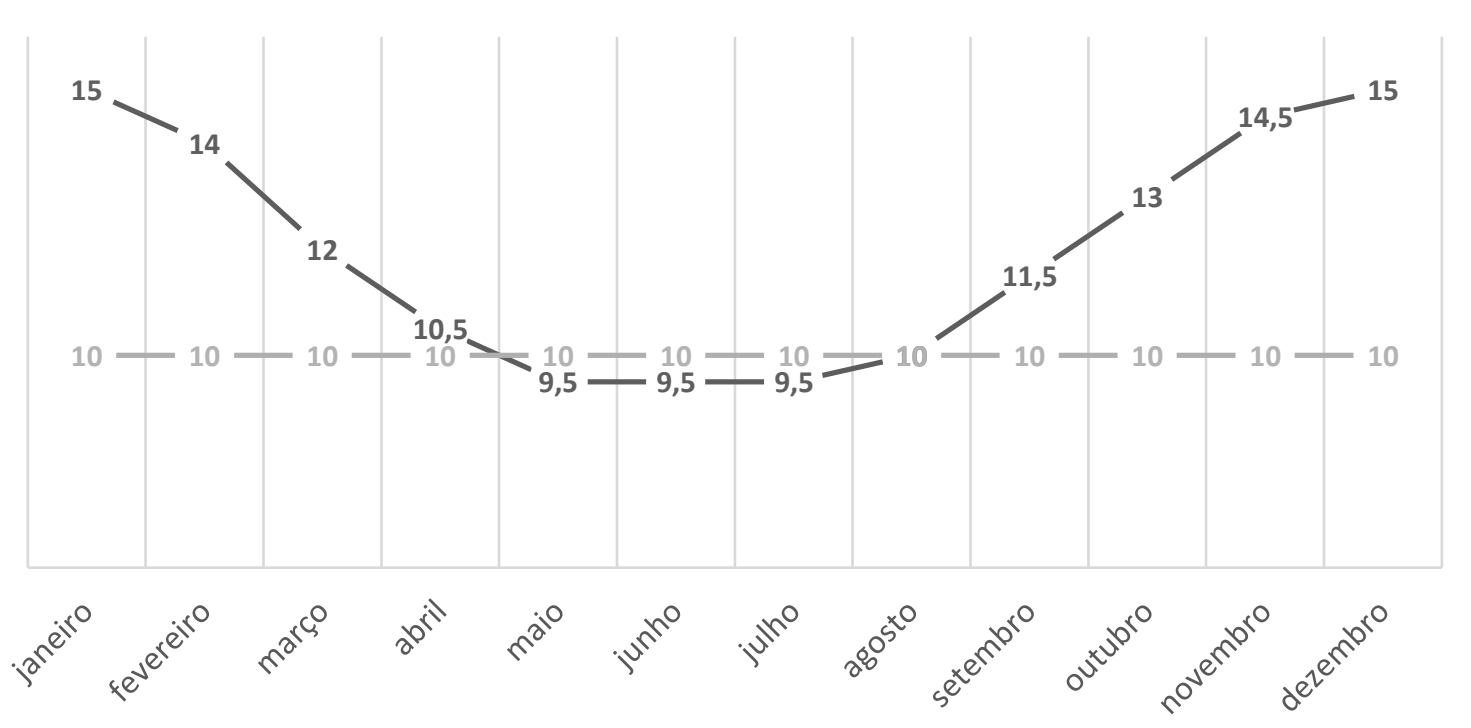

Fonte: (RIBEIRO, J.D., 2017).

Legenda: Linha cinza escuro demonstra a oscilação da luz ao longo dos meses do ano, simulando as estações do ano; linha cinza clara demonstra a ausência de oscilação luminosa prévia ao ano de 2012.

Além do programa de luz e disponibilização de ninhos artificiais, os pinguins recebem materiais para a confecção de ninhos, como feno e folhas, durante toda a estação reprodutiva. Dessa forma, ainda que o comportamento de cavar ninhos no solo fosse impedido pelo tipo de piso disponibilizado no recinto, os animais eram estimulados a montar seus ninhos com o material disponibilizado (figura 8). 0 histórico reprodutivo desse plantel (p.e. cópula, incubação, nascimento de filhotes, etc.- figura 9) contribuiu diretamente para sua escolha desta instituição como local de desenvolvimento do estudo. 
Figura 8 - Início da estação reprodutiva na Sabina - Escola Parque do Conhecimento.
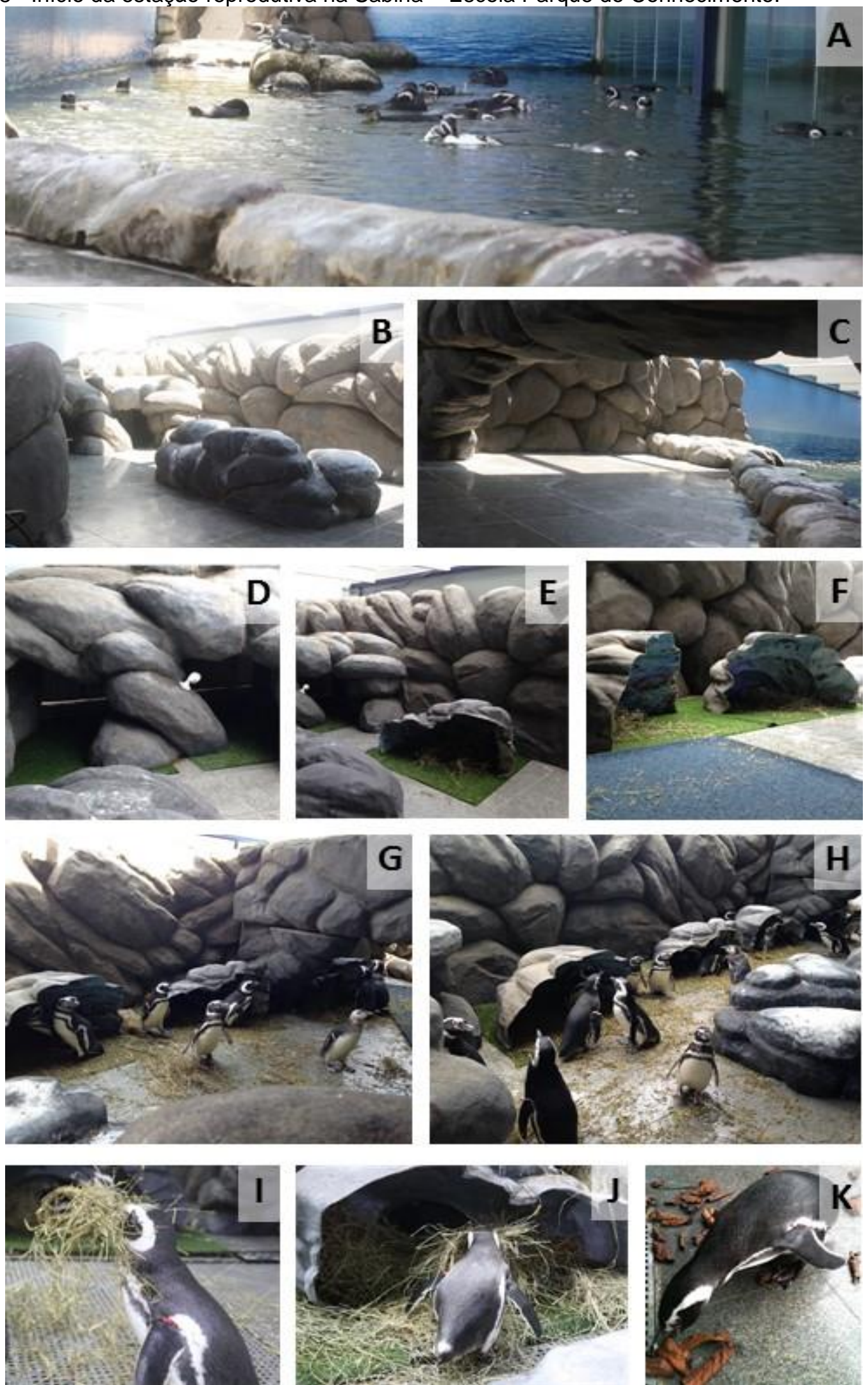

Fonte: (RIBEIRO, J.D., 2017).

(A) Início de setembro, animais ainda permanecem mais tempo na água quase não saindo para área seca; $(B, C, D, E, F)$ Área seca já preparada para receber os animais para a reprodução, com os ninhos e carpetes para diminuir impacto nas patas e possíveis lesões; $(G, H)$ Animais começando a ocupar os ninhos levando feno e defendendo seu território; (I, J, K) Machos levando coletando feno e folhas secas e levando para seus ninhos. 
Figura 9 - Estação reprodutiva na Sabina - Escola Parque do Conhecimento.
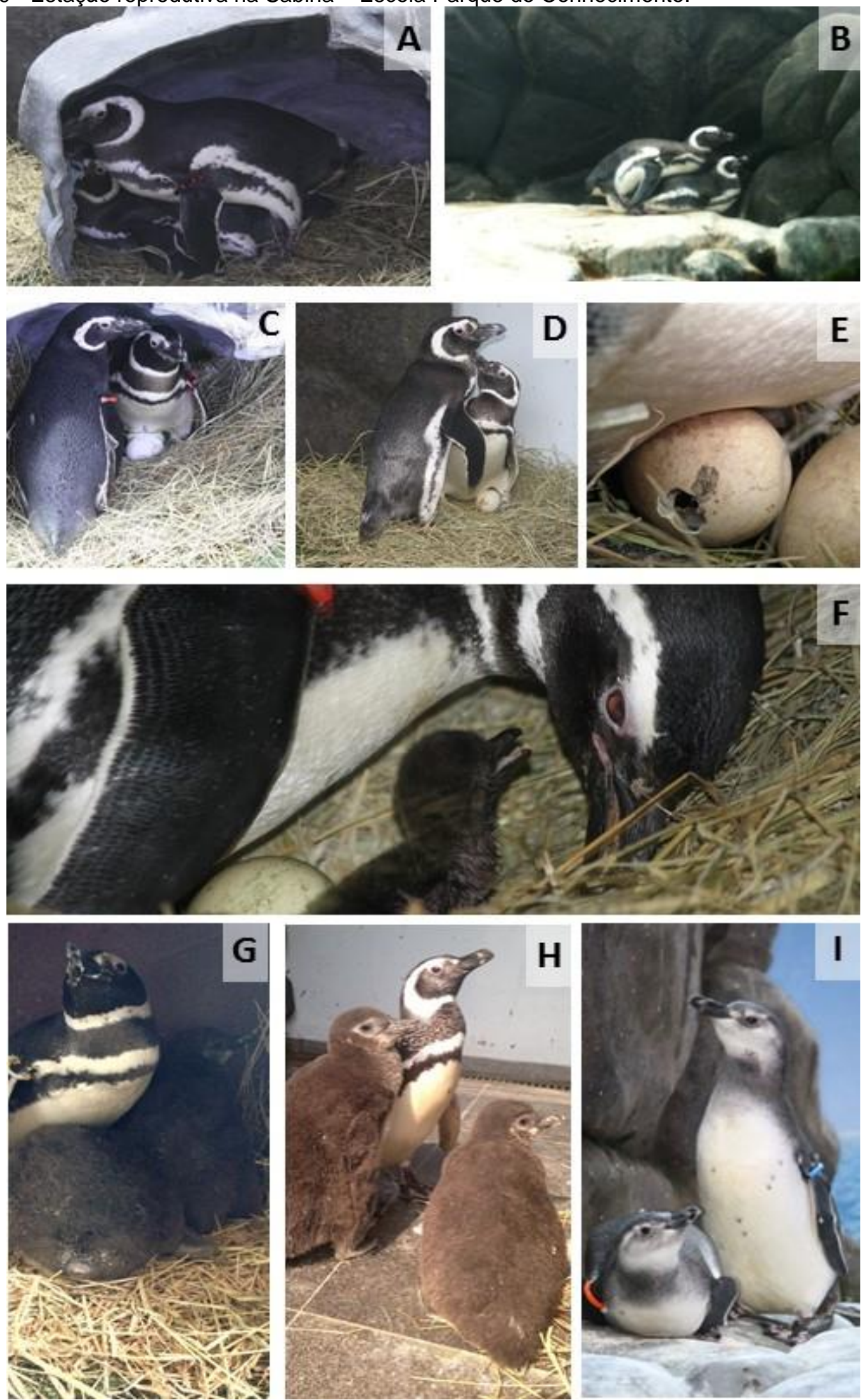

Fonte: (RIBEIRO, J.D., 2017).

(A, B) Cópulas; (C, D) Incubação dos ovos nos ninhos; (E) Detalhe de ovo que começa a ser quebrado por filhote prestes a nascer; $(F)$ Pinguim alimentando filhote recém-nascido enquanto segundo ovo ainda é incubado; (G) Dois filhotes ainda em período de guarda; (H) Filhotes em período de creche já fora do ninho; (I) Filhote emancipados, já com penas impermeáveis 


\subsubsection{Animais}

Foram utilizadas amostras de 18 pinguins-de-Magalhães adultos (9 machos e 9 fêmeas) do plantel permanente da Sabina - Escola Parque do Conhecimento. Todos os animais eram provenientes de vida-livre e passaram por um período de reabilitação antes de serem transferidos ao cativeiro, o que ocorreu ainda em seu primeiro ano de vida (a maioria em 2009). Durante o estudo, os pinguins tinham, em média, 6 anos de idade (ano 1:4-6 anos; ano 2: $5-7$ anos).

A seleção dos animais para o estudo foi feita por meio do histórico reprodutivo. Para o grupo de animais pareados foram selecionados animais que já haviam apresentado comportamentos considerados reprodutivos (p.e. busca por ninho, formação de par, proximidade entre casal e posturas anteriores) e possuíssem um parceiro durante a estação reprodutiva. Já para o grupo de animais não pareados, foram selecionados indivíduos que, apesar de terem apresentado algumas características reprodutivas, não possuíssem um par especifico. Usando estes parâmetros e os dados obtidos em cada temporada, os animais foram classificados em quatro grupos; pinguins não pareados (NP), pinguins pareados e sem postura de ovos (PSP), pinguins pareados com postura de ovos (PP) e pinguins pareados com postura resultando em filhotes (PF). Apesar dos pinguins apresentarem índices altos de monogamia interanual, diversos motivos levaram os animais a migrarem de um grupo para outro entre as duas estações. Afim de respeitar a dinâmica da população, nem sempre indivíduos considerados pareados ou não pareados foram mantidos na mesma classificação ao longo do monitoramento. Isto porque a troca de pares por diferentes razões (p.e. morte, disputa, etc.) foi observada mais de uma vez durante o período total amostrado (figura 10). 
Figura 10 - Dinâmica de pareamento dos animais estudados.

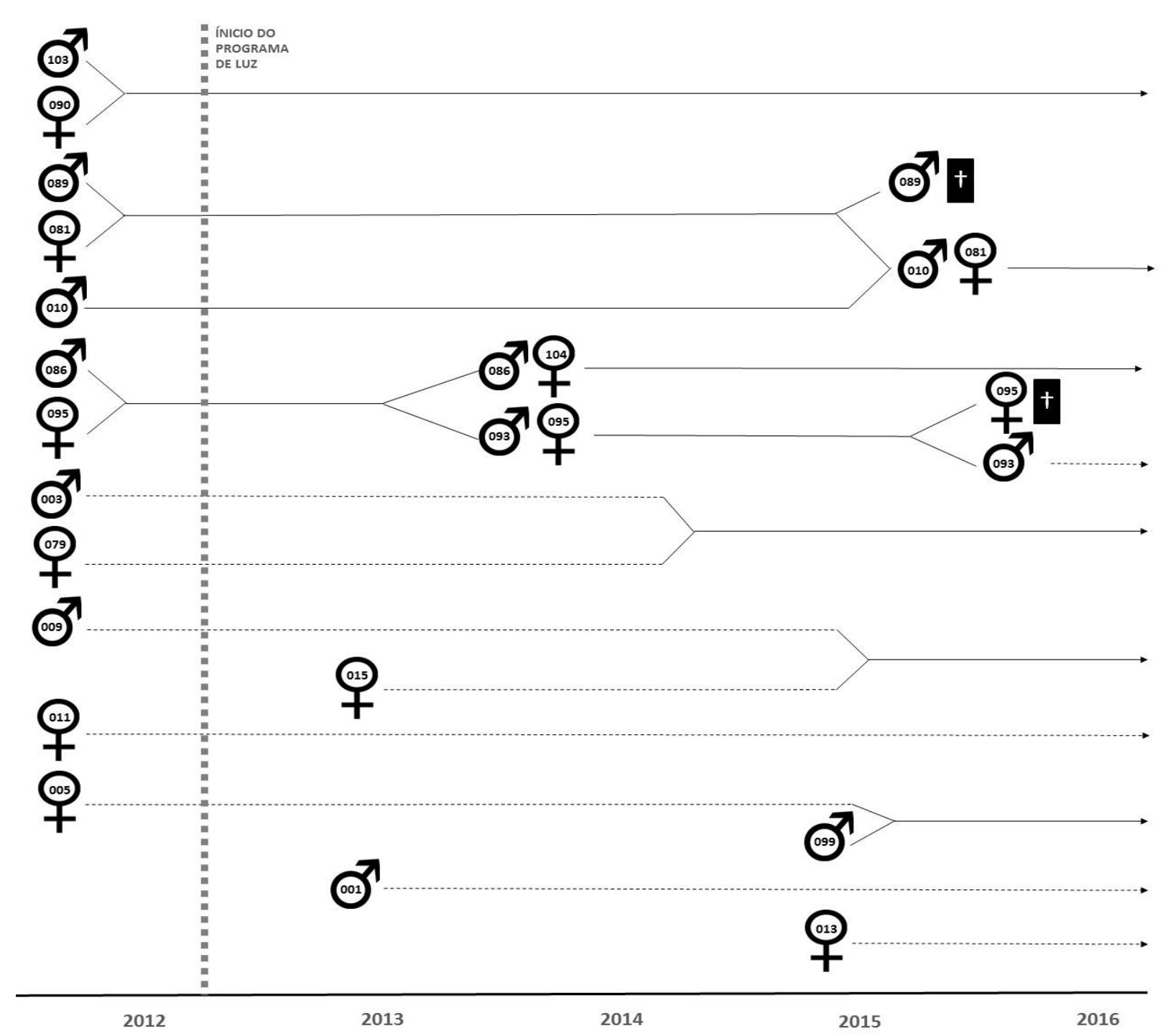

Fonte: (RIBEIRO, J.D., 2017).

Legenda: Os anos de início das temporadas reprodutivas estudadas estão sinalizados por linhas pontilhadas. Animais são divididos entre machos e fêmeas por meio dos seus símbolos, e possuem sua numeração de registro; casais são unidos por linhas contínuas, e animais não pareados possuem linhas fragmentadas. Dois animais morreram durante o experimento (sem qualquer vínculo com o estudo apresentado), estes estão sinalizados por uma cruz.

O manejo nutricional foi igual para todos os animais monitorados. Eles foram alimentados duas vezes ao dia ad libitum, com uma variedade de pescados (sardinha, chicharro, manjuba e trilha) sendo a sardinha o mais frequente. Adicionalmente, todos os indivíduos receberam suplementação vitamínica diária uma hora antes da primeira alimentação da manhã. A troca de ar do recinto foi feita por meio de aparelhos de ar condicionado que também mantinham controladas a temperatura e a umidade do ambiente, sendo a primeira variável de acordo com a 
estação do ano $\left(15-25^{\circ} \mathrm{C}\right)$. O recinto foi higienizado de 3 a 4 vezes ao dia com uma lavadora de alta pressão. Periodicamente foi realizada uma limpeza mais severa com desinfetantes. Durante a estação reprodutiva, os ninhos também receberam um manejo especifico, todo o feno acumulado foi trocado periodicamente afim de prevenir a contaminação ambiental por fungos e bactérias oportunistas. $O$ tanque de água salgada era equipado com filtração compatível com sua dimensão e havia controle de qualidade de água semanal. $\mathrm{O}$ acesso ao tanque de água era livre aos pinguins durante todo $o$ ano.

\subsubsection{Coleta de amostras e dados comportamentais}

As amostras de fezes foram coletadas semanalmente durante duas estações reprodutivas, ano 1 (setembro/ 2014 a janeiro/ 2015) e ano 2 (setembro/ 2015 a janeiro/2016). O horário das coletas foi padronizado entre 10:00 e 13:00 para evitar ao máximo oscilações circadianas nas secreções hormonais. Para a realização das coletas, nenhum tipo de contenção ou manipulação foi feita aos animais, os mesmos permaneciam soltos no recinto e as coletas eram realizadas conforme os animais defecavam. A porção fecal era cuidadosamente separada da porção de urato e armazenada em microtubos plásticos identificados que eram refrigerados do momento da coleta até o congelamento $\left(-20^{\circ} \mathrm{C}\right)$ que era feito ao final do período diário.

Para a observação dos comportamentos, inicialmente foi realizado um padrão de atividades dos animais. Tal processo consiste em três dias consecutivos de observação, utilizando-se do método scan para contagem de atividade e inatividade dos animais a cada 15 minutos (LEHNER, 1996). O padrão de atividade foi realizado entre 10:00 as 16:30, evitando horários de alimentação dos animais e limpeza do recinto. O perfil gerado revelou que o horário de maior atividade dos animais era as 14:30 (Anexo A), sendo assim os registros comportamentais foram realizados semanalmente neste horário por meio do método de amostragem focal por intervalo de tempo (ALTMANN, 1974; MARTIN, 2000). Os registros foram feitos a cada 30 segundos e, em sessões de 30 minutos, totalizando, em média, 990 registros de comportamentos (495 minutos) para cada animal durante o período amostral. 
Os comportamentos foram separados em duas grandes categorias, comportamentos não-reprodutivos e comportamentos reprodutivos com base em trabalhos que relatam comportamento de pinguins do gênero Spheniscus tanto em vida-livre quanto em cativeiro (EGGLETON, 1979; MERRITT, 1987; MULLERSCHWAZE, 1984; STOKES, 1998). Os comportamentos não-reprodutivos foram agrupados numa mesma categoria e não foram o foco deste trabalho, já o repertório comportamental reprodutivo esperado está descrito no anexo B. A proximidade entre os indivíduos pareados foi inclusa como comportamento sexual a fim se relacionar os comportamentos de proximidade e proceptividade. Este parâmetro também foi observado nos animais não pareados e registrados quando estes passavam a demonstrá-lo. A permanência de animais em ninhos também foi registrada para todos os grupos. Por último, a permanência dos animais na água foi também considerado um comportamento importante, uma vez que pinguins-de-Magalhães são animais migratórios e iniciam a chegada nas colônias em meados de setembro (logo este comportamento pode indicar corretamente 0 início da estação reprodutiva). Características físicas do ambiente, como temperatura, densidade e salinidade, foram anotadas assim como observações extras de manutenções e manejos, a fim de relacionar possíveis perturbações que pudessem afetar o padrão comportamental dos animais durante o estudo.

\subsubsection{Extração de metabolitos hormonais e ensaios enzimáticos}

O protocolo de extração dos metabólitos de hormônios nas fezes foi baseado nos métodos descritos por Tempel e Gutierrez (2004) e modificada por Pereira et al. (2010). Inicialmente as amostras foram acondicionadas em uma temperatura de $30^{\circ} \mathrm{C}$ por 24 horas e então liofilizadas por aproximadamente 24 horas, amostras excessivamente úmidas passaram novamente pelo processo. Em seguida, as amostras foram trituradas e homogeneizadas e uma alíquota de $0,1 \mathrm{~g}$ de fezes de cada amostra foram colocadas em tubos de ensaio secos e limpos e acrescidos de $2 \mathrm{ml}$ de metanol PA $80 \%$ (amostras menores receberam volume proporcional de metanol; 1:2) e agitadas em vortex (Scientific-M37615, Thermo Scientific, Massachusetts, USA) por 30 segundos e posteriormente em agitador horizontal (Orbit 1000, Labnet International Inc., New Jersey, EUA) a 250 rpm por, no mínimo, 
12 horas. Após este processo, os tubos foram novamente agitados em Vórtex e, seguidamente centrifugadas (Scientific-Heraeus Megafuge 16R Centrifuge, Thermo Scientific, Massachusetts, EUA) em 400G por 15 minutos para que o sobrenadante pudesse ser transferido para um novo tubo de ensaio de vidro tampado e estocado em freezer $\left(-20^{\circ} \mathrm{C}\right)$ até o ensaio imunoenzimático.

Os ensaios imunoenzimáticos foram realizados segundo protocolo de Brown, Walker e Steinman (2004) para os três hormônios mensurados, progesterona, estrógeno e andrógeno. Todas as concentrações foram mensuradas em duplicata por meio de alíquotas de proporção 1:4 entre o extrato fecal e o tampão do ensaio imunoenzimático, conforme protocolo. Os anticorpos utilizados foram fornecidos pela Dra. Coralie Munro (Universidade da Califórnia, Davis, CA, EUA). Para testosterona foi utilizado o anticorpo monoclonal R156/7 com reatividade cruzada para testosterona (100\%), 5a-di-hidrotestosterona $(57,3 \%)$, androsterona $(0,4 \%)$, androstenediona $(0,2 \%)$ e inferior a $0,04 \%$ para todos os demais metabólitos; para progesterona o anticorpo monoclonal $\mathrm{CL} 415 \mathrm{com}$ reatividade cruzada com diversos metabolitos, incluindo 4-pregnen-3,20-diona (100\%), 4-pregnen-3a-ol-20-ona

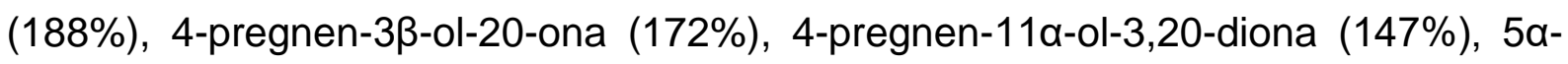

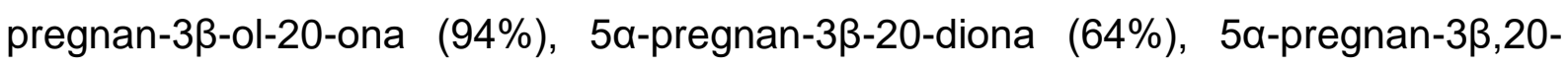
diona (55\%), 5-pregnan-3-ol-20-ona (12.5\%), 5-pregnan-3-20-diona (8.0\%), 4-

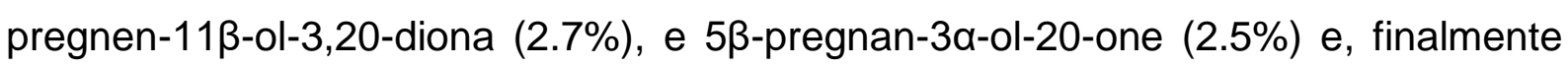
para o estradiol, o anticorpo policlonal R0008 com as seguintes reações cruzadas, $17 \beta$-estradiol $(100 \%)$, estrona $(0,73 \%)$, sulfato de estrona, progesterona, testosterona, cortisol, corticosterona e androstenediona $(<0,01 \%)$.

O ensaio foi previamente validado segundo princípios de validação estabelecidos por Goymann (2005), utilizando-se dos testes descritos por Brown, Walker e Steinman (2004) com a demonstração de curva de paralelismo entre diluições seriadas dos extratos fecais (1:2 a 1:1024) e a curva padrão para cada hormônio (andrógeno: 0,045 - $12 \mathrm{ng} / \mathrm{mL}$; progesterona: 0,78 - $200 \mathrm{ng} / \mathrm{mL}$; estradiol: $1,95-500 \mathrm{ng} / \mathrm{mL}$ ), curva de dose-resposta (andrógeno: $y=0,9043 x+0,247$ $R^{2}=0,9913$; progesterona: $y=0,4177 x+0,162 R^{2}=0,9465$; estradiol: $y=0,239 x+1,9336$ $\left.R^{2}=0,9895\right)$, com coeficientes de variação inter e intra-ensaio $<14 \%$ e $<15 \%$ respectivamente para todos os ensaios. Também foi observada a demonstração da 
validação biológica através da correlação de níveis hormonais com comportamentos observados nos animais (comportamentos agonísticos, cópulas e posturas)

\subsubsection{Análise estatística}

As concentrações de hormônios nas fezes e as porcentagens de registros de comportamentos são apresentadas como médias \pm erro padrão. Os dados foram analisados pelo SAS System Windows (SAS Institute Inc., Cary, NC, USA). Os resultados hormonais e comportamentais são apresentados por médias mensais dos comportamentos e das concentrações de cada hormônio ( $\mathrm{ng} / \mathrm{g}$ de fezes) em cada grupo. Comparações estatísticas foram feitas entre grupos nos meses de um mesmo ano amostral. Para os dados comportamentais, os resultados apareceram por meio de porcentagem de registros dos comportamentos conforme descrito nos materiais e métodos. Testes paramétricos foram utilizados para dados que obedeceram às premissas estatísticas da normalidade dos resíduos e homogeneidade das variâncias, ao passo que testes não paramétricos foram utilizados para os dados que não as obedeceram. O nível de significância utilizado para rejeição foi de $5 \%$ $(p<0,05)$.

\subsection{RESULTADOS}

Entre os indivíduos monitorados, foi registrada a postura de 7 ovos por estação reprodutiva (total de 14 posturas), sendo que em ambas temporadas os tamanhos de ninhada variaram de 1 a 2 ovos. No ano 1, todos os ovos estavam férteis (100\% fertilidade) e resultaram em dois filhotes (eclodibilidade de $28,57 \%$ ). No ano 2, apenas 4 dos 7 ovos eram férteis (57,1\% fertilidade), entretanto, todos os ovos férteis resultaram em nascimento de filhotes (100\% de eclodibilidade). Todos os ovos foram incubados pelos próprios animais, sendo retirados apenas para limpeza dos ninhos, ovoscopias e pesagens.

Os resultados das temporadas reprodutivas nos anos 1 e 2 (2014/ 2015 e 2015/ 2016, respectivamente) e da dinâmica populacional do plantel encontram-se 
detalhados na figura 11. Há um aumento evidente na porcentagem de animais pareados após o início do programa de luz, esta progressão também é vista no número de posturas e número de filhotes. Em números absolutos, houveram, um filhote em 2013, dois em 2014 e 4 em 2015, todos mantidos com os pais desde a incubação até sua emancipação.

Figura 11 - Dados reprodutivos da Sabina - Parque Escola do Conhecimento de 2010 - 2016.

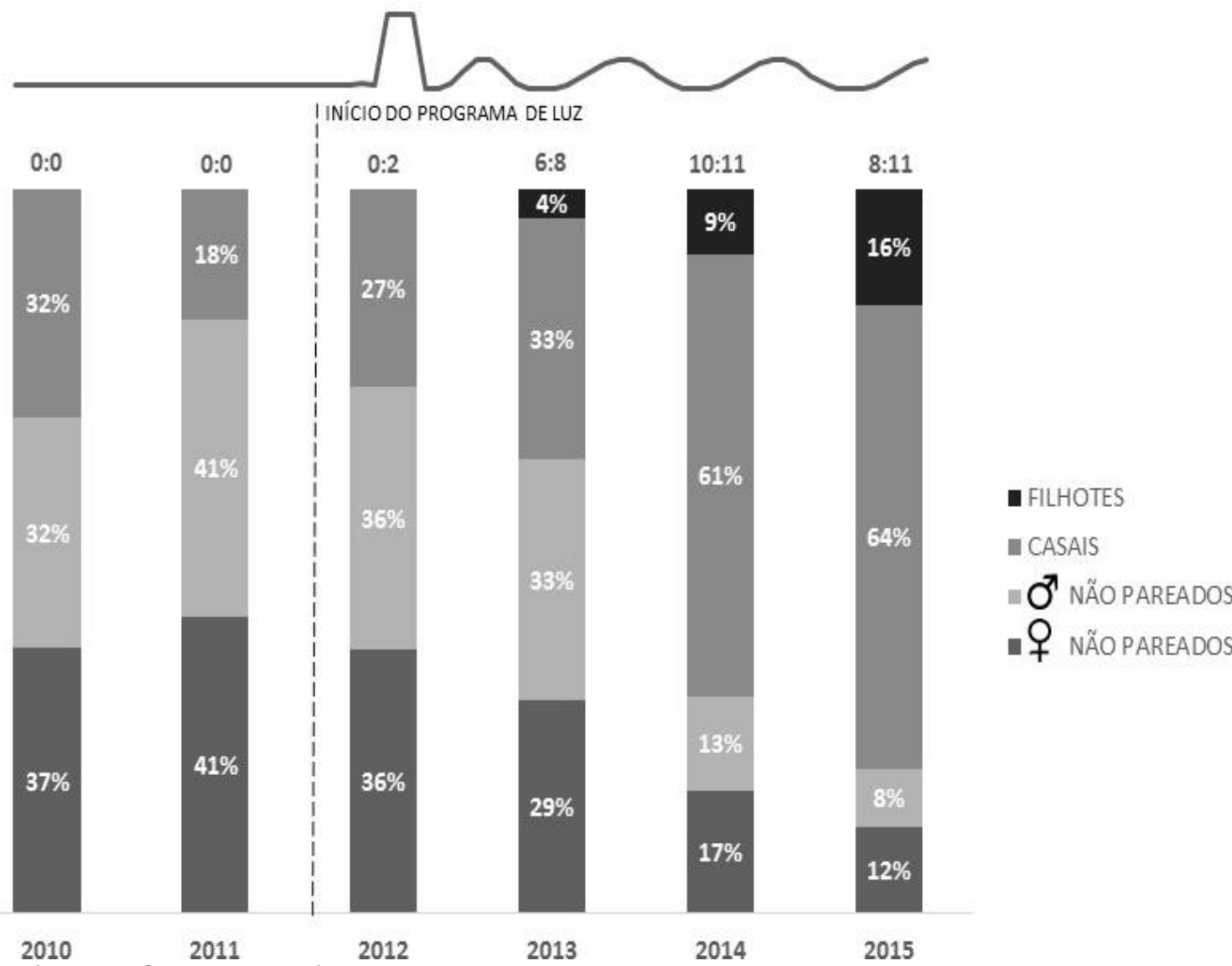

Fonte: (RIBEIRO, J. D., 2017).

Legenda: Linha acima do gráfico representa as oscilações luminosas antes e depois da inserção do programa de luz (marcado pela linha pontilhada); valores acima das colunas apresentam o número de ovos férteis em relação ao número total de ovos nas temporadas reprodutivas de cada ano. $O$ ano registrado no eixo horizontal do gráfico é o ano de início da temporada reprodutiva, entretanto o resultado é referente a toda a temporada (setembro - fevereiro).

As médias dos registros comportamentais de machos e fêmeas estão compilados nas figuras 12 e 13, respectivamente. A proximidade entre o par foi demonstrada de forma evidente entre os grupos pareados, mostrando médias altas em todos os meses dos anos 1 e 2 , exceto no início da temporada, em setembro. Animais do grupo NP demonstram alguma aproximação entre indivíduos nos meses finais da temporada. A permanência em ninho, que é esperado para esta espécie de 
maneira semelhante entre machos e fêmeas, é evidenciada, assim como a proximidade entre pares, nos grupos pareados durante todos os meses, com exceção de setembro. O grupo PSP apresentou a permanência em ninho, apesar da ausência de postura. No ano 1, apenas os machos do grupo NP apresentaram o comportamento de utilização do ninho (com baixa frequência), ao passo que no ano 2 ambos os sexos exibiram esses comportamentos.

Os comportamentos reprodutivos derivados dos etogramas resultaram em um número baixo de registros, deixando as médias mais altas nos meses e grupos que apresentavam incubação de ovos. Comportamentos exclusivamente sexuais foram observados com uma baixa frequência durante os etogramas, e por isso foram somados aos comportamentos reprodutivos (anexo B). Ainda assim, há maior intensidade destes comportamentos nos grupos pareados, principalmente PP e PF. Comportamentos classificados como reprodutivos também foram vistos no grupo NP, mas com menor intensidade. Durante outros momentos de observação dos animais, como no momento de coleta de amostras, comportamentos agonísticos entre machos e uma alta frequência de cópulas foram registrados no mês de outubro para os dois anos.

Já para a permanência de animais na água, todos os grupos mostraram um comportamento semelhante. Setembro (ano 1 e 2) foi o mês de maior permanência de animais na água para todos os grupos. Já os meses de novembro, dezembro e janeiro registraram médias mais baixas, a exceção das fêmeas do grupo NP no ano 1 e as fêmeas do grupo PF no ano 2. Excetuando outubro para machos e novembro para fêmeas, não há diferença significativa entre médias do grupo NP e dos grupos pareados. 
Figura 12 - Médias dos registros comportamentais dos machos nos anos 1 e 2.

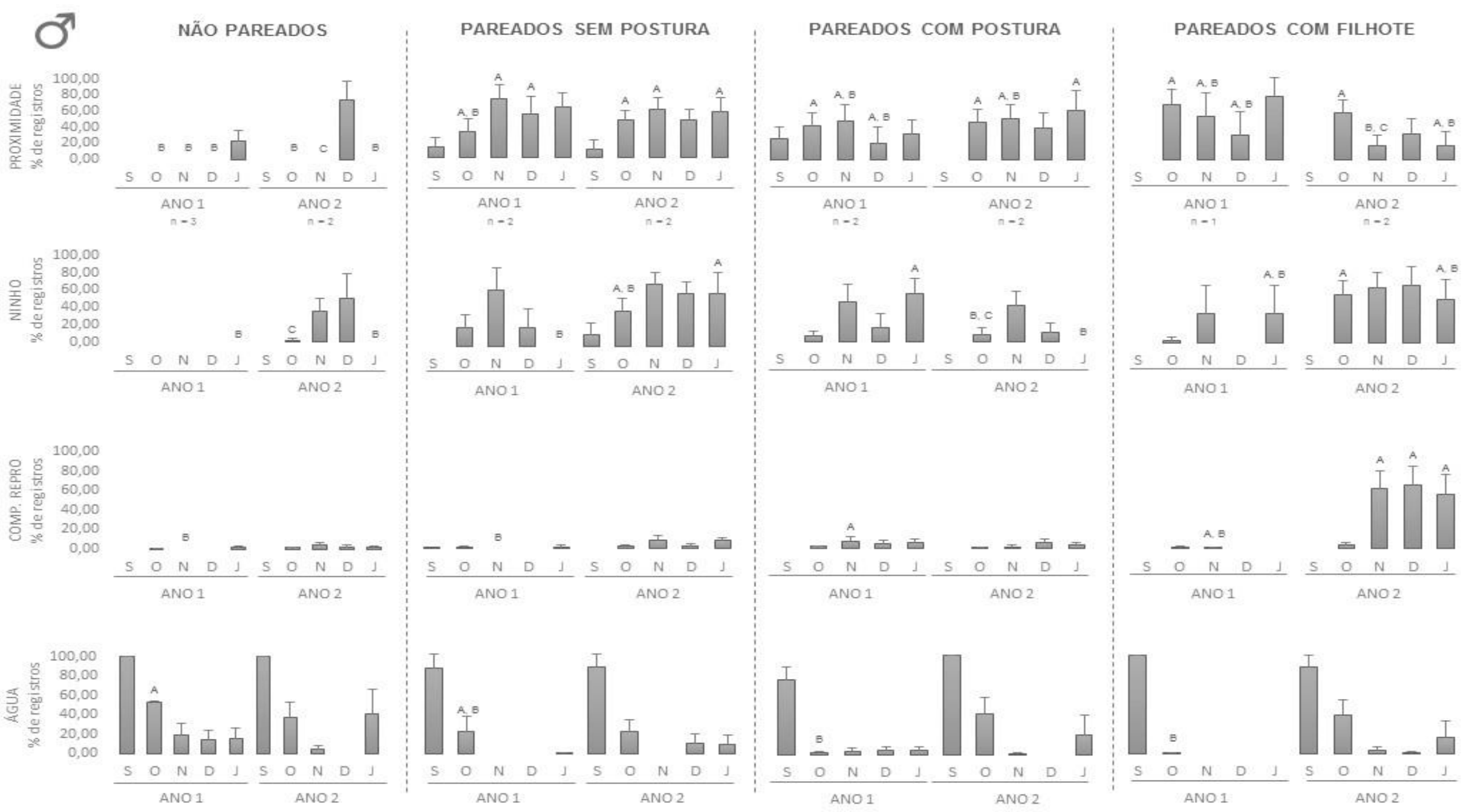

Fonte: (RIBEIRO, J.D.; 2017).

Legenda: Letras sobrescritas sinalizam diferenças significativas entre médias dos registros comportamentais dos grupos durante os mesmos meses; a comparação foi feita separada no ano 1 e ano 2 ( $p<0,05$ LSD test). Média zero sinaliza ausência do comportamento no mês. 
Figura 13 - Médias dos registros comportamentais das fêmeas nos anos 1 e 2.

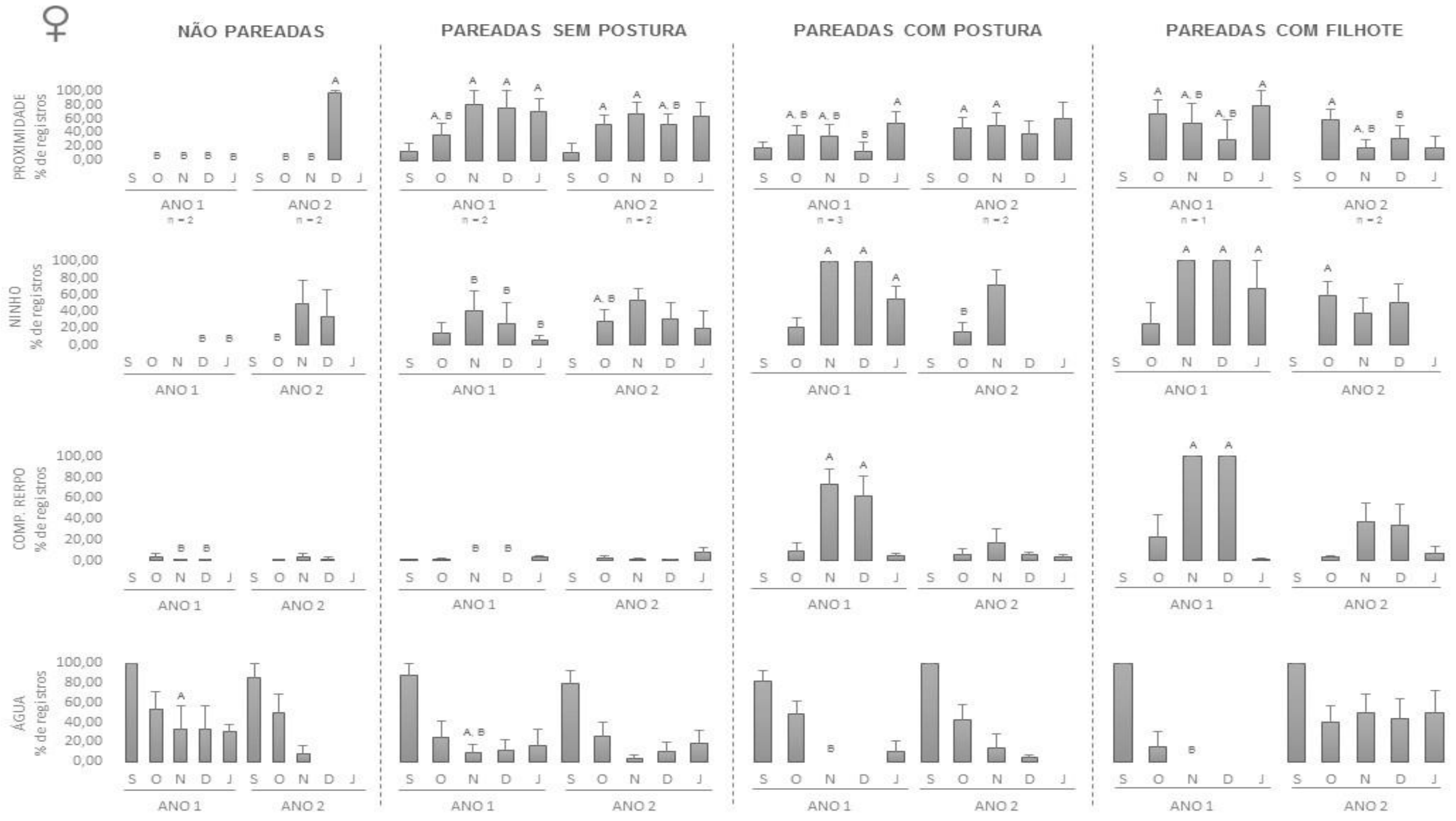

Fonte: (RIBEIRO, J.D.; 2017).

Legenda: Letras sobrescritas sinalizam diferenças significativas entre médias dos registros comportamentais dos grupos durante os mesmos meses; a comparação foi feita separada no ano 1 e ano 2 ( $p<0,05$ LSD test). Média zero sinaliza ausência do comportamento no mês. 
Apesar do grande esforço para se obter amostras fecais semanais de todos os animais, isso não foi possível pois as coletas além de feitas com os animais livres no recinto, eram também efetuadas em um horário restrito (das 10:00 - 13:00). Assim, há semanas em que alguns animais não tiveram suas fezes coletadas e, consequentemente, alguns meses sem médias hormonais para os grupos de classificação. Em geral, isso ocorreu devido permanência dos animais na água ou permanência em ninhos de difícil acesso, inviabilizando a coleta. Ao todo, durante os dois períodos amostrados foram coletadas 283 amostras entre fêmeas e machos.

As médias mensais das concentrações de metabólitos de andrógenos, progestágenos e estrógenos nos machos estão compiladas na figura 14, e separadas pelos grupos amostrais. A média total dos valores de andrógenos ao longo do ano 1, 0,38 $\pm 0,04 \mathrm{ng} / \mathrm{g}$, é significativamente menor do que no ano 2, 0,55 $\pm 0,04 \mathrm{ng} / \mathrm{g}$ ( $p<0,0019$; Wilcoxon test). De modo geral, a exceção do grupo PF, no ano 1 os machos demonstraram maiores níveis de andrógenos fecais em outubro com uma redução gradativa nos meses de novembro e dezembro. Já em janeiro, apenas os grupos PP e PF mantiveram os níveis de andrógenos baixos, ao passo que os grupos NP e PSP apresentaram uma discreta elevação. Dois grupos destacam-se com médias mais altas no ano 2, o NP e o PF, sendo que o primeiro manteve sua média elevada durante 4 dos 5 meses monitorados. Assim como nos andrógenos, o ano 2 apresentou valores médios de estrógenos e progestágenos fecais maiores que no ano 1. Para progestágenos, os anos 1 e 2 apresentaram médias gerais de $5,47 \pm 0,40$ e $8,00 \pm 0,50 \mathrm{ng} / \mathrm{g}$, respectivamente $(p<0,0008$; Wilcoxon test), enquanto que para estrógenos os anos 1 e 2 obtiveram médias gerais de $18,37 \pm 2,13$ e $28,62 \pm 2,73 \mathrm{ng} / \mathrm{g}$, respectivamente $(p<0,0096$; Wilcoxon test).

Fêmeas tiveram posturas concentradas nos meses de outubro e novembro. No ano 1 , entre 28/10 e 16/11 e, no ano 2, entre 15/10 e 9/11. A figura 15 mostra as médias de concentrações de metabólitos hormonais dos grupos por mês. Para andrógenos, o menor valor médio nas fêmeas foi 0,16 $\pm 0,02 \mathrm{ng} / \mathrm{g}$ no grupo NP em setembro do ano 2, sendo o maior valor médio de 3,08 $\pm 0,54 \mathrm{ng} / \mathrm{g}$ no grupo PP em dezembro do ano 2 (valor 7 vezes mais alto que os machos do mesmo grupo no período). As médias altas aparecem em forma de picos, o mesmo ocorre com os progestágenos e estrógenos. Os valores de progestágenos variam de 2,30 ng/ g a 
19,53 $\pm 10,27$ ng/ g (PP em janeiro do ano 1 e PSP em novembro do ano 1, respectivamente). Para estrógenos, o menor valor foi registrado no grupo PP em dezembro do ano $1(13,31 \pm 2,06 \mathrm{ng} / \mathrm{g})$, logo após as posturas, enquanto que o maior valor, pertence ao grupo PSP em outubro do ano $1(246,92 \pm 213,70 \mathrm{ng} / \mathrm{g})$. Outros picos podem ser visualizados na figura 13, entretanto, alguns picos importantes pré-posturas não foram registrados dada a ausência de amostras já relatada no início desta seção. 
Figura 14 - Médias das concentrações de hormônios fecais dos machos nos anos 1 e 2.

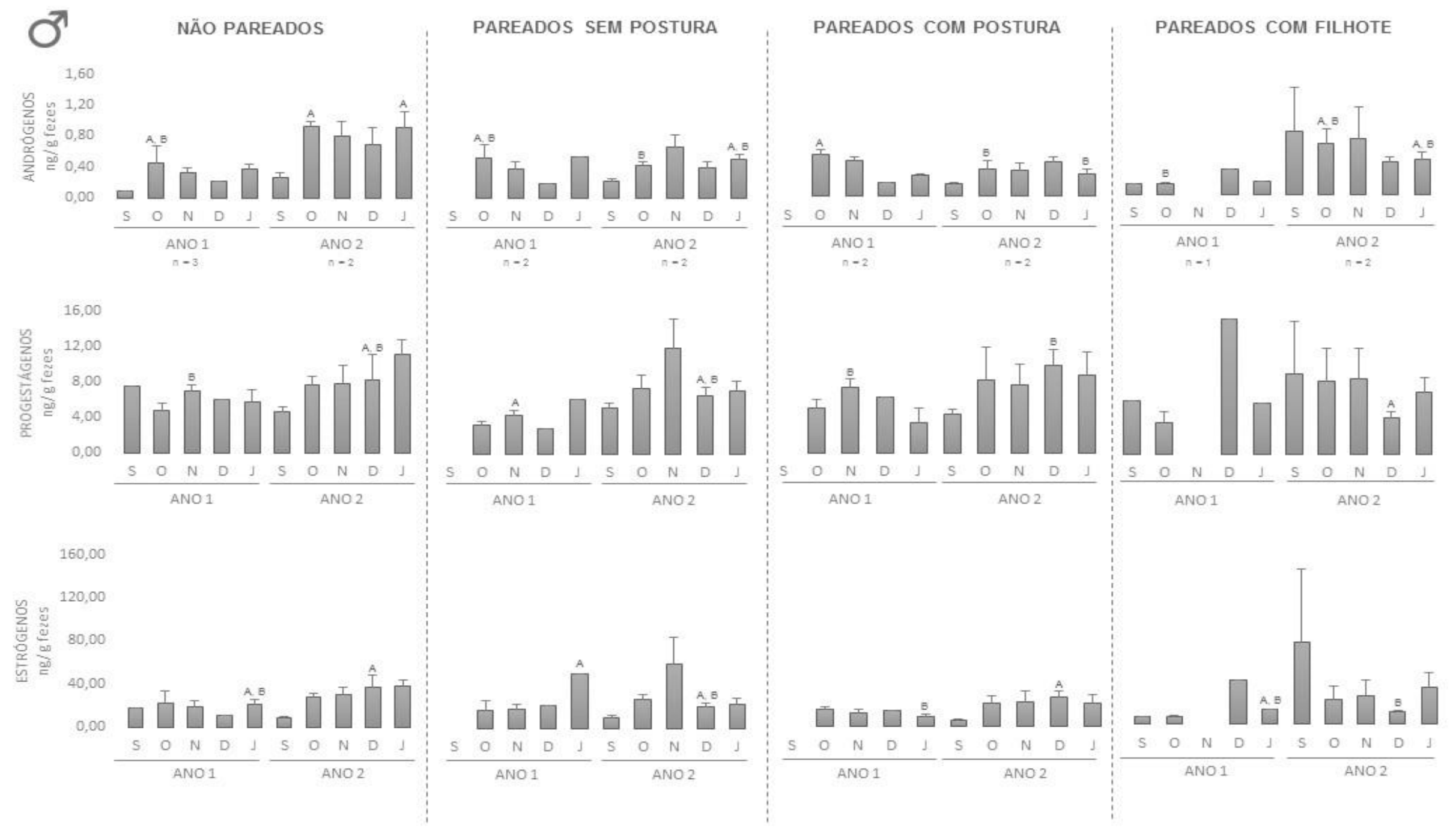

Fonte: (RIBEIRO, J.D.; 2017).

Legenda: Letras sobrescritas sinalizam diferenças significativas entre médias das concentrações hormonais dos grupos durante os mesmos meses; a comparação foi feita separada no ano 1 e ano 2 ( $p<0,05$ LSD test). Meses sem médias não tiveram êxito na coleta de amostras para aquele grupo. 
Figura 15 - Médias das concentrações de hormônios fecais das fêmeas nos anos 1 e 2.

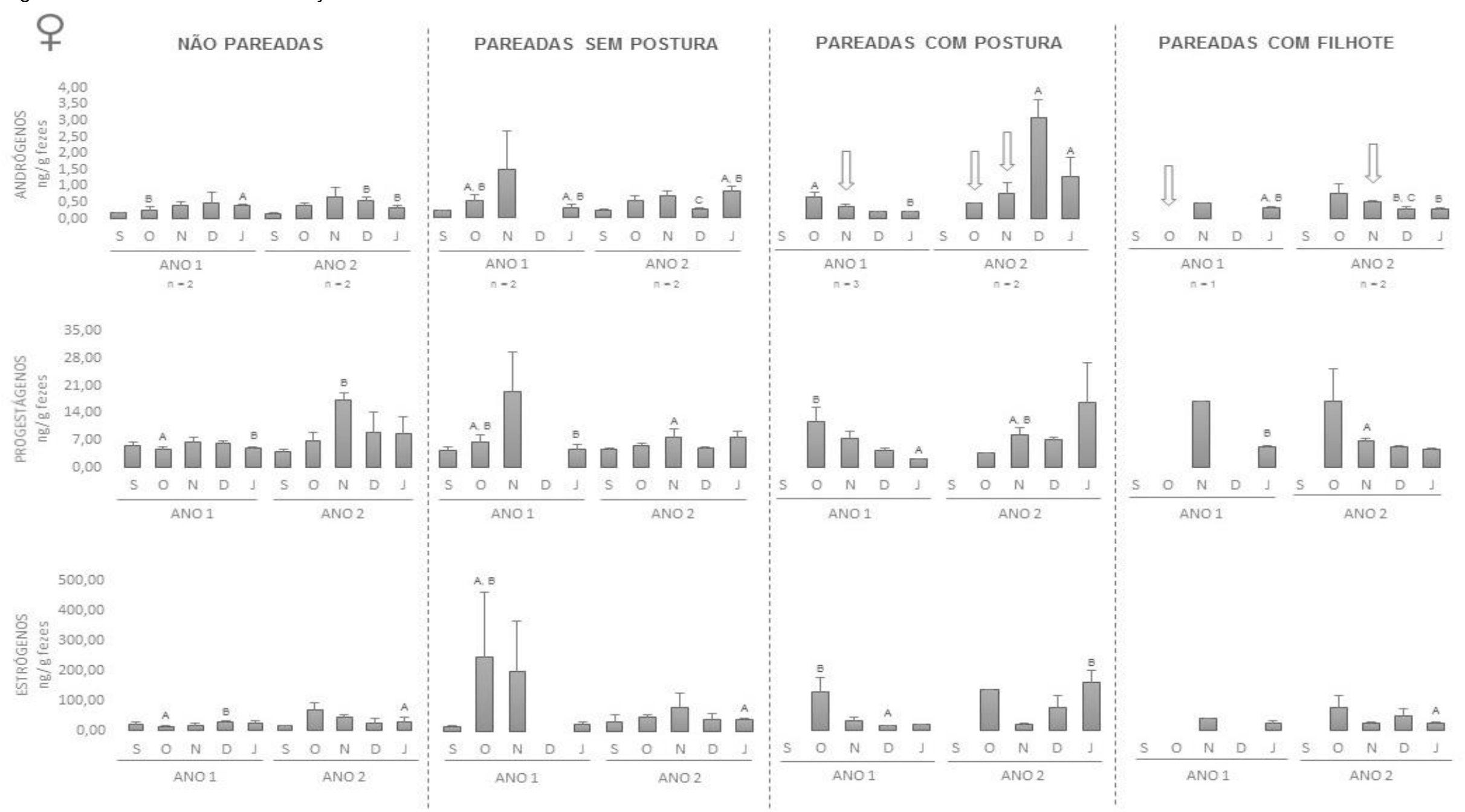

Fonte: (RIBEIRO, J.D.; 2017).

Legenda: Letras sobrescritas sinalizam diferenças significativas entre médias das concentrações hormonais dos grupos durante os mesmos meses; a comparação foi feita separada no ano 1 e ano 2 ( $p<0,05$ LSD test). Meses sem médias não tiveram êxito na coleta de amostras para aquele grupo. Setas brancas apontam meses em que houveram posturas. 


\subsection{DISCUSSÃO}

\section{Fatores associados ao sucesso reprodutivo no local estudado}

O crescimento reprodutivo demonstrado entre os anos de 2010 e 2016 no plantel de pinguins-de-Magalhães do local de estudo, evidencia que o recinto e o manejo dos animais cumprem prerrogativas importantes. Janet Gailey-Phipps (1978) em sua avaliação geral da manutenção e reprodução de pinguins de diversas espécies em cativeiro, aponta algumas diretrizes para o sucesso reprodutivo em cativeiro. As principais delas são, o número de indivíduos no plantel, o tamanho da piscina, suplementação vitamínica e dieta adequada. Outros autores posteriormente confirmaram essas diretrizes e acrescentaram, para algumas espécies, a atenção ao substrato do recinto para espécies que fazem ninhos no solo (excluindo-se o gênero Aptenodytes, o qual faz a incubação em cima das patas) (BLAY; CÔTE, 2001; MARSHALL et al., 2016; SCHWEIZER, 2016).

Estas prerrogativas refletem a correta mimetização do habitat pelo cativeiro onde a espécie é mantida, de forma a estimulá-los a seguirem seu ciclo de vida natural. A grande maioria das espécies de pinguins é gregária formando colônias de altas densidades para a reprodução. Uma vez em suas colônias, formam ninhos utilizando geralmente pedras e gravetos ou, em alguns casos, fazendo buracos no chão. A ampla maioria dos pinguins são migratórios e, mesmo quando residentes, fazem longas viagens em busca de uma ampla variedade de alimentos (WILLIAMS, 1995; GARCIA-BORBOROGLU; BOERSMA, 2013). Juntas, essas características explicam a estabilidade do plantel e o sucesso reprodutivo destas espécies ex situ, e todas elas foram atendidas pelo local de estudo. Somado a estes requisitos está o programa de luz, indicado para pinguins mantidos em recintos fechados e com restrições de luminosidade natural (DIEBOLD; BRANCH; HENRY; 1999; DAWSON et al., 2001; AZA, 2014). Apesar do local de estudo contar com a luz natural durante o dia, a ausência de oscilações estacionais poderia ter prejudicado o desenvolvimento reprodutivo dos animais. Ainda que esta seja uma prática rotineira em muitas instituições no mundo, não há relatos da utilização da mesma em outros recintos para a espécie no Brasil, circunstância que pode explicar o baixo sucesso reprodutivo entre os mantenedores de pinguins-de-Magalhães. Observados estes parâmetros, constatamos que o progresso reprodutivo visto na Sabina durante estes 
seis anos são resultado da somatória d os fatores acima citados, não sendo possível isolar um fator de maior importância uma vez que todos os animais recebem o mesmo tratamento.

Os comportamentos durante a estações reprodutivas

Um dos objetivos deste trabalho foi procurar comportamentos que evidenciassem momentos endócrinos importantes. Entretanto, o formato escolhido para registrar esses comportamentos parece não ter sido totalmente eficaz para registrar, de forma coerente, a gama de comportamentos propostos. Considerando que os etogramas eram realizados em curtos períodos de tempo (30 minutos), muitos comportamentos importantes distribuídos em outros momentos do dia não foram registrados com a ênfase almejada. Ainda que tenhamos analisado o padrão de atividades do plantel, o número de registros para corte, cópulas e comportamentos agonísticos capturados pelos etogramas não foi suficiente para as comparações entre grupos. Entre os comportamentos reprodutivos se sobressaíram aqueles vinculados a incubação dos ovos, gerando um desequilíbrio na análise que não permitiu a observação de elevações significativas nos comportamentos agonísticos, de corte ou cópula. Contudo, apesar das limitações da técnica, machos em geral concentraram seus comportamentos de corte, cópula e territorialidade no mês de outubro em ambos os anos. Este padrão comportamental pode estar relacionado aos níveis mais elevados de andrógenos em outubro, corroborando a teoria de Wingfield et al. (1990) sobre a correlação entre secreção de testosterona, agressividade e comportamentos sexuais (p.e. cópula). Porém, o mesmo autor afirma que esteroides sexuais, particularmente os andrógenos, parecem ser incompatíveis com os comportamentos vinculados ao cuidado parental, principalmente em sistemas monogâmicos. Esta suposição não parece ser aplicável aos pinguins de Magalhães, visto que machos do grupo PF durante o ano 2 exibiram altos níveis de andrógenos fecais mesmos em meses de intensa incubação dos ovos e cuidado com os filhotes. Embora a amostra seja limitada para extrapolações mais abrangentes, acreditamos que esse perfil endócrino possa estar associado com o alto nível de agressividade apresentado por esses indivíduos para a manutenção do casal e defesa do ninho, uma vez que na espécie é comum a proximidade entre ninhos devido a alta densidade das colônias reprodutivas. 
A proximidade entre casais foi observada em todos os grupos. Grupos pareados demonstraram o comportamento de forma mais uniforme e, em geral, crescente dentro da estação reprodutiva. Já animais do grupo NP, quando apresentaram este comportamento, o fizeram no final da temporada, talvez como uma tentativa tardia de pareamento (muito comum para animais mais jovens). Embora a proximidade seja esperada para animais monogâmicos, em vida livre, com as viagens em busca de alimentos e o revezamento no cuidado parental, este comportamento não é tão evidente durante toda a temporada (ANCEL; BEAULIE; GILBERT; 2013). Uma vez que o cativeiro oferece abundância de alimentos durante todos os períodos, reduzindo a necessidade de forrageio, esta proximidade fica bem mais visível durante toda a estação reprodutiva.

A permanência dos animais nos ninhos parece ser o comportamento mais fidedigno dos grupos pareados. Ele pôde ser percebido quase de forma complementar entre machos e fêmeas nos grupos com postura (PP e PF), evidenciando a incubação e guarda dos ninhos realizada sempre por ao menos um dos componentes do par. Pinguins-de-Magalhães dividem os turnos de incubação e cuidado parental, e no período inicial da incubação os turnos são mais longos para cada indivíduo, durando dias, e após o nascimento do filhote e conforme seu crescimento esses turnos são reduzidos a algumas horas (BOERSMA; STOKES; YORIO, 1990; WILLIAMS, 1995). No cativeiro, os turnos parecem ser menores mesmo durante a incubação, pois há constância nos recursos alimentícios. No grupo PP no ano 2, houve perda dos ovos em dezembro, em consequência, os animais deixaram de frequentar o ninho. O mesmo grupo apresentou elevação dos níveis hormonais após este período, o que corrobora com os achados de Fowler et al. (1994), sugerindo um comportamento semelhante a animais que possuem mais de uma ninhada. Já o grupo PSP apresentou uma média elevada de permanência em ninho, ainda que não houve postura. Este comportamento foi observado, principalmente em machos que, associado a isso, também apresentaram níveis elevados de andrógenos. De acordo com a literatura, tal atitude pode estar 
associada a manutenção do ninho e do par ('FOWLER, 1993 apud FOWLER et al, 1994). Animais do grupo NP não demonstraram permanência em ninho no ano 1 , entretanto, passaram a demonstrá-la no final da estação do ano 2, sugerindo, novamente, uma maior maturidade destes animais com o avanço da idade.

Quanto a permanência dos animais na água, o mês de setembro dos dois anos, demonstrou médias elevadas em todos os grupos, sendo que alguns deles apresentou $100 \%$ dos animais na água. Esse dado é compatível com o início da estação reprodutiva dos animais de vida livre, que varia de meados a final do mês de setembro (WILLIAMS, 1995; BOERSMA et al., 2013). Tal informação também sugere a eficiência do programa de luz em mimetizar as oscilações luminosas no cativeiro e, conduzir o comportamento dos animais de forma equivalente ao visto em natureza. Ao longo do restante da estação reprodutiva, este comportamento foi pouco observado nos animais pareados, demonstrando a tendência destes animais em manter o foco na reprodução. O grupo NP demonstrou índices mais elevados deste comportamento, principalmente no ano 1, já no ano 2, os animais pareceram demonstrar um interesse maior na atividade reprodutiva do plantel, diminuindo seus intervalos de tempo na água. Ainda que não houvesse diferença significativa na permanência dos grupos na água na maioria dos meses, o mês de outubro, registrou uma ampla diferença entre grupos pareados e não pareados, sinalizando o início da estação para os animais maduros.

\section{Oscilações hormonais sexuais durante as estações reprodutivas}

Estudos mostram que as oscilações plasmáticas de hormônios sexuais nos pinguim-de-Magalhães seguem o padrão encontrado em outras aves reprodutoras sazonais de clima temperado, incluindo outras espécies de pinguins. Machos e fêmeas maduros apresentam um padrão bifásico de secreção hormonal. Os animais já chegam as colônias com níveis hormonais elevados, que se mantem até as posturas de ovos do casal. Ao início da incubação animais passam a secretar níveis basais de hormônios sexuais (GROSCOLAS et al., 1986; WILLIAMS, 1992; FOWLER et al., 1994; O’BRIEN et al., 2015). Casais de pinguins que conseguem

${ }^{1}$ FOWLER, Gene Scott. Ecological and endocrinological aspects of long-term pair bonds in the Magellanic Penguin (Spheniscus magellanicus). PhD dissertation, University of Washington, Seatle. 1993. 
realizar a postura, mas, falham durante a incubação dos ovos ou perdem a ninhada, em sua maioria, apresentam novos níveis elevados de hormônios sexuais. Fowler et at. (1994) sugere que esse comportamento equivale ao padrão encontrado para animais com mais de uma ninhada, entretanto esta situação não é relatada em pinguins-de-Magalhães.

O presente estudo também encontrou o aspecto bifásico nas oscilações dos metabólitos hormonais, podendo ser observado principalmente nas fêmeas e machos do grupo PF no ano 2. É provável que o ano 1 também demonstrasse esse perfil para o mesmo grupo, entretanto, a perda de dados mencionada anteriormente ocasionou a ausência de tal informação. As fêmeas do grupo PF, obtiveram médias elevadas nos três hormônios sexuais testados e, em seguida a postura dos ovos, no início de novembro, há uma queda nos valores até o final da estação reprodutiva. $O$ mesmo padrão bifásico pode der registrado nos machos do grupo PF, uma vez que suas médias foram elevadas nos meses de outubro e novembro e mantiveram-se mais baixas entre dezembro e janeiro.

Já no grupo PP, na qual os animais realizam a postura mas perdem os ovos durante a incubação, fêmeas e machos no ano 1 apresentaram elevações hormonais em outubro (não há dados para setembro) e as posturas em meados de novembro. Contudo, mesmo com a falha na incubação, não houve uma nova elevação dos níveis hormonais, diferindo dos resultados encontrados por Fowler et. al (1994) na mesma espécie em vida livre. Uma explicação para essa discrepância de respostas endócrinas pode estar associada a idade reprodutiva dos casais, visto que em média a população apresentava apenas 5 anos no período do estudo (ou seja, idade intermediária entre animais completamente maduros e imaturos). Já no ano 2, fêmeas do grupo PP apresentaram novos picos de esteroides sexuais após a perda da primeira ninhada (novembro), enquanto que os machos não demonstraram a mesma tendência. O grupo PSP que, apesar de ter demonstrado comportamentos de casal, não apresentou posturas, teve oscilações bem parecidas com o grupo PP. Picos de estrógenos e progéstagenos sem uma ovipostura subsequente já foram relatadas em galinhas domésticas e grous-americanos (Grus americana), e foram relacionados a eventos de preparação do eixo hipotalâmico-hipofisario-gonadal (LAGUE; VAN TIENHOVEN; CUNNINGHAM, 1975; BROWN et al., 2016). Por essa razão, não foi possível chegar a uma conclusão definitiva sobre as causas dessa 
ausência de postura entre as fêmeas do grupo PSP, principalmente no mês de novembro (ano 1). Novamente, é possível que a ausência de um padrão bem estabelecido de oscilações hormonais nos grupos pareados ocorra em virtude da idade dos animais monitorados. Em vida livre, pinguins-de-Magalhães atingem a maturidade sexual entre os quatro e oito anos de vida, dependendo do sexo, fêmeas aparentam ser um pouco mais precoces (BOERSMA et al., 2013).

O monitoramento do grupo não pareado (NP) tinha como principal objetivo demonstrar se haveriam diferenças entre as oscilações dos metabolitos hormonais destes animais em relação aos animais pareados. Sendo assim, o grupo contemplou animais que não demonstraram pareamento exclusivo. A análise estatística entre os grupos revelou que não há diferenças significativas entre as médias de metabolitos hormonais para a maioria dos meses. Entretanto, diferenças significativas ocorreram nos meses em que fêmeas pareadas apresentaram picos hormonais provavelmente associados a postura de ovos. Tal resultado pode ser um importante indício de imaturidade sexual para as fêmeas do grupo NP. Em machos NP, as principais diferenças apareceram entre os metabolitos de andrógenos. No ano 1, não houve diferença significativa nos andrógenos entre os grupos, mas no ano 2 houve uma manutenção dos níveis elevados durante quase toda a temporada reprodutiva, enquanto que nos grupos pareados boa parte dos indivíduos apresentou uma queda pós-postura. Essa informação sugere que para machos o pareamento não é fundamental para configurá-lo como um reprodutor em potencial, sendo que com base nos resultados endócrinos os machos do grupo NP poderiam, a princípio, ser aproveitados para programas de reprodução assistida. Uma confirmação dessa hipótese foi obtida em uma colheita de sêmen ao final do ano 1, na qual três machos do grupo NP forneceram amostras seminais consideradas de excelente qualidade (alta concentração e motilidade) (RIBEIRO, em fase de elaboração) ${ }^{2}$. Por fim, houve um aumento significativo nas médias hormonais de machos entre o ano 1 e o ano 2 , também sugerido um ganho na maturidade dos machos de todos os grupos, essa diferença não foi vista nas fêmeas.

2 Ribeiro J. D. Coleta de sêmen em pinguim-de-Magalhães (Spheniscus magellanicus) mantido em cativeiro. A ser editado; 2014. 


\section{REFERÊNCIAS}

ALTMANN, J. Observational study of behavior: sampling methods. Behaviour 49.3: 227-266. 1974.

ANCEL, André; BEAULIEU, Michaël; GILBERT, Caroline. The different breeding strategies of penguins: a review. Comptes rendus biologies, v. $336, n$. 1, p. 1-12, 2013.

AZA Penguin Taxon Advisory Group. Penguin (Spheniscidae) Care Manual. Silver Spring, MD: Association of Zoos and Aquariums. 2014

BIRDLIFE INTERNATIONAL. 2016. Spheniscus magellanicus. The IUCN Red List of Threatened Species 2016: e. T22697822A93642328. Disponível em:<http://dx.doi.org/10.2305/IUCN.UK.2016-3.RLTS.T22697822A93642328.en>.

Acesso em: 05 de dezembro de 2016.

BOERSMA, P. D.; FRERE, E.; KANE, O.; POZZI, L. M.; PÜTZ, K.; RAYA REY, A.; REBSTOCK, G. A.; SIMEONE, A.; SMITH, J.; VAN BUREN; A.; YORIO, P.; GARCIA-BORBOROGLU, P. Magellanic penguin. In: GARCÍA-BORBOROGLU, P. G.; BOERSMA, P. D. (Ed.). Penguins - natural history and conservation. Seattle: University of Washington Press, 2013. p 233-263.

BOERSMA, P. D.; STOKES, DAVID L.; YORIO, PABLO M. Reproductive variability and historical change of Magellanic Penguins (Spheniscus magellanicus) at Punta Tombo, Argentina. Penguin biology, v. 7, p. 15-44, 1990.

BROWN, Janine; WALKER, Sue; STEINMAN, Karen. Endocrine manual for the reproductive assessment of domestic and non-domestic species. Endocrine Research Laboratory, Department of Reproductive Sciences, Conservation and Research Center, National Zoological Park, Smithsonian Institution, Handbook, p. 1-93, 2004.

BROWN, Megan E. et al. Female gonadal hormones and reproductive behaviors as key determinants of successful reproductive output of breeding whooping cranes (Grus americana). General and comparative endocrinology, v. 230, p. 158-165, 2016.

CENTRO NACIONAL DE PESQUISA E CONSERVAÇÃO DE AVES SILVESTRES (CEMAVE). Projeto nacional de monitoramento do pinguim-de-Magalhães Spheniscus magellanicus. Cabedelo: CEMAVE, 2010. 34 p.

DAWSON, A.; KING, V. M.; BENTLEY, G. E.; BALL, G. F. Photoperiodic control of seasonality in birds. Journal of Biological Rhythms, v. 16, n. 4, p. 365-380, 2001. 
DIEBOLD, E. N.; BRANCH, S.; HENRY, L. Management of penguin populations in North American zoos and aquariums. Marine Ornithology, v. 27, p. 171-176, 1999.

EGGLETON, P.; SIEGFRIED, W. R. Displays of the Jackass Penguin. Ostrich 50:139-167. 1979

FOWLER, Gene S. Behavioral and hormonal responses of Magellanic penguins (Spheniscus magellanicus) to tourism and nest site visitation. Biological Conservation, v. 90, n. 2, p. 143-149, 1999.

FOWLER, Gene S. et al.. Reproductive endocrinology and weight change in relation to reproductive success in the Magellanic penguin (Spheniscus magellanicus). General and comparative endocrinology, v. 94, n. 3, p. 305-315, 1994.

GAILEY-PHIPPS, J. A world survey of penguins in captivity. International Zoo Yearbook, v.18, p. 7-13, 1978.

GOYMANN, W. Noninvasive monitoring of hormones in bird droppings: physiological validation, sampling, extraction, sex differences, and the influence of diet on hormone metabolite levels. Annals N. Y. Acad. Sci. 1046: 35-53, 2005.

GROSCOLAS, René. Changes in body mass, body temperature and plasma fuel levels during the natural breeding fast in male and female emperor penguinsAptenodytes forsteri. Journal of Comparative Physiology B: Biochemical, Systemic, and Environmental Physiology, v. 156, n. 4, p. 521-527, 1986.

HAU, M. Timing of breeding in variable environments: tropical birds as model systems. Horm. Behav. 40: 281-290, 2001.

LAGUE, P.C., VAN TIENHOVEN, A., CUNNINGHAM, F.J. Concentrations of estrogens, progesterone and $\mathrm{LH}$ during the ovulatory cycle of the laying chicken [Gallus domesticus]. Biol. Reprod. 12, 590-598.1975.

LEHNER, P.N. Handbook of ethological methods. Cambridge: Cambridge University Press. 1996.

MARTIN, P.; BATESON, P. Measuring behavior: an introductory guide. 2 ed. Cambridge: Cambridge University Press. 222p. 2000.

MERRITT, K.; KING, N.E. Behavioral sex differences and activity patterns of captive Humboldt Penguins (Spheniscus humboldti). Zoo biology, 6(2), 129-138. 1987.

MULLER-SCHEWAZE, D. The Behaviour of Penguins: adapted to ice and tropics. New York: State University of New York Press. 1984. 
O'BRIEN, J. K. et al. Reproductive physiology of the female Magellanic penguin (Spheniscus magellanicus): Insights from the study of a zoological colony. General and comparative endocrinology, v. 225, p. 81-94, 2016.

SICK, H. Ornitologia Brasileira. Rio de Janeiro: Nova Fronteira, 2001. 926 p.

STOKES, D. L.; BOERSMA, P. D. Where Breeding Magellanic penguins Spheniscus magellanicus forage: satellite telemetry results and their implications for penguin conservation. Marine Ornithology, v. 27, p. 59-65, 1999.

STOKES, David L.; BOERSMA, P. Dee. Nest-site characteristics and reproductive success in Magellanic penguins (Spheniscus magellanicus). The auk, p. 34-49, 1998.

TEMPEL, D.J.; GUTIÉRREZ, R.J. Factors Related to fecal corticosterone levels in California Spotted Owls: implications for assessing chronic stress. Cons. Biol. 18: 538-547, 2004.

The IUCN Red List of Threatened Species. Version 2016-3. Disponível em: <www.iucnredlist.org>. Acesso em: 05 de dezembro de 2016.

WINGFIELD, John C. et al. The" challenge hypothesis": theoretical implications for patterns of testosterone secretion, mating systems, and breeding strategies. The American Naturalist, v. 136, n. 6, p. 829-846, 1990.

WILLIAMS, T. D. Reproductive endocrinology of macaroni (Eudyptes chrysolophus) and gentoo (Pygoscelis papua) penguins: I. Seasonal changes in plasma levels of gonadal steroids and $\mathrm{LH}$ in breeding adults. General and comparative endocrinology, v. 85, n. 2, p. 230-240, 1992.

WILLIAMS, T. D. The penguins: Spheniscidae. Oxford: Oxford University Press, 1995. 295 p. 


\section{INFLUÊNCIA DO PROGRAMA DE LUZ NA RESPOSTA COMPORTAMENTAL E HORMONAL DE PINGUINS-DE-MAGALHÃES (SPHENISCUS MAGELLANICUS) EM CATIVEIRO}

\subsection{RESUMO}

Pinguins-de-Magalhães (Spheniscus magellanicus) são frequentemente mantidos em zoológicos e aquários brasileiros, principalmente na região sudeste. Bandos de animais de vida livre são avistados em águas brasileiras apenas durante sua migração invernal, retornando às regiões das colônias para a reprodução. Trata-se de uma espécie de reprodução sazonal e, como em outras espécies de aves, são guiados sobretudo pelo fotoperíodo. Contudo, muitas instituições que a abrigam esta espécie em baixas latitudes não dispõe de um programa de luz que simule estágios do ciclo anual dos pinguins (reprodução, muda e migração) em seus recintos. A "Sabina-Escola Parque do Conhecimento" na cidade de Santo André (São Paulo) é um centro educacional que abrigava um plantel de 20 pinguins-de-Magalhães (11 machos e 9 fêmeas) sem histórico reprodutivo prévio. Em fevereiro de 2012, foi introduzido um programa de luz simulando o fotoperíodo de uma região da Patagônia (latitude $45^{\circ} \mathrm{S}$ ). Em abril do mesmo ano, iniciamos um monitoramento hormonal não invasivo semanal em 12 animais (6 machos e 6 fêmeas), estes também tiveram seus comportamentos reprodutivos registrados. Apesar dos esforços e qualidade dos equipamentos utilizados no programa de luz, uma falha no timer analógico acarretou em um aumento de luz durante os meses de inverno. Este aumento induziu comportamentos reprodutivos nos três casais monitorados, estimulando até a postura de dois ovos por uma das fêmeas. Além disso, o incidente provocou uma segunda muda em todos os animais monitorados entre os meses de agosto e outubro, ao menos, quatro meses após a primeira muda. Este estudo demonstra a aplicabilidade de programas de luz em pinguins-de-Magalhães, e levanta a possibilidade da sua aplicação como ferramenta para indução de uma "segunda estação reprodutiva" no manejo reprodutivo de espécies de pinguins ameaçadas. 


\subsection{INTRODUÇÃO}

Flutuações estacionais regulares em ambientes temperados e árticos são extremamente previsíveis e possuem uma alta correlação com as mudanças anuais no fotoperíodo, dessa maneira, não é de se estranhar que a maioria das aves de altas latitudes baseie-se primariamente no comprimento do dia para controlar sua reprodução (SHARP, 1986; HAU, 2001). Pinguins são aves marinhas, restritas ao hemisfério sul que também são guiadas por estes fatores. Estão distribuídas principalmente em ambientes antárticos, subantárticos e temperados, com somente duas exceções que habitam ambientes tropicais (pinguim-de-Humboldt e pinguimde-Galápagos) e, ainda que haja consideráveis diferenças entre suas adaptações reprodutivas, as oscilações luminosas participam ativamente no desencadeamento das estações reprodutivas (WILLIAMS, 1995, GARCÍA-BORBOROGLU; BOERSMA, 2013).

Dentre as 18 espécies existentes, está o pinguim-de-Magalhães (Spheniscus magellanicus), avistado habitualmente em águas costeiras do sul e sudeste do país se beneficiando da fartura de recursos de pesca nos meses de inverno (STOKES; BOERSMA, 1999; SICK, 2001; CEMAVE, 2010). O ciclo anual de atividades destas aves é bem definido e marcado pelas estações do ano. A estação reprodutiva é iniciada em meados de setembro no qual grandes colônias são formadas na costa da Argentina, Chile e Illhas Falklands/ Malvinas, desde a Terra do Fogo $\left(55^{\circ} \mathrm{S}\right)$ até latitudes $41^{\circ} \mathrm{S}$ no Atlântico e $33^{\circ} \mathrm{S}$ no Pacífico (BOERSMA et al., 2013; BIRDLIFE INTERNATIONAL, 2016), ao término da reprodução, os animais permanecem nos locais das colônias para a troca de penas e, em meados de Abril, seguem para a migração em busca por alimentos chegando a costa brasileira (WILLIAMS, 1995; BOERSMA et al., 2013).

Durante a intensa migração invernal, diversos são os desafios enfrentados por esta espécie, sendo os principais a competição por recursos alimentares com a pesca comercial, a captura acidental em redes de pesca, a poluição crônica por petróleo e também as alterações climáticas (YORIO et al., 1999; TASKER et al., 2000; LUNA et al., 2002; GARCÍA-BORBOROGLU et al. 2006, 2010; BOERSMA, 2008; BIRDLIFE INTERNATIONAL, 2016). A consequência de todas estas ameaças durante a migração dos pinguins é o encalhe de centenas a milhares de animais 
anualmente em praias brasileiras, com uma ampla maioria de animais juvenis (SICK, 2001; CEMAVE, 2010; STOKES et al., 2014). Além dos animais mortos há também um importante número de encalhes de animais doentes, ou até de grandes grupos geralmente associados a manchas de óleo no mar. Nestes casos há grande esforço de centros de reabilitação para recuperá-los e soltá-los de volta ao mar, mas diante de alguma impossibilidade, estas aves são encaminhadas ao cativeiro (SILVAFILHO; RUOPPOLO, 2006, CEMAVE, 2010).

A população mundial desta espécie gira em torno de 1.100 .000 a 1.600 .000 pares reprodutivos e, apesar de ser o pinguim do gênero Spheniscus mais abundante em regiões temperadas, a acentuada diminuição das principais colônias da Argentina nas últimas décadas, tornou-a classificada como "Quase Ameaçada" pela lista vermelha da União Internacional para a Conservação da Natureza (IUCN) nas suas duas últimas edições (2013 e 2016). A espécie também é listada no Apêndice II da Convenção Internacional sobre o Comércio Internacional das Espécies de Flora e Fauna Selvagens em Perigo de Extinção (CITES).

Em vistas deste cenário enfrentado pelos pinguins-de-Magalhães, e do constante influxo de alguns indivíduos ao cativeiro, este último recebe um papel fundamental para o estudo e conservação da espécie. Uma vez que a reprodução em cativeiro é um importante aliado da conservação de espécies, é necessário que os animais mantidos em cativeiro tenham estímulos semelhantes aos encontrados em vida-livre, expressando comportamentos semelhantes como a sazonalidade fortemente presente no ciclo do pinguim-de-Magalhães e principalmente a reprodução. No Brasil, a reprodução ex situ é considerada incipiente, com registros escassos de posturas e nascimentos. Diversas razões podem ser atribuídas a essa falha reprodutiva, entre elas, as principais são: condições inadequadas de cativeiro, alta rotatividade de indivíduos nos planteis e enfermidades.

Sendo assim, a finalidade deste trabalho é demonstrar a influência das oscilações luminosas no ciclo de atividades anuais de pinguins-de-Magalhães mantidos em cativeiro e como a simples ferramenta de um programa de luz associado ao manejo correto pode mimetizar o ciclo regular dos animais de vida livre e induzir a reprodução dos animais. 


\subsection{MATERIAIS E MÉTODOS}

\subsubsection{Animais, manejo e recinto}

Para o estudo foram utilizadas amostras de 12 pinguins-de-Magalhães adultos (6 machos e 6 fêmeas) residentes do plantel permanente da Sabina Escola Parque do Conhecimento localizado na cidade de Santo André, São Paulo (234' $\left.55^{\prime \prime} S 46^{\circ} 31^{\prime} 52^{\prime \prime} \mathrm{W}\right)$. Todos os animais eram provenientes de vida-livre e passaram por um período de reabilitação antes de serem transferidos. Tal processo ocorreu ainda no primeiro ano de vida dos pinguins, facilitando o registro de suas idades, portanto, no início do estudo, os animais tinham, em média, 4 anos de idade. O critério para a seleção dos animais foi por meio da avaliação do comportamento dos animais. Foram selecionados 6 animais (3 casais) que expressassem comportamento de proximidade entre os pares, e procura por ninho. Estes comportamentos foram escolhidos, pois até o início do estudo, não havia ocorrido nenhuma postura de ovos ou cópulas haviam sido observadas, estes casais comporiam o grupo de animais pareados (PAR). Outros 6 animais (3 machos e 3 fêmeas) foram selecionados com base na ausência de manifestação dos comportamentos relatados anteriormente e, portanto, comporiam o grupo de animais não pareados (NPAR). Ao início do estudo, todos os animais já haviam realizado a muda de penas anual entre fevereiro e março de 2012. Os pinguins eram alimentados duas vezes ao dia ad libitum, com uma variedade de pescados que incluíam, sardinha, manjuba, betara e pescada, sendo o primeiro pescado o mais frequente. Todos os animais receberam suplementação vitamínica diária junto a primeira alimentação da manhã.

Os pinguins eram alojados em recinto com capacidade para 28 indivíduos, com área total de $144 \mathrm{~m}^{2}$, incluindo área seca de $33 \mathrm{~m}^{2}$ e uma piscina de $81 \mathrm{~m}^{2}$, com 110.000 litros de água salgada. A área seca tinha piso liso e algumas áreas de capachos de vinil e grama sintética para prevenção de pododermatites. O recinto era lavado 3 a 4 vezes ao dia com uma lavadora de alta pressão e periodicamente recebia uma limpeza mais severa com desinfetantes. $O$ tanque de água salgada era equipado com filtração compatível com sua dimensão e havia controle de qualidade de água semanal. $\mathrm{O}$ acesso ao tanque de água era livre aos pinguins durante todo o 
ano. A troca de ar era totalmente realizada por meio de aparelhos de ar condicionado, os quais também mantinham o controle da temperatura e da umidade do ambiente, sendo a primeira variável de acordo com a estação do ano $\left(15-25^{\circ} \mathrm{C}\right)$. As luzes do recinto eram uma mescla de luz natural e artificial, o teto de vidro do recinto permitia a entrada de luz natural, com o reforço de luzes artificiais (lâmpadas de descarga de alta intensidade - iodeto de quartzo hydrargyrum, HQI). O teto de vidro era equipado com toldos de proteção para que não houvesse entrada de luz externa no período noturno. Todos os dias, a mescla de luz artificial e natural era mantida aos pinguins por 10 horas (8:00 - 18:00), sem qualquer oscilação estacional.

\subsubsection{Programa de luz}

O programa de luz foi iniciado em fevereiro de 2012 com o objetivo de mimetizar as oscilações luminosas que estimulam constantemente pinguins em vida livre nestes indivíduos mantidos em cativeiro. Para isso, foi escolhida a latitude da região com uma das maiores colônias reprodutivas de pinguins-de-Magalhães, Punta Tombo na Argentina, tal região fica na latitude $45^{\circ} \mathrm{S}$ e, a partir desta informação, as horas diárias de luz foram calculadas para execução do programa. Utilizou-se de um timer analógico para ligar e desligar as luzes conforme os horários estipulados. As alterações ocorriam a cada 15 dias para que não houvesse oscilação superior a 45 minutos de um dia para o outro. Desta forma, os animais recebiam uma variação luminosa entre 9h e meia e 15 horas de luz, pois, respeitouse também, os horários de visitação do parque (8:00 - 17:00). Sendo assim, a última alteração do timer analógico antes do período de inverno (constante em 9h e meia de luz) ocorria em meados de maio, sendo alterado novamente, só em início de agosto. Uma falha no sistema do timer acarretou na permanência das luzes ligadas durante 24 horas durante 3 meses, desde a última conferência do aparelho (15/maio/2017) até sua nova verificação em agosto. Este período seria equivalente ao inverno, e os animais teriam a menor amplitude de luz diária (9,5 h/ dia). A figura 16 exibe, por meio de um gráfico, as 3 variações de osculação luminosas mencionadas neste trabalho, a manutenção de luz constante, a oscilação de luz 
almejada para correta mimetização, e a oscilação de luz efetivamente realizada em decorrência da falha no equipamento.

Uma vez que que os animais haviam recebido um estímulo luminoso muito maior ao natural, optou-se por modificar toda a programação original de luz, e permitir que os animais experimentassem um período de menor amplitude de luz diária, antes que fossem novamente estimulados com a luminosidade crescente. Desta forma, as oscilações luminosas originalmente pretendidas na implantação do programa de luz, só retornariam ao normal em março de 2013, permitindo aos animais um curto período de inverno e o retorno ao verão. Deste modo, durante os 12 meses monitorados neste estudo, os pinguins experimentaram duas estações reprodutivas induzidas por meio da luz.

Figura 16 - Programa de luz feito durante o monitoramento dos pinguins-de-Magalhães.

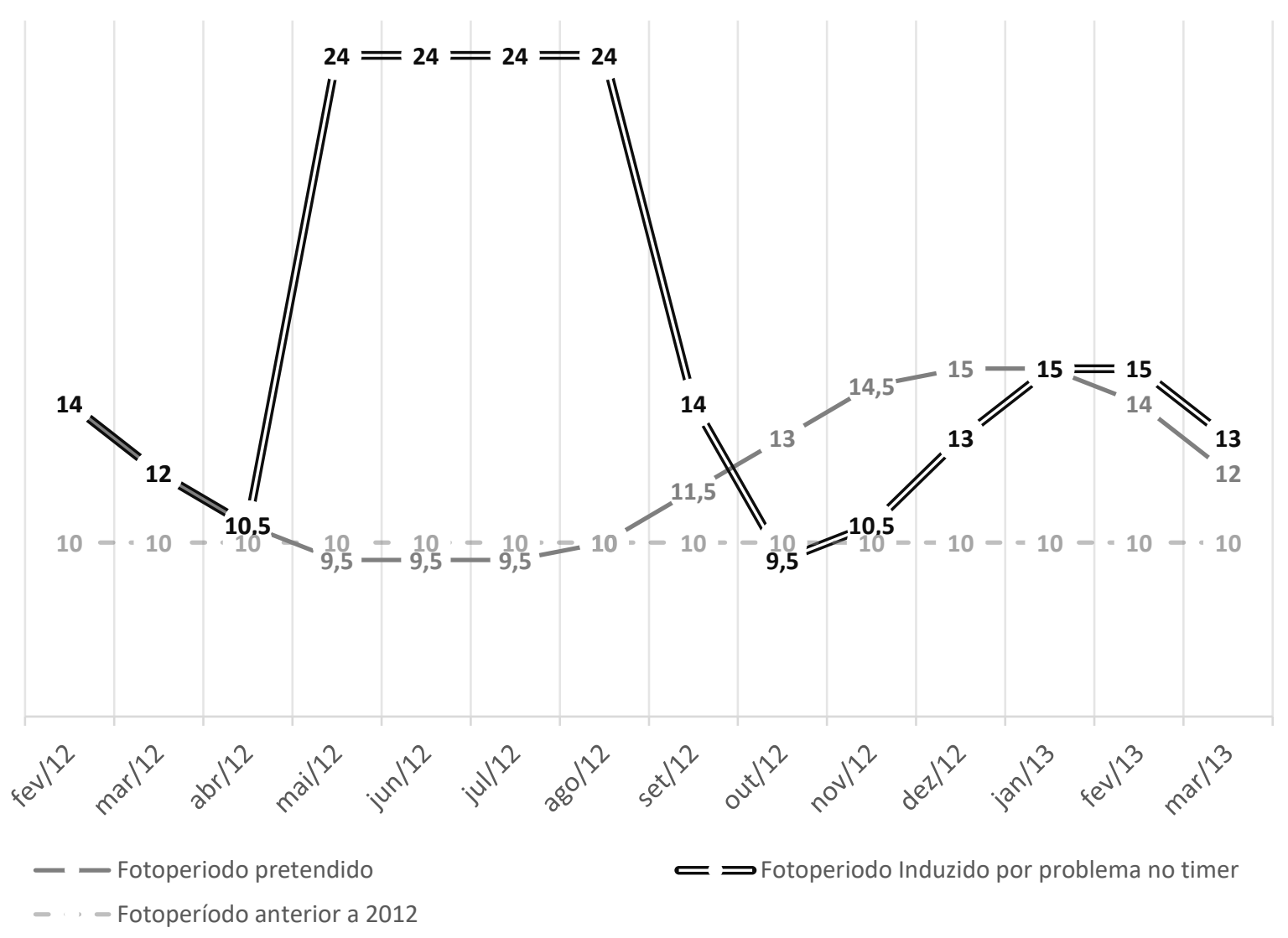

Fonte: RIBEIRO, J.D., 2017

Legenda: A linha cinza claro segmentada (Fotoperíodo anterior a fevereiro de 2012) mostra a ausência de oscilação luminosa aos pinguins-de-Magalhães no período anterior a 2012; a linha cinza escuro (Fotoperiodo pretendido) mostra a oscilação luminosa pretendida para o recinto de acordo com informações de vida livre, iniciada em fevereiro de 2012; a linha dupla preta (Fotoperíodo induzido por problemas no timer) mostra a falha ocorrida e o remanejamento das horas de luz oferecidas aos animais naquele ano. 


\subsubsection{Coleta de amostras e dados comportamentais}

As amostras de fezes foram coletadas semanalmente pelo período de um ano (abril/ 2012 a março/ 2013), o horário das coletas foi padronizado entre 10:00 e 13:00 para evitar, ao máximo, oscilações circadianas nas secreções dos metabólitos hormonais. Nenhum tipo de contenção ou manipulação foi feita para a coleta de amostras dos animais, os mesmos permaneciam soltos no recinto e as coletas eram realizadas conforme a defecação fosse observada. A porção fecal era cuidadosamente separada da porção de urato e armazenada em microtubos plásticos identificados, estes eram refrigerados até o congelamento $\left(-20^{\circ} \mathrm{C}\right)$, feito ao final de cada período diário de coletas.

Para a observação dos comportamentos, inicialmente foi realizado um padrão de atividades dos animais. Tal processo consiste em três dias consecutivos de observação, utilizando-se do método scan para contagem de atividade e inatividade dos animais a cada 15 minutos (LEHNER, 1996). O padrão de atividade foi realizado entre 10:00 as 16:30, evitando horários de alimentação dos animais e limpeza do recinto. O perfil gerado revelou que o horário de maior atividade dos animais era as 14:30 (Anexo A), sendo assim os registros comportamentais foram realizados semanalmente neste horário por meio do método de amostragem focal por intervalo de tempo (ALTMANN, 1974; MARTIN, 2000). Os registros eram feitos a cada 30 segundos em sessões de 30 minutos para animais pareados e registros com intervalo de 45 segundos e sessões de 45 minutos para animais não pareados, num total de 60 registro em cada sessão. Ao longo do ano amostral, houve um total de 2.880 registros de comportamento (1.440 minutos) para animais pareados e 2.340 registros de comportamento (1.755 minutos) para animais não pareados.

Os comportamentos foram separados em duas grandes categorias, comportamentos não-reprodutivos e comportamentos reprodutivos com base em trabalhos que relatam comportamento de pinguins do gênero Spheniscus tanto em vida-livre quanto em cativeiro (EGGLETON, 1979; MERRITT, 1987; MULLERSCHWAZE, 1984; STOKES, 1998). Os comportamentos não-reprodutivos foram agrupados numa mesma categoria e não foram o foco deste trabalho, já o repertório comportamental reprodutivo esperado está descrito no anexo $\mathrm{B}$. A proximidade entre os indivíduos pareados foi inclusa como comportamento sexual a fim se relacionar 
os comportamentos de proximidade e proceptividade. Este parâmetro também foi observado nos animais não pareados e registrados quando estes passavam a demonstrá-lo. A permanência de animais em ninhos também foi registrada para os grupos. Por último, a permanência dos animais na água foi também considerado um comportamento importante, em razão da sazonalidade destes animais e do ciclo anual marcado, não só pelo período reprodutivo, mas também pela migração invernal, logo este comportamento pode indicar a eficiência do programa de luz iniciado. Características físicas do ambiente, como temperatura, densidade e salinidade, foram anotadas assim como observações extras de manutenções e manejos, a fim de relacionar possíveis perturbações que pudessem afetar o padrão comportamental dos animais durante o estudo.

\subsubsection{Extração de metabolitos hormonais e ensaios enzimáticos}

O protocolo de extração dos metabólitos de hormônios nas fezes foi baseado nos métodos descritos por Tempel e Gutierrez (2004) e modificada por Pereira et al. (2010). Inicialmente as amostras foram acondicionadas em uma temperatura de $30^{\circ} \mathrm{C}$ por 24 horas e então liofilizadas por aproximadamente 24 horas, amostras excessivamente úmidas passaram novamente pelo processo. Em seguida, as amostras foram trituradas e homogeneizadas e uma alíquota de $0,1 \mathrm{~g}$ de fezes de cada amostra foram colocadas em tubos de ensaio secos e limpos e acrescidos de $2 \mathrm{ml}$ de metanol PA $80 \%$ (amostras menores receberam volume proporcional de metanol; 1:2) e agitadas em Vórtex (Scientific-M37615, Thermo Scientific, Massachusetts, USA) por 30 segundos e posteriormente em agitador horizontal (Orbit 1000, Labnet International Inc., New Jersey, EUA) a 250 rpm por, no mínimo, 12 horas. Depois deste processo, os tubos eram novamente agitados em Vórtex e seguidamente centrifugadas (Scientific-Heraeus Megafuge 16R Centrifuge, Thermo Scientific, Massachusetts, EUA) em 400G por 15 minutos para que o sobrenadante pudesse ser transferido para um novo tubo de ensaio de vidro tampado e estocado em freezer $\left(-20^{\circ} \mathrm{C}\right)$ até o ensaio imunoenzimático.

Os ensaios imunoenzimáticos foram realizados segundo protocolo de Brown Walker e Steinman (2004) para os três hormônios mensurados, progesterona, estrógeno e andrógeno. Todas as concentrações foram mensuradas em duplicata 
por meio de alíquotas de proporção 1:4 entre o extrato fecal e o tampão do ensaio imunoenzimático conforme protocolo. Os anticorpos utilizados foram fornecidos pela Dra. Coralie Munro (Universidade da Califórnia, Davis, CA, EUA). Para testosterona foi utilizado o anticorpo monoclonal $\mathrm{R} 156 / 7$ com reatividade cruzada para testosterona (100\%), 5a-di-hidrotestosterona (57,3\%), androsterona (0,4\%), androstenediona $(0,2 \%)$ e inferior a $0,04 \%$ para todos os demais metabólitos; para progesterona o anticorpo monoclonal CL $415 \mathrm{com}$ reatividade cruzada com diversos metabolitos, incluindo 4-pregnen-3,20-diona (100\%), 4-pregnen-3a-ol-20-ona

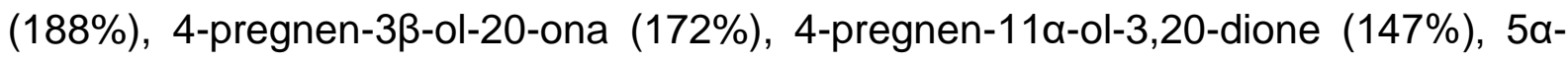

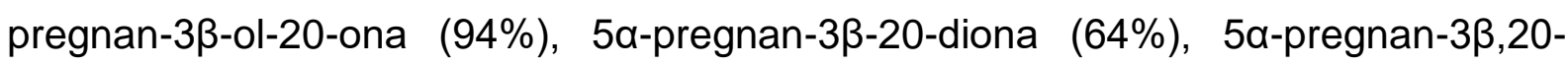
diona (55\%), 5-pregnan-3-ol-20-ona (12.5\%), 5-pregnan-3-20-diona (8.0\%), 4-

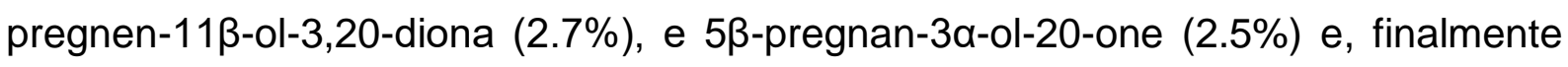
para estradiol, o anticorpo policlonal R0008 com as seguintes reações cruzadas, $17 \beta$-estradiol $(100 \%)$, estrona $(0,73 \%)$ e para sulfato de estrona, progesterona, testosterona, cortisol, corticosterona e androstenediona, inferior a 0,01\%.

O ensaio foi previamente validado segundo princípios de validação estabelecidos por Goymann (2005), utilizando-se dos testes descritos por Brown, Walker e Steinman (2004) com a demonstração de curva de paralelismo entre diluições seriadas dos extratos fecais (1:2 a 1:1024) e a curva padrão para cada hormônio (andrógeno: 0,045 - 12 ng/ mL; progesterona: 0,78 - 200 ng/ mL; estradiol: 1,95 - $500 \mathrm{ng} / \mathrm{mL}$ ), curva de dose-resposta (andrógeno: $\mathrm{y}=0,9043 \mathrm{x}+0,247$ $R^{2}=0,9913$; progesterona: $y=0,4177 x+0,162 R^{2}=0,9465$; estradiol: $y=0,239 x+1,9336$ $\left.R^{2}=0,9895\right)$, coeficientes de variação inter e intra-ensaio $<14 \%$ e $<15 \%$ respectivamente). Também foi observada a demonstração da validação biológica através da correlação de níveis hormonais com comportamentos observados nos animais (comportamentos agonísticos, cópulas, posturas).

\subsubsection{Análise estatística}

As concentrações de hormônios nas fezes e as porcentagens de registros de comportamentos são apresentadas como médias \pm erro padrão. As comparações de médias de concentração hormonais e médias de registros comportamentais são entre os grupos (pareados e não pareados) e são apresentadas em duas etapas. A 
primeira compara as médias mensais de cada grupo em cada mês do ano amostral. Já a segunda etapa apresenta as médias de acordo com o número de horas de luz fornecida aos animais no período em que foram coletadas $(9,5 \mathrm{~h} ; 10,5 \mathrm{~h}$; 13h, 15h e 24h), não há diferenciação, portanto, dos meses, ou seja, meses com mesma amplitude de horas de luz estão agrupados. Os dados foram analisados pelo SAS System Windows (SAS Institute Inc., Cary, NC, USA). Testes paramétricos foram utilizados para dados que obedeceram às premissas estatísticas da normalidade dos resíduos e homogeneidade das variâncias e teste não paramétricos foram utilizados para os dados que não as obedeceram. O nível de significância utilizado para rejeição foi de $5 \%(p<0,05)$.

\subsection{RESULTADOS}

Durante o ano amostral, foi registrada postura de dois ovos por uma das fêmeas pareadas. As posturas ocorreram em 10 e 12 de Junho de 2012 quando o programa de luz fornecia $24 \mathrm{~h}$ de luz por dia para todos os animais do plantel. $\mathrm{O}$ primeiro ovo foi quebrado pelo próprio casal dois dias após a postura e na sequência foi feita a postura do segundo ovo. O segundo ovo foi submetido a ovoscopia 16 dias após sua postura e foi diagnosticado como infértil. Ainda assim, o ovo foi mantido no ninho para que os pais pudessem incubá-lo e que tal comportamento servisse de estímulo para os demais animais.

Entre os meses de agosto e outubro, todos os animais amostrados repetiram a muda de penas que já havia sido realizada entre janeiro e maio do mesmo ano. $\mathrm{Na}$ figura 17 é possível comparar anos anteriores e posteriores ao monitoramento, comparando porcentagens de animais em muda em cada mês de cada ano. Estes dados se referem apenas aos 12 animais pertencentes ao monitoramento entre os anos de 2010 e 2015, portanto, foram excluídos desta relação os outros animais do plantel. O intervalo entre a postura de ovos do casal monitorado (junho) e a muda (macho - setembro e fêmea - outubro) mostrou-se semelhante ao intervalo regular para os dois eventos demonstrado pelos animais dentro de uma estação reprodutiva normal. 
Figura 17 - Dispersão das mudas entre os animais monitorados de 2010 - 2015.

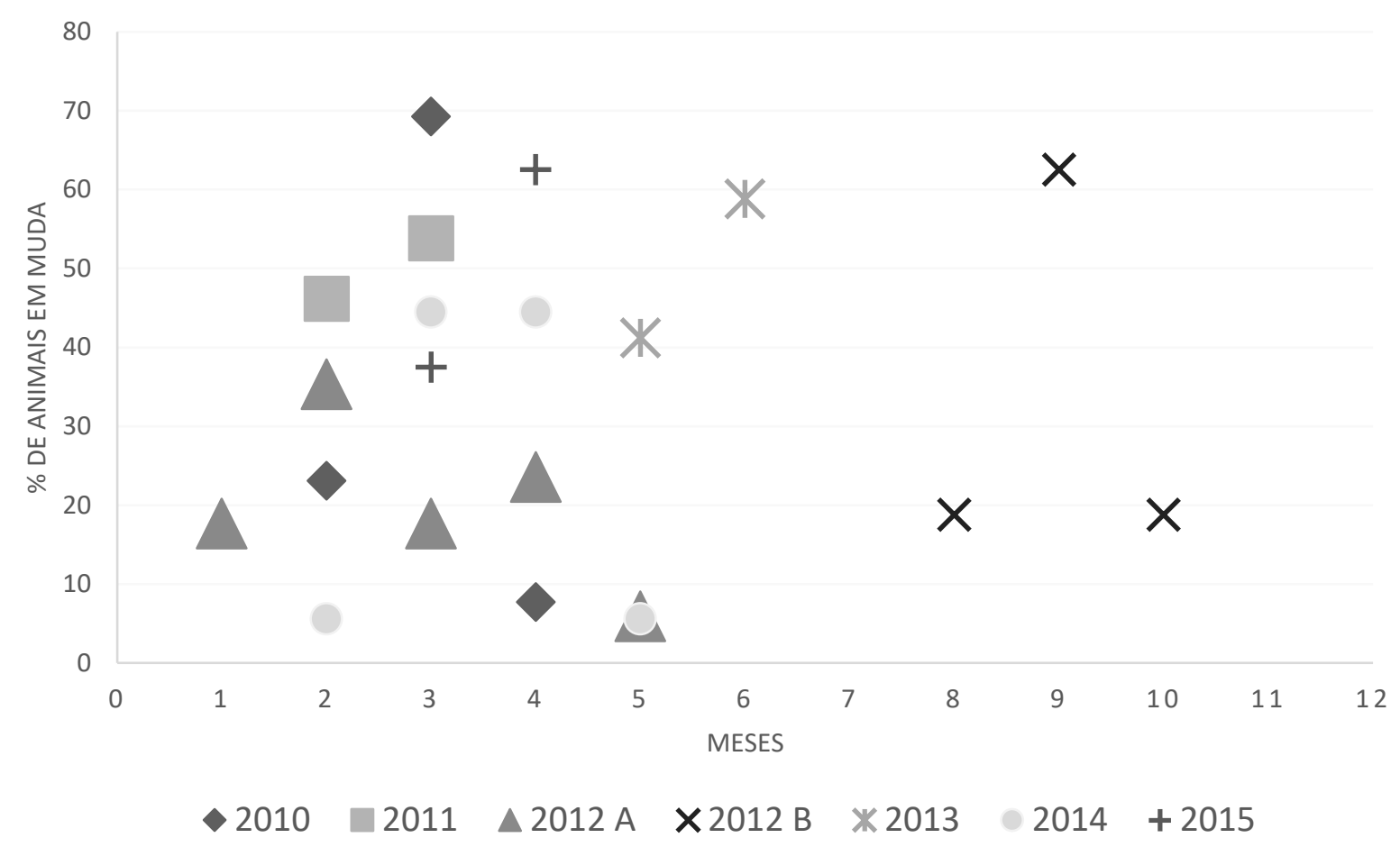

Fonte: (RIBEIRO, J.D; 2017).

Legenda: Os símbolos representam as mudas de cada ano demonstradas em porcentagem de animais em muda em cada mês; os meses são representados por números, sendo o número "1" equivalente a janeiro e assim sucessivamente. Note que o ano de 2012 tem dois períodos distintos, "A" e "B". O "A" representa a muda no início do ano e, o "B", a muda após a superexposição a luz nos meses de agosto, setembro e outubro de 2012.

O número total de amostras de fezes coletadas no ano amostral foi de 364 amostras (fêmeas $=167$ e machos $=197$ ). As figuras 18 e 19 exibem, respectivamente, as médias das concentrações de metabólitos hormonais mensais em machos e fêmeas. Médias de andrógenos nos machos apresentam valores significativamente mais elevados no grupo pareado para a maioria dos meses. Dois picos podem ser observados nos machos pareados, o primeiro em abril $(6,60 \pm 5,64$ $\mathrm{ng} / \mathrm{g})$ e, o segundo em janeiro $(1,54 \pm 1,13 \mathrm{ng} / \mathrm{g})$, neste último, machos NPAR também apresentam um pico $(0,74 \pm 0,33 \mathrm{ng} / \mathrm{g})$, mas não de igual proporção ao grupo PAR. Os picos aparecem algum tempo após o aumento de horas de luz. Ainda que isso não seja tão perceptível em abril/2012 quanto em janeiro/2013, é preciso observar que os animais recebiam luz constante há quatro anos e tiverem sua primeira oscilação positiva em fevereiro, dois meses antes do pico. Para o segundo pico há gradualmente o aumento de luz desde outubro. 
Oscilações de progestágenos se mostram semelhantes nos dois grupos, com diferença apenas em setembro, quando é maior no grupo não pareado. Estrógenos também parecem ter valores semelhantes nos dois grupos e ambos apresentam um pico em janeiro (pareados; 96,29 $\pm 52,42$ ng/ g e não pareados; 51,13 $\pm 16,75 \mathrm{ng}$ / g), sendo estes os maiores valores para estrógenos durante o monitoramento.

Nas fêmeas, as oscilações dos três hormônios parecem mais coordenadas, mantendo níveis levemente mais elevados nos meses com maior incidência luminosa. Esse comportamento é visualizado de maneira mais clara nas fêmeas PAR. Neste grupo, os picos se apresentam de forma concomitante entre os três hormônios (figura 19). São dois picos importantes durante o ano amostral, em junho (andrógeno 1,17 \pm 0,67 ng/ g; estrógeno 76,63 $\pm 25,24 \mathrm{ng} / \mathrm{g}$ e progestágenos mais elevados já em maio 21,31 $\pm 20,25 \mathrm{ng} / \mathrm{g}$ ) e em fevereiro (andrógenos 0,92 \pm 0,16; estrógenos $111,21 \pm 17 \mathrm{ng} / \mathrm{g}$ e progestágenos 18,92 $\pm 2,71 \mathrm{ng} / \mathrm{g}$ ). O primeiro pico resultou nas posturas de ovos mencionadas no início, já o segundo pico, apesar de possuir nível hormonal mais elevado de estrógenos, não gerou nenhuma postura. 
Figura 18 - Médias das concentrações hormonais mensais em machos pareados e não pareados.

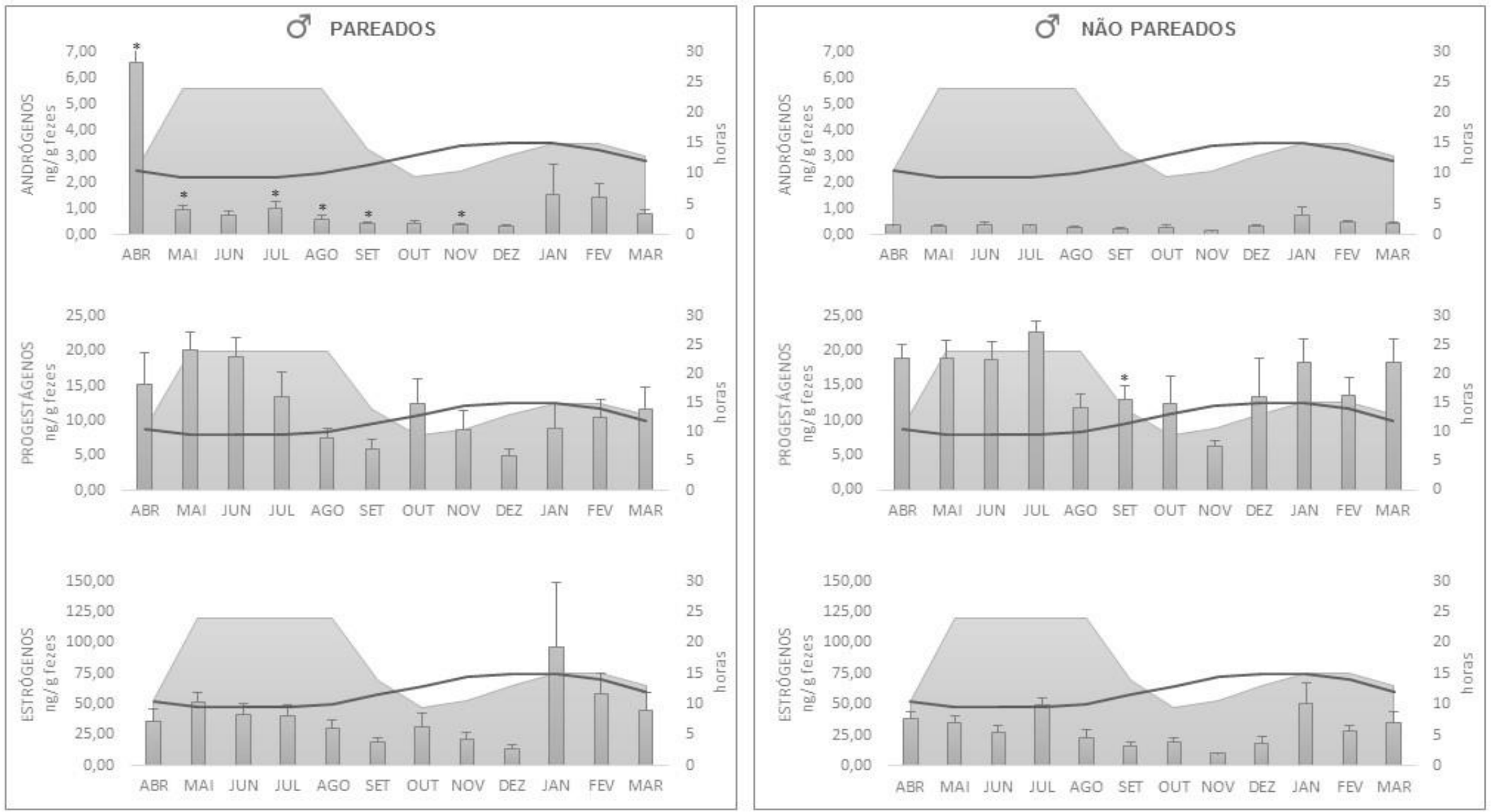

Fonte: (RIBEIRO, J. D.; 2017)

Legenda: Área sombreada no gráfico representa o fotoperíodo realizado, enquanto que a linha cinza escuro demonstra como seria a oscilação luminosa correta para o período. As barras são as médias e erro padrão das concentrações hormonais em cada mês. $\left(^{*}\right)$ sinaliza média mais alta entre medias com diferença significativa entre grupos no mesmo mês $(p<0,05$; Wilcoxon test). 
Figura 19 - Médias das concentrações hormonais mensais em fêmeas pareadas e não pareadas.
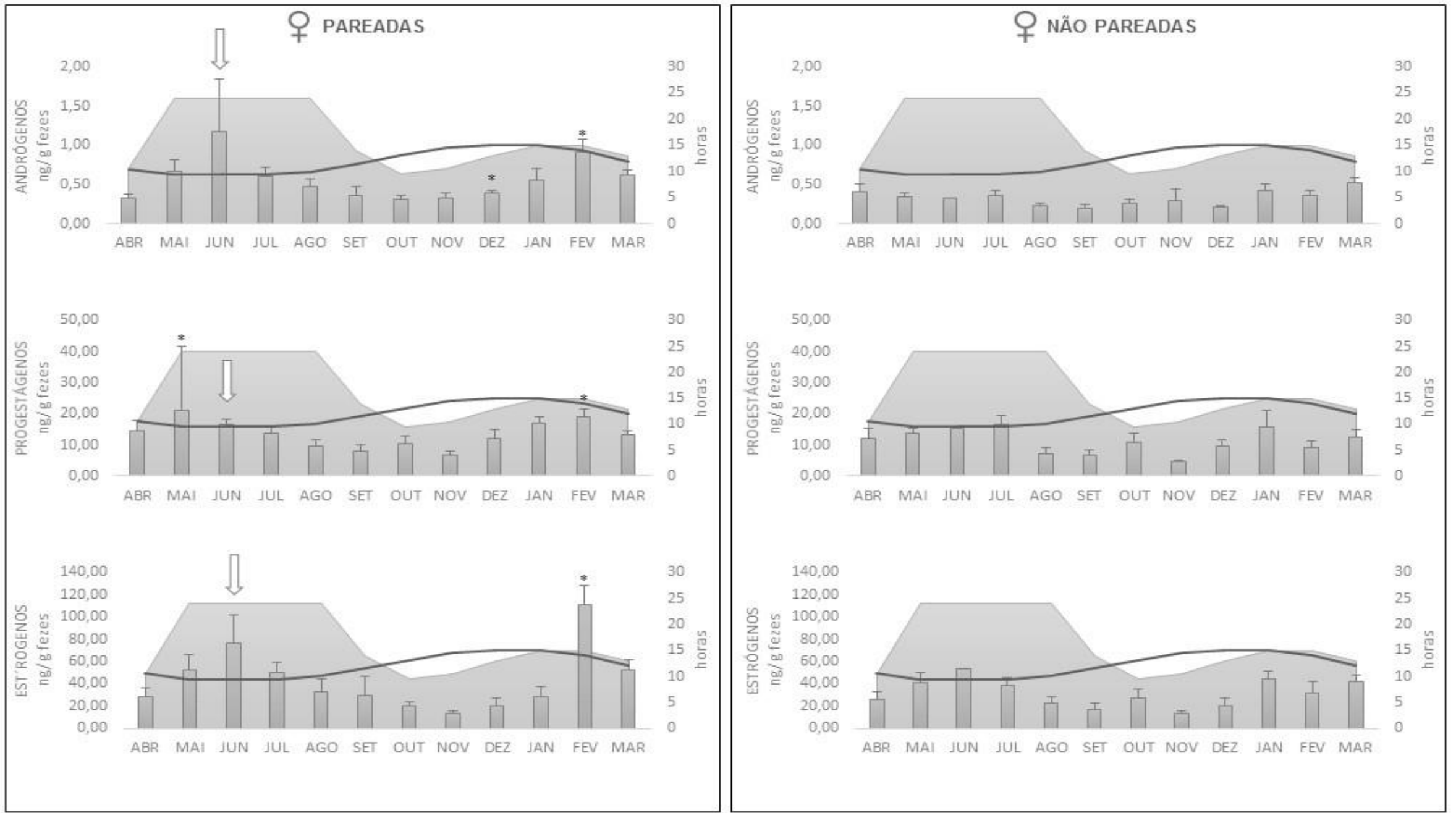

Fonte: (RIBEIRO, J. D.; 2017).

Legenda: Área sombreada no gráfico representa o fotoperíodo realizado, enquanto que a linha cinza escuro demonstra como seria a oscilação luminosa correta para o período. As barras são as médias e erro padrão das concentrações hormonais em cada mês. $\left(^{*}\right)$ sinaliza média mais alta entre medias com diferença significativa entre grupos no mesmo mês $(p<0,05$; Wilcoxon test). Setas brancas sinalizam a postura dos ovos. 
Para os comportamentos, as médias para os registros mensais de machos e fêmeas estão compiladas nas figuras 20 e 21 , respectivamente. O comportamento de proximidade entre o casal foi registrado nos animais do grupo PAR durante todos os meses. Machos e fêmeas do grupo NPAR apresentaram o comportamento em meses isolados e distintos (machos em outubro e fêmea em abril). A proximidade entre os animais PAR não parece oscilar conforme a variação luminosa, entretanto se manifesta de forma oposta à permanência dos animais na água. Quanto ao comportamento de permanência em ninho, também registrado de forma evidente entre fêmeas e machos do grupo PAR, parece ser influenciado pelas oscilações luminosas e chega a desaparecer nos meses de novembro e dezembro, logo após a indução do fotoperíodo mais baixo. A exceção do mês de abril, que mesmo com a baixa incidência de luz $(10,5 \mathrm{~h})$ tem a manifestação de tal comportamento. Animais NPAR apresentam médias para permanência em ninho nos mesmos meses que apresentaram proximidade entre outro indivíduo (machos em outubro e fêmea em abril), contudo, demonstram índices ainda mais baixos.

Comportamentos reprodutivos foram observados e registrados nos dois grupos de machos e fêmeas. Nas fêmeas, pareadas apresentaram médias significativamente maiores do que no grupo NPAR. Em machos, as médias foram semelhantes aos dois grupos. Com exceção das fêmeas NPAR, que não demonstram um comportamento coordenado, os grupos parecem ser influenciados pelo fotoperíodo, com médias maiores em períodos de exposição maior a luz, sendo o oposto também verdadeiro. Durante todo o período de monitoramento, poucas cópulas foram registradas. Comportamentos mais comumente visualizados entre pares eram allopreening, vocalizações e cortejos. Já em relação a permanência dos animais na água, destacam-se as fêmeas NPAR, apresentando médias elevadas durante todo o ano. Fêmeas PAR tem médias significativamente menores em todos os meses (exceto dezembro) e apresentam aumento deste comportamento em resposta ao declínio acentuado na amplitude de luz. Machos não apresentam diferenças entre os grupos ao longo do ano, apenas em novembro, quando $100 \%$ dos machos NPAR permanecem na água. Assim como nas fêmeas pareadas, notase o aumento deste comportamento nos grupos de machos quando há declínio na amplitude luminosa. 
Figura 20 - Médias dos registros comportamentais mensais em machos pareados e não pareados.

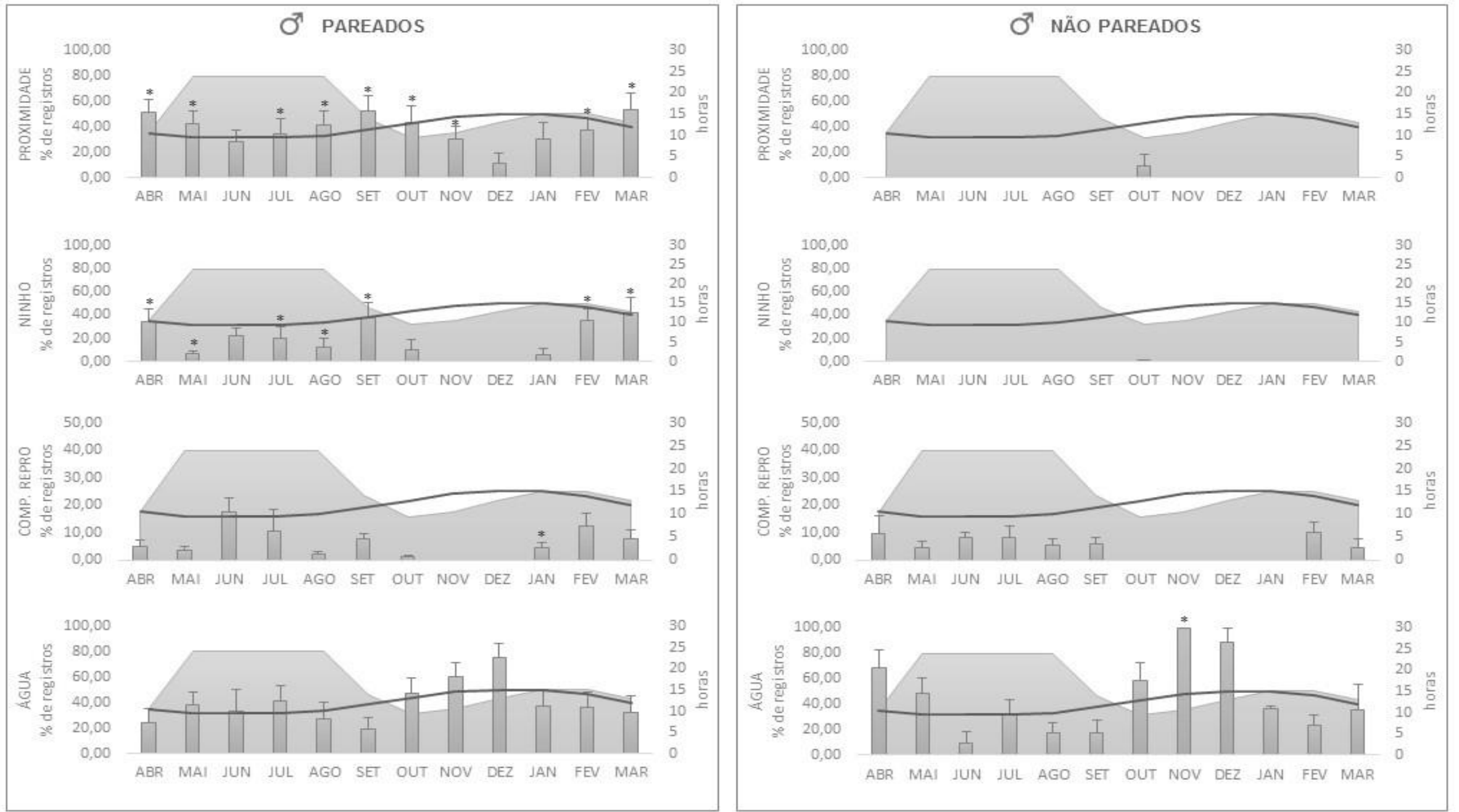

Fonte: (RIBEIRO, J. D.; 2017)

Legenda: Área sombreada no gráfico representa o fotoperíodo realizado, enquanto que a linha cinza escuro demonstra como seria a oscilação luminosa correta para o período. As barras são as médias e erro padrão dos registros comportamentais em cada mês. $\left(^{*}\right)$ sinaliza média mais alta entre medias com diferença significativa entre grupos no mesmo mês $(p<0,05$; Wilcoxon test). 
Figura 21 - Médias dos registros comportamentais mensais em fêmeas pareadas e não pareadas.
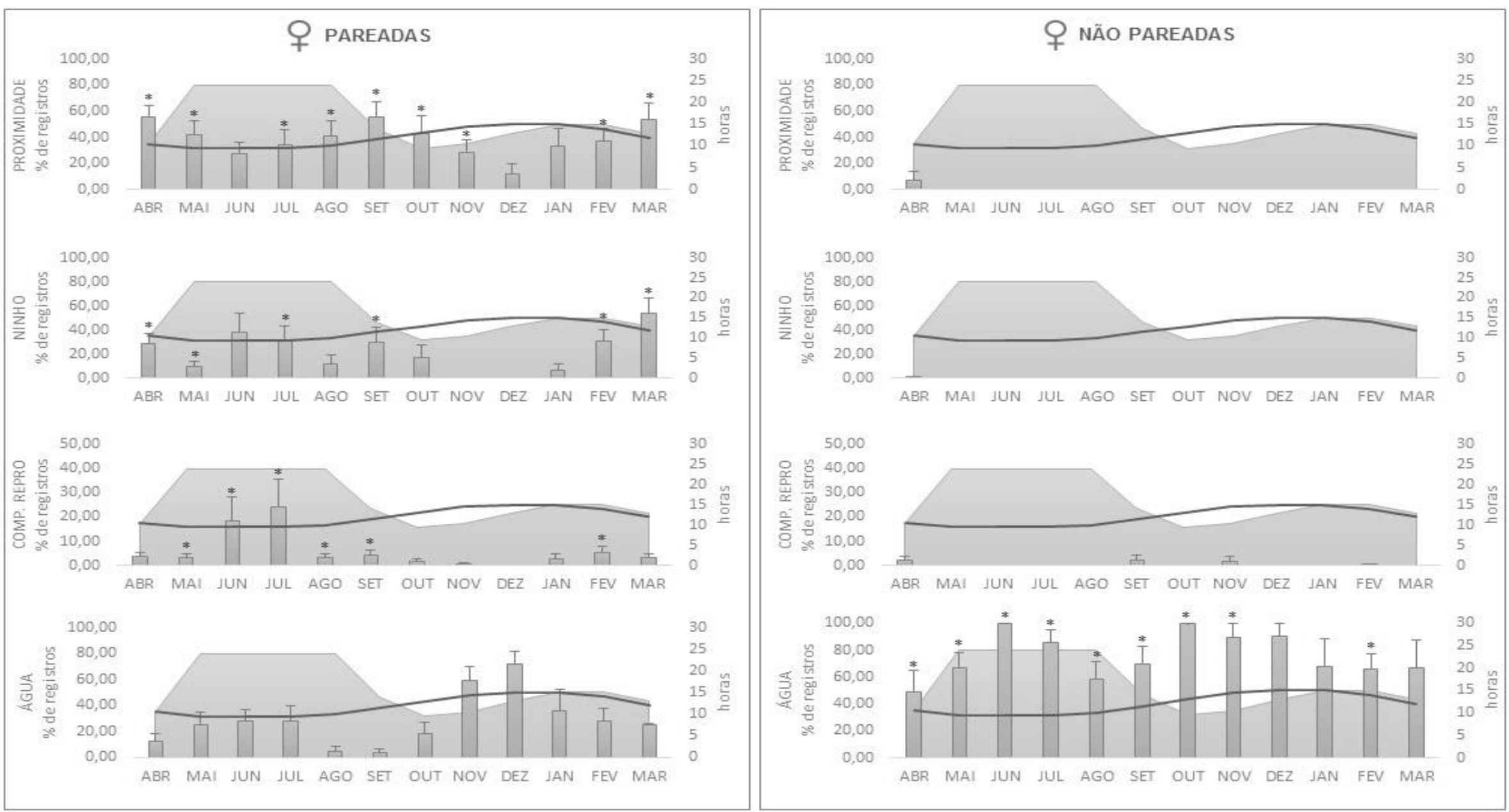

Fonte: (RIBEIRO, J. D.; 2017).

Legenda: Área sombreada no gráfico representa o fotoperíodo realizado, enquanto que a linha cinza escuro demonstra como seria a oscilação luminosa correta para o período. As barras são as médias e erro padrão dos registros comportamentais em cada mês. $\left(^{*}\right)$ sinaliza média mais alta entre medias com diferença significativa entre grupos no mesmo mês $(p<0,05$; Wilcoxon test). 
Resultados apresentados sob o prisma da variação de amplitude luminosa demonstram as médias de concentrações de andrógenos para machos de forma a possibilitar a comparação entre os níveis dos grupos. Machos NPAR parecem demonstrar níveis mais basais, enquanto machos PAR demonstram níveis mais elevados. Contudo, só há diferença significativa entre os grupos em $14 \mathrm{~h}$ e $24 \mathrm{~h}$, quanto machos pareados apresentam valores mais altos (figura 22), isso ocorre, provavelmente, pela ampla variação dos níveis mensais dentre os machos do grupo PAR. Para estrógenos, os valores são semelhantes entre os dois grupos de machos, sendo o maior valor em $15 \mathrm{~h}$ para os dois grupos. Já pra progestágenos, machos NPAR apresentam concentrações maiores com 10,5h, 13h e 14h, demonstrando valores mais altos com a luz em 24h. Fêmeas PAR apresentam valores para andrógenos e progestágenos significativamente mais elevados em $13 \mathrm{~h}$ e $24 \mathrm{~h}$ quando comparados ao grupo NPAR. Os valores de estrógenos nas fêmeas PAR também apresentam valores mais elevados em $13 \mathrm{~h}$ e $24 \mathrm{~h}$, entretanto não diferem significativamente do grupo de fêmeas NPAR (figura 23).

O comportamento de proximidade entre casal, assim como visto anteriormente, se diferiu quase completamente entre grupos PAR e NPAR. O registro de maior intensidade deste comportamento para fêmeas e machos pareados foi com 14 horas de luz. O mesmo ocorreu com a permanência em ninho, registrando maior média de registros em 14h. Os comportamentos reprodutivos apresentam médias maiores nos grupos PAR quando expostos a 24 horas de luz. Em fêmeas, os grupos diferem de forma mais intensa, apresentando médias semelhantes apenas em 9,5h e 15h. Já nos machos, diferença significativa aparece somente em 15h, quando o grupo NPAR não apresenta o comportamento. Quanto a permanência dos animais na água, machos e fêmeas PAR apresentam suas maiores médias em 13h, enquanto machos NPAR em 10,5h. Fêmeas NPAR apresentam 100\% do tempo monitorado na água com 9,5 horas de exposição a luz. Desta forma, dentre as fêmeas há diferença significativa deste comportamento entre os grupos em todas as exposições a luz, exceto 15h, sempre com médias mais elevadas para o grupo NPAR. Para machos, só há diferença significativa em 10,5h e 13h, quando o grupo NPAR apresenta médias maiores. 
Figura 22 - Médias de concentrações hormonais e registros comportamentais de machos pareados e não pareados de acordo com a exposição a luz.
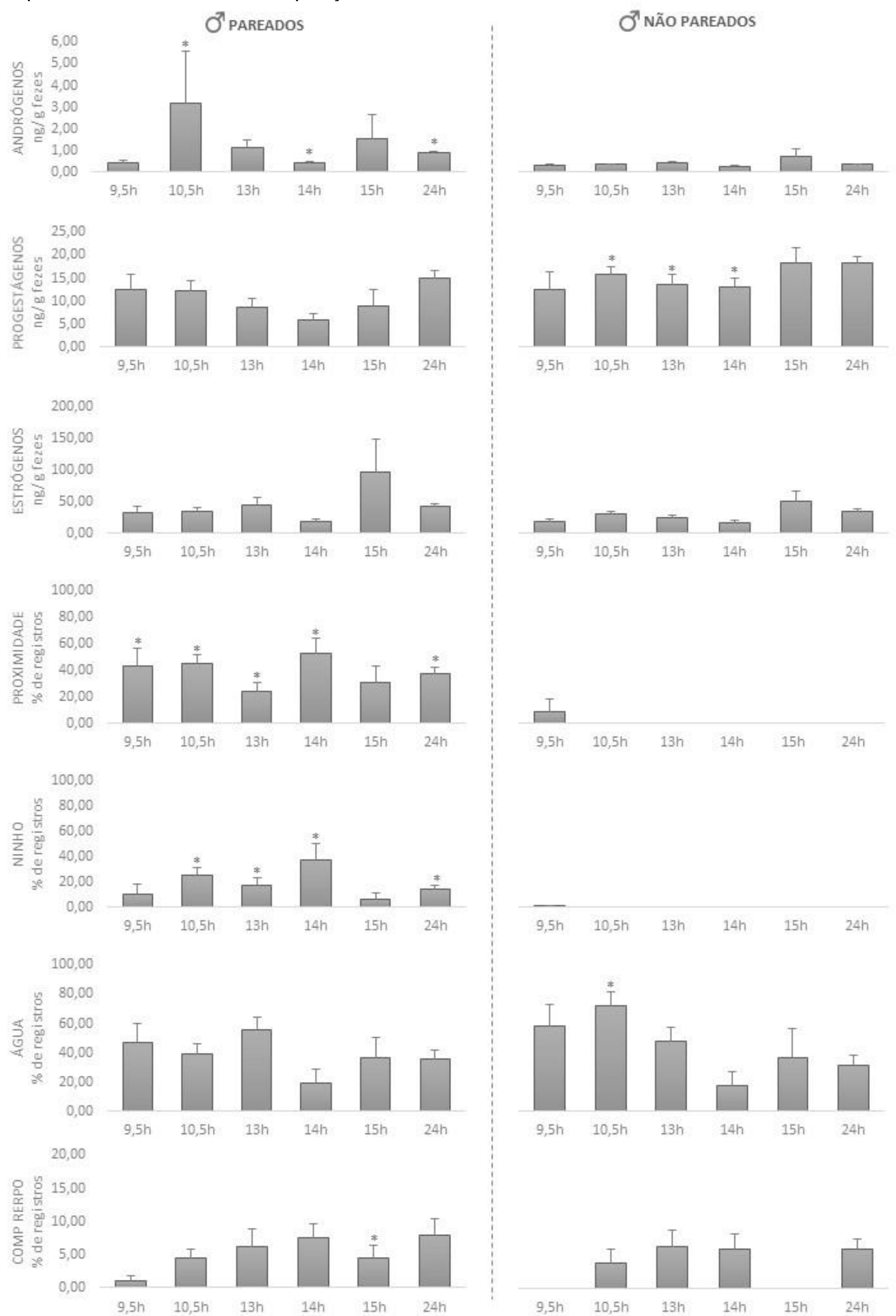

Fonte: (RIBEIRO, J.D.; 2017). 
Figura 23 - Médias de concentrações hormonais e registros comportamentais de fêmeas pareadas e não pareadas de acordo com a exposição a luz.
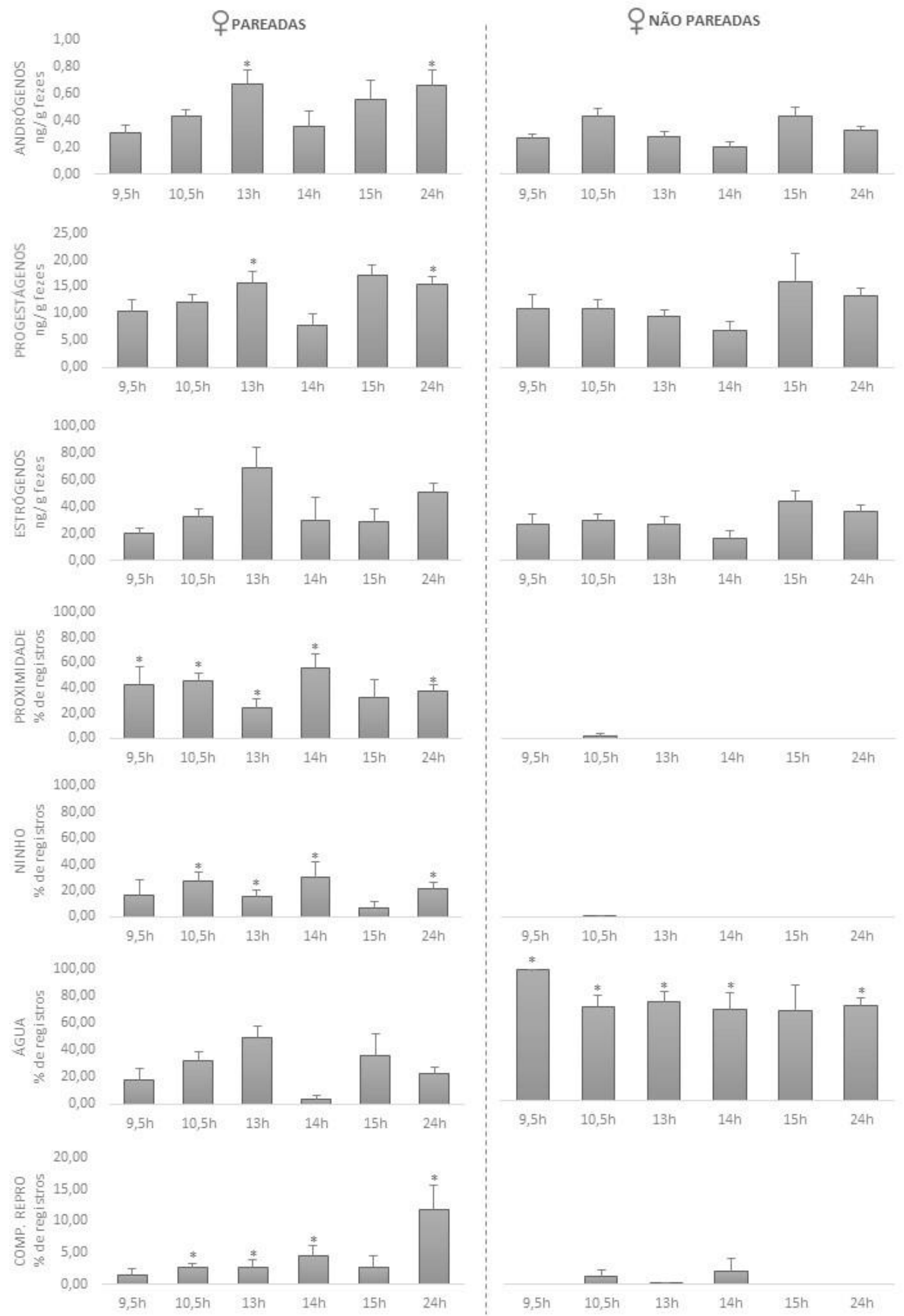

Fonte: (RIBEIRO, J.D.; 2017). 


\subsection{DISCUSSÃO}

O estudo da ação de oscilações luminosas diárias em aves determinando sazonalidade reprodutiva, especialmente em animais de clima temperado e subtropical não é algo novo, ainda mais quando nos referimos a aves de criação. $O$ estudo deste mecanismo para avicultura industrial foi essencial para seu desenvolvimento, aprimoramento e sucesso, visto que aves de postura chegam a índices reprodutivos altíssimos com o uso correto dessa tecnologia (LEWIS, 2006). Embora com um cunho diferente, pesquisas descritivas com passeriformes de clima temperado tem demonstrado a ação das oscilações luminosas na sazonalidade destes animais há alguns anos. Entretanto, pouca informação tem sido revertida em benefícios das aves mantidas em cativeiro em regiões diferentes do seu fotoperíodo natural (NELSON, 1972; HAU, 2001). Para aves marinhas e migratórias o número de pesquisas neste sentido é ainda menor e, ainda que haja muitos estudos descrevendo o comportamento destes animais em vida livre, poucos tentam estabelecer ligação com o fotoperíodo ao que o animal está exposto, (AZA, 2014), porém, nossos achados contribuem com estas informações para manutenção adequada de pinguins-de-Magalhães em cativeiro.

Pinguim-de-Magalhães tem um ciclo anual marcado por 3 eventos principais, a reprodução, muda de penas e a migração invernal. Os dois primeiros apresentam diferenças endócrina importantes reportadas em estudos com outras espécies de pinguins (GROSCOLAS et al., 1986; OTSUKA, MACHIDA, WAZA, 2004). São momentos completamente opostos na produção de esteroides sexuais. A reprodução é acompanhada de um aumento nos níveis hormonais, enquanto que a muda, em geral, apresenta os valores mais basais. Não há informações sobre o período de migração invernal. Uma vez que pinguins são aves pelágicas migratórias, pouco se sabe sobre a endocrinologia nesse período (FOWLER et al., 1994). Entretanto, sabe-se que os animais deixam as colônias reprodutivas após a muda com níveis extremamente baixos de esteroides sexuais (GROSCOLAS et al., 1986; WILLIAMS, 1992). Os resultados obtidos no monitoramento demonstraram a mesma tendência, principalmente entre fêmeas e machos PAR. Animais NPAR também a demonstram, porém de forma mais sutil, fator que pode estar diretamente relacionado com a imaturidade sexual neste grupo. 
Fêmeas PAR apresentaram um aumento inicial nos níveis hormonais em maio (figura 19) seguido pelo pico em junho, tal elevação inicial é compatível com dados de literatura que relatam um nível mais elevado de hormônios sexuais cinco semanas antes da postura dos ovos (O'BRIEN et. al., 2015). Esse pico resultou na postura de dois ovos por uma das fêmeas. Machos PAR (figura 18), neste mesmo período, apresentaram um pico de andrógenos em abril que, apesar de ter um fotoperíodo mais baixo $(10,5 \mathrm{~h})$ em relação aos meses subsequentes, pode ter ocorrido em resposta tardia à introdução do programa de luz em fevereiro, uma vez que a alteração ofereceu aos animais um aumento em 4 horas de luz, de forma progressiva, entre fevereiro e março. Infelizmente não há dados do monitoramento nestes dois meses.

Após os meses de superexposição a luz (agosto), os pinguins iniciaram um novo processo de muda. Nesta espécie, a troca das penas ocorre uma única vez ao ano, em um momento equivalente ao final do período reprodutivo antecedendo o início da migração (WILLIAMS, 1995; BOERSMA et al., 2013). Uma vez que os animais tiveram um período simulando dias longos, responderam ao final deste com o processo de muda, igual aconteceria numa estação reprodutiva normal. O tempo entre as posturas e a muda do casal monitorado foi equivalente ao tempo observado entre a postura e muda nos animais in situ, aproximadamente 3 a 4 meses (WILLIAMS, 1995; BOERSMA et al., 2013). A muda de penas foi seguida por um período de "migração" induzida pela diminuição de horas no fotoperíodo fornecido. A evidência desta indução é visível no aumento da média de permanência dos animais dos dois grupos na água durante os meses de outubro a dezembro. Neste mesmo período, houve diminuição nos esteroides sexuais de todos os grupos, sugerindo que a hipótese de que no período de migração estes animais mantêm níveis basais de hormônios sexuais seja realmente verdadeira (GROSCOLAS et al., 1986; WILLIAMS, 1992).

Com o aumento da luz em novembro, houve novamente variação nos níveis hormonais e nos comportamentos dos pinguins monitorados. Machos PAR apresentaram um novo pico de andrógenos em janeiro, quando a luz atinge 15h, machos NPAR também apresentaram um pico, mas com nível menor em relação ao grupo PAR (figura 18). Fêmeas PAR pareceram demonstrar uma resposta mais progressiva, pois as elevações dos três hormônios começaram a ser percebidas em 
dezembro (13h) e o pico apareceu somente em fevereiro (15h), não evoluindo para posturas. As fêmeas NPAR não parecem ter apresentado elevações hormonais suficientes para formação de picos, entretanto, é possível notar a variação na secreção hormonal oscilando conforme a luz.

No período em que machos e fêmeas do grupo PAR apresentaram o aumento inicial de níveis hormonais, ainda houve um índice mais elevado de permanência destes na água, entretanto próximos aos picos, houve uma queda brusca destes registros, concordando com os estudos que sugerem que as alterações endócrinas reprodutivas iniciais devem ocorrer no período final da migração, com os animais ainda no mar (GROSCOLAS et al., 1986, FOWLER et al., 1994; WILLIAMS, 1995). Já animais NPAR pareceram demonstrar uma fase de imaturidade sexual, evidenciada principalmente pelas fêmeas, pois além de não apresentarem picos também permanecem a maior parte do ano na água. Tal comportamento foi descrito em literatura e afirma que animais juvenis voltam as colônias em um momento mais tardio da estação reprodutiva (dezembro), permanecendo pouco tempo nas áreas de nidificação, deixando as colônias para pequenas viagens de forrageio antes do período de muda (BOERSMA et al, 1990). A diferenciação destas nuances de comportamentos foi possível ainda que os dois grupos de animais do monitoramento estivessem em uma fase intermediária entre a imaturidade e maturidade reprodutiva para a espécie, 4 a 8 anos de idade em pinguins-de-Magalhães (BOERSMA et al., 2013),

Assim como os níveis hormonais pareceram variar conforme a oscilação luminosa, também os comportamentos dos pinguins apresentaram essa tendência. Os comportamentos reprodutivos e a permanência em ninhos dos machos e fêmeas PAR apresentaram índices mais elevados quando em meses com maior amplitude de luz ou, em meses com muda de penas, pois, neste período, os animais tendem a permanecer nos ninhos e há aumento do allopreening entre casais para ajudar na remoção de penas antigas. Nos meses de novembro e dezembro, não houve expressão de comportamentos reprodutivos ou permanência em ninho, uma vez que os animais estão na água. O comportamento de proximidade entre os casais é visto nos animais do grupo PAR durante todo o ano, mas com diferentes intensidades. Isso sugere que em um ambiente restrito, como o cativeiro, a monogamia expressa pelos pinguins-de-Magalhaes pode ser intensificada e expressada ainda em 
períodos fora da estação reprodutiva. Entretanto, não há como saber o comportamento destes casais in situ na água, principalmente durante a migração. Machos e fêmeas NPAR não apresentaram proximidade entre casais ou permanência em ninho com intensidade relevante, mas os machos NPAR apresentaram frequência nos comportamentos reprodutivos durante 0 mesmo período dos machos PAR, contudo com menor intensidade.

A expectativa com as figuras 22 e 23 era constatar qual exposição de luz puderia apresentar um melhor empenho reprodutivo. Nas fêmeas PAR, 13h, 15h, e 24h de exposição a luz demonstraram um maior aumento dos três esteroides sexuais. Enquanto para machos PAR, a oscilação mais marcante pareceu ser a dos andrógenos e, com aumento significativo em 10,5h, 13h e 24h.. Contudo, é preciso ter cautela nesta comparação, uma vez que os animais podem levar até três anos para se adaptarem a um novo programa de luz (AZA, 2014). De qualquer maneira, as figuras representam, de maneira contundente a diferença hormonal $\mathrm{e}$ comportamental entre diferentes exposições a luz para animais PAR e NPAR, sugerindo uma possível transição entre animais maduros e imaturos para uma faixa etária similar.

Os doze meses de monitoramento pareceram demonstrar a resposta endócrina e comportamental dos animais ao fotoperíodo, indicando que o desenvolvimento do ciclo anual dos pinguins-de-Magalhães seja mesmo regido pela variação luminosa das estações do ano. Tais oscilações hormonais também sugerem que o ciclo possa ser manipulado, possivelmente diminuindo o intervalo entre estações reprodutivas. Uma vez que dois picos foram observados em um espaço de 12 meses e com animais jovens, sendo provável que animais maduros poderiam responder ainda melhor a tal estímulo. Esta poderia ser uma ferramenta de extrema importância para os membros da família Spheniscidae, uma vez que 60\% das espécies recebem uma classificação de risco pela IUCN (2016). 


\section{REFERÊNCIAS}

ALTMANN, J. Observational study of behavior: sampling methods. Behaviour 49.3: 227-266. 1974.

AZA Penguin Taxon Advisory Group. Penguin (Spheniscidae) Care Manual. Silver Spring, MD: Association of Zoos and Aquariums. 2014.

BIRDLIFE INTERNATIONAL. 2016. Spheniscus magellanicus. The IUCN Red List of Threatened Species 2016: e. T22697822A93642328. Disponível em:<http://dx.doi.org/10.2305/IUCN.UK.2016-3.RLTS.T22697822A93642328.en>. Acesso em: 05 de dezembro de 2016.

BOERSMA, P. D.; STOKES, DAVID L.; YORIO, PABLO M. Reproductive variability and historical change of Magellanic Penguins (Spheniscus magellanicus) at Punta Tombo, Argentina. Penguin biology, v. 7, p. 15-44, 1990.

BOERSMA, P. D. Penguins as marine sentinels. BioScience, v. 58, n. 7, p. 597607, 2008.

BOERSMA, P. D.; FRERE, E.; KANE, O.; POZZI, L. M.; PÜTZ, K.; RAYA REY, A.; REBSTOCK, G. A.; SIMEONE, A.; SMITH, J.; VAN BUREN; A.; YORIO, P.; GARCIA-BORBOROGLU, P. Magellanic penguin. In: GARCÍA-BORBOROGLU, P. G.; BOERSMA, P. D. (Ed.). Penguins - natural history and conservation. Seattle: University of Washington Press, 2013. p 233-263.

BROWN, Janine; WALKER, Sue; STEINMAN, Karen. Endocrine manual for the reproductive assessment of domestic and non-domestic species. Endocrine Research Laboratory, Department of Reproductive Sciences, Conservation and Research Center, National Zoological Park, Smithsonian Institution, Handbook, p. 1-93, 2004.

CENTRO NACIONAL DE PESQUISA E CONSERVAÇÃO DE AVES SILVESTRES (CEMAVE). Projeto nacional de monitoramento do pinguim-de-Magalhães Spheniscus magellanicus. Cabedelo: CEMAVE, 2010. 34 p.

EGGLETON, P.; SIEGFRIED, W. R. Displays of the Jackass Penguin. Ostrich 50:139-167. 1979.

FOWLER, Gene S. et al. Reproductive endocrinology and weight change in relation to reproductive success in the Magellanic penguin (Spheniscus magellanicus). General and comparative endocrinology, v. 94, n. 3, p. 305-315, 1994.

GARCÍA-BORBOROGLU, P. G.; BOERSMA, P. D. (Ed.). Penguins - natural history and conservation. Seattle: University of Washington Press, 2013. p 233-263. 
GARCÍA-BORBOROGLU, P.; BOERSMA, P. D.; RUOPPOLO, V.; SILVA-FILHO R. P.; ADORNES, A. C.; CONTE-SENA, D.; VELOZO, R.; KOLESNIKOVAS, C. M.; DUTRA, G.; MARACINI, P.; NASCIMENTO, C. C.; RAMOS-JÚNIOR, V.; BARBOSA, L.; SERRA, S. Magellanic penguin mortality in 2008 along the SW Atlantic coast. Marine Pollution Bulletin, v. 60, n. 10, p. 1652-1657, 2010.

GARCÍA-BORBOROGLU, Pablo et al. Chronic oil pollution harms Magellanic penguins in the Southwest Atlantic. Marine Pollution Bulletin, v. 52, n. 2, p. 193198, 2006.

GOYMANN, W. Noninvasive monitoring of hormones in bird droppings: physiological validation, sampling, extraction, sex differences, and the influence of diet on hormone metabolite levels. Annals N. Y. Acad. Sci. 1046: 35-53, 2005.

HAU, M. Timing of breeding in variable environments: tropical birds as model systems. Horm. Behav. 40: 281-290, 2001.

LEHNER, P.N. Handbook of ethological methods. Cambridge: Cambridge University Press. 1996.

LEWIS, Peter; MORRIS, Trevor. Poultry lighting: the theory and practice. Hampshire, UK: Northcot, 2006

LUNA, G.; HENNICKE, J.; WALLACE, R.; SIMEONE, A.; WOLFAARDT, A.; WHITTINGTON, P.; ELLIS, S.; MCGOVERN, M. Spheniscus penguin conservation workshop: Final Report. Apple Valley: IUCN/ SSC Conservation Breeding Specialist Group, 2002. 83 p.

MARTIN, P.; BATESON, P. Measuring behavior: an introductory guide. 2 ed. Cambridge: Cambridge University Press. 222p. 2000.

MERRITT, K.; KING, N.E. Behavioral sex differences and activity patterns of captive Humboldt Penguins (Spheniscus humboldti). Zoo biology, 6(2), 129-138. 1987.

MULLER-SCHEWAZE, D. The Behaviour of Penguins: adapted to ice and tropics. New York: State University of New York Press. 1984.

NELSON, R. W. On photoperiod and captivity breeding of northern peregrines. Raptor Res, v. 6, p. 57-72, 1972.

OTSUKA, Ryoko; MACHIDA, Takeo; WADA, Masaru. Hormonal correlations at transition from reproduction to molting in an annual life cycle of Humboldt penguins (Spheniscus humboldti). General and comparative endocrinology, v. 135, n. 2, p. 175-185, 2004.

SHARP, Peter J. Strategies in avian breeding cycles. Animal Reproduction Science, v. 42, n. 1-4, p. 505-513, 1996. 
SICK, H. Ornitologia Brasileira. Rio de Janeiro: Nova Fronteira, 2001. 926 p.

SILVA-FILHO, R. P.; RUOPPOLO, V. Sphenisciformes (Pinguim). In Zalmir Cubas, Jean Carlos Ramos Silva; José Luiz Catão-Dias. (Org.). Tratado de Animais Selvagens Medicina Veterinária. São Paulo: Editora Roca, p.309-323. 2006.

STOKES, D. L.; BOERSMA, P. D. Where Breeding Magellanic penguins Spheniscus magellanicus forage: satellite telemetry results and their implications for penguin conservation. Marine Ornithology, v. 27, p. 59-65, 1999.

STOKES, David L. et al. Conservation of migratory Magellanic penguins requires marine zoning. Biological Conservation, v. 170, p. 151-161, 2014.

STOKES, David L.; BOERSMA, P. Dee. Nest-site characteristics and reproductive success in Magellanic penguins (Spheniscus magellanicus). The auk, p. 34-49, 1998.

TASKER, Mark L. et al. The impacts of fishing on marine birds. ICES Journal of Marine Science: Journal du Conseil, v. 57, n. 3, p. 531-547, 2000.

TEMPEL, D.J.; GUTIÉRREZ, R.J. Factors Related to fecal corticosterone levels in California Spotted Owls: implications for assessing chronic stress. Cons. Biol. 18: 538-547, 2004.

The IUCN Red List of Threatened Species. Version 2016-3. Disponível em: <www.iucnredlist.org >. Acesso em: 05 de dezembro de 2016.

WILLIAMS, T. D. Reproductive endocrinology of macaroni (Eudyptes chrysolophus) and gentoo (Pygoscelis papua) penguins: I. Seasonal changes in plasma levels of gonadal steroids and $\mathrm{LH}$ in breeding adults. General and comparative endocrinology, v. 85, n. 2, p. 230-240, 1992.

WILLIAMS, T. D. The penguins: Spheniscidae. Oxford: Oxford University Press, 1995. 295 p.

YORIO, P.; FRERE, E.; GANDINI, P.; CONWAY, W. Status and conservation of seabirds breeding in Argentina. Bird Conservation International, v. 9, p. 299-314, 1999. 


\section{CONSIDERAÇÕES FINAIS}

O monitoramento realizado a esta população de pinguins-de-Magalhães de cativeiro evidenciou que, o cumprimento de requisitos para a espécie, associados a um programa de luz, influenciam diretamente no sucesso reprodutivo dos animais. Esta espécie de pinguim demonstra ser altamente responsiva as oscilações luminosas. Apresentando variações endócrinas importantes quanto expostos a mais ou menos horas de luz por dia.

As respostas endócrinas encontradas sugerem a possibilidade de diminuição no intervalo entre estações reprodutivas. Essa informação é muito valiosa para o manejo reprodutivo desta espécie em cativeiro. Podendo ser ainda mais valiosa caso possa ser extrapolada a outras espécies de pinguins ameaçadas de extinção, como o pinguim-africano (Spheniscus demersus) e o pinguim-de-Galápagos (Spheniscus medinculus).

Não houveram comportamentos que pudessem classificar, de forma clara, os animais com melhores ou piores reprodutores. Neste ponto, foi apenas possível comprovar o que a literatura afirma sobre a agressividade dos machos e aumento da atividade de cópula em decorrência a níveis altos de testosterona. Entretanto, o fato deste dado também ter sido encontrado no grupo de animais não pareados, traz uma informação útil caso se tenha intenção de usar um macho não pareado para alguma manipulação de reprodução assistida, por exemplo, coleta de sêmen.

Ademais, o presente estudo registra um monitoramento hormonal nãoinvasivo associado a informações comportamentais e de maturidade sexual elaborado durante um ano em 12 animais e 10 meses (duas estações reprodutivas) em 18 animais, registrando uma enorme gama de informações endócrinas a respeito dos três principais esteroides sexuais somados as informações comportamentais. Tal registro jamais foi feito para essa espécie. 
ANEXOS 
Anexo A - Padrão de atividades dos animais.

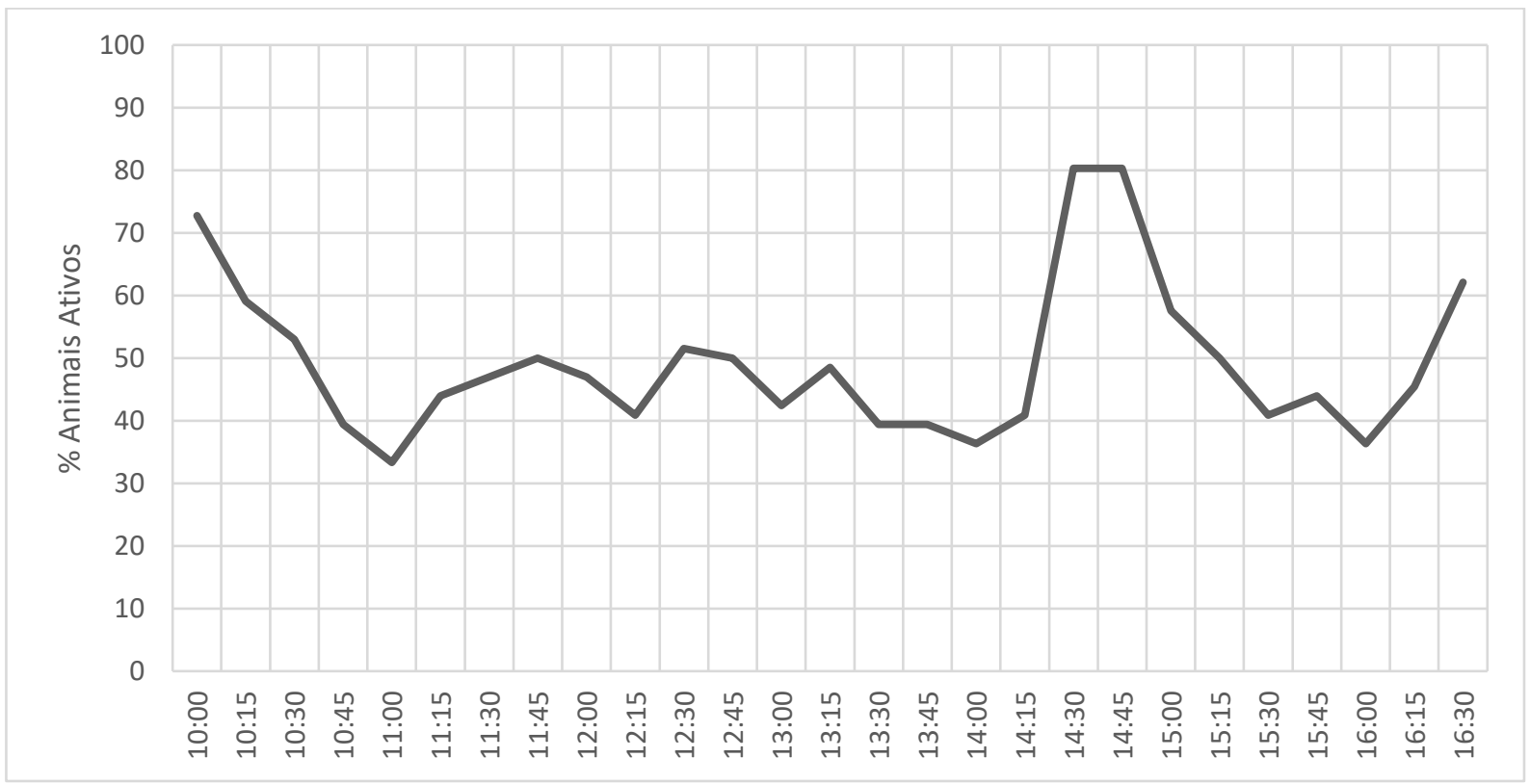

Fonte: (RIBEIRO, J. D.; 2017) 
Anexo B - Descrição dos comportamentos reprodutivos.

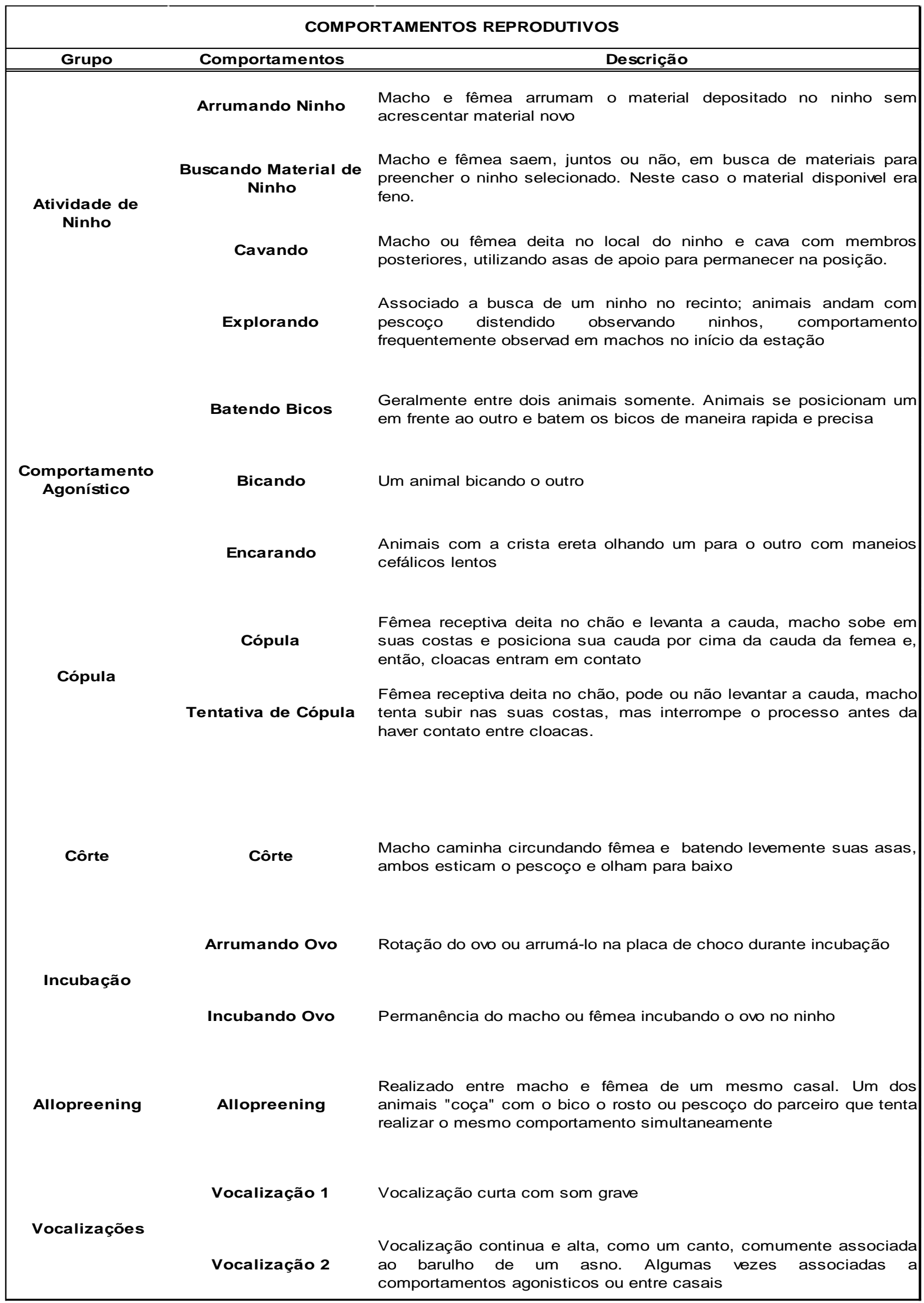

Fonte: (RIBEIRO, J.D.; 2017). 